\title{
Water-Soluble Phosphinothiols for Traceless Staudinger Ligation and Integration with Expressed Protein Ligation
}

\author{
Annie Tam, Matthew B. Soellner, and Ronald T. Raines* \\ Contribution from the Departments of Chemistry and Biochemistry, \\ University of Wisconsin-Madison, Madison, WI 53706
}

\begin{tabular}{|c|c|c|c|}
\hline Page & Contents & Page & Contents \\
\hline S1 & Table of Contents & S39 & ${ }^{1} \mathrm{H}$ NMR Spectrum of Compound 17 \\
\hline S2 & ${ }^{13} \mathrm{C}$ NMR Assay of $28+15$ & S40 & ${ }^{13} \mathrm{C}$ NMR Spectrum of Compound 17 \\
\hline S3 & MALDI-TOF Mass Spectrum of 32 & S41 & ${ }^{31} \mathrm{P}$ NMR Spectrum of Compound 17 \\
\hline S4 & ${ }^{1} \mathrm{H}$ NMR Spectrum of Compound 3 & S42 & ${ }^{1} \mathrm{H}$ NMR Spectrum of Compound 18 \\
\hline S5 & ${ }^{13} \mathrm{C}$ NMR Spectrum of Compound 3 & S43 & ${ }^{13} \mathrm{C}$ NMR Spectrum of Compound 18 \\
\hline S6 & ${ }^{31} \mathrm{P}$ NMR Spectrum of Compound 3 & S44 & ${ }^{1} \mathrm{H}$ NMR Spectrum of Compound 19 \\
\hline S7 & ${ }^{1} \mathrm{H}$ NMR Spectrum of Compound 5 & S45 & ${ }^{13} \mathrm{C}$ NMR Spectrum of Compound 19 \\
\hline S8 & ${ }^{13} \mathrm{C}$ NMR Spectrum of Compound $\mathbf{5}$ & S46 & ${ }^{1} \mathrm{H}$ NMR Spectrum of Compound 20 \\
\hline s9 & ${ }^{31} \mathrm{P}$ NMR Spectrum of Compound $\mathbf{5}$ & S47 & ${ }^{13} \mathrm{C}$ NMR Spectrum of Compound 20 \\
\hline $\mathrm{S} 10$ & ${ }^{1} \mathrm{H}$ NMR Spectrum of Compound 6 & S48 & ${ }^{31} \mathrm{P}$ NMR Spectrum of Compound 20 \\
\hline $\mathrm{S} 11$ & ${ }^{13} \mathrm{C}$ NMR Spectrum of Compound $\mathbf{6}$ & S49 & ${ }^{1} \mathrm{H}$ NMR Spectrum of Compound 21 \\
\hline $\mathrm{S} 12$ & ${ }^{31} \mathrm{P}$ NMR Spectrum of Compound $\mathbf{6}$ & S50 & ${ }^{13} \mathrm{C}$ NMR Spectrum of Compound 21 \\
\hline $\mathrm{S} 13$ & ${ }^{1} \mathrm{H}$ NMR Spectrum of Compound 7 & S51 & ${ }^{31} \mathrm{P}$ NMR Spectrum of Compound $\mathbf{2 1}$ \\
\hline $\mathrm{S} 14$ & ${ }^{13} \mathrm{C}$ NMR Spectrum of Compound 7 & S52 & ${ }^{1} \mathrm{H}$ NMR Spectrum of Compound 22 \\
\hline $\mathrm{S} 15$ & ${ }^{31} \mathrm{P}$ NMR Spectrum of Compound 7 & S53 & ${ }^{13} \mathrm{C}$ NMR Spectrum of Compound 22 \\
\hline S16 & ${ }^{1} \mathrm{H}$ NMR Spectrum of Compound 8 & S54 & ${ }^{31} \mathrm{P}$ NMR Spectrum of Compound 22 \\
\hline $\mathrm{S} 17$ & ${ }^{13} \mathrm{C}$ NMR Spectrum of Compound 8 & S55 & ${ }^{1} \mathrm{H}$ NMR Spectrum of Compound 23 \\
\hline S18 & ${ }^{31} \mathrm{P}$ NMR Spectrum of Compound 8 & S56 & ${ }^{13} \mathrm{C}$ NMR Spectrum of Compound 23 \\
\hline S19 & ${ }^{1} \mathrm{H}$ NMR Spectrum of Compound 9 & S57 & ${ }^{31} \mathrm{P}$ NMR Spectrum of Compound $\mathbf{2 3}$ \\
\hline S20 & ${ }^{13} \mathrm{C}$ NMR Spectrum of Compound 9 & S58 & ${ }^{1} \mathrm{H}$ NMR Spectrum of Compound 24 \\
\hline $\mathrm{S} 21$ & ${ }^{31}$ P NMR Spectrum of Compound 9 & S59 & ${ }^{13} \mathrm{C}$ NMR Spectrum of Compound 24 \\
\hline $\mathrm{S} 22$ & ${ }^{1} \mathrm{H}$ NMR Spectrum of Compound 10 & S60 & ${ }^{31} \mathrm{P}$ NMR Spectrum of Compound 24 \\
\hline S23 & ${ }^{13} \mathrm{C}$ NMR Spectrum of Compound 10 & S61 & ${ }^{1} \mathrm{H}$ NMR Spectrum of Compound 25 \\
\hline $\mathrm{S} 24$ & ${ }^{31} \mathrm{P}$ NMR Spectrum of Compound 10 & S62 & ${ }^{13} \mathrm{C}$ NMR Spectrum of Compound 25 \\
\hline S25 & ${ }^{1} \mathrm{H}$ NMR Spectrum of Compound 11 & S63 & ${ }^{31} \mathrm{P}$ NMR Spectrum of Compound 25 \\
\hline S26 & ${ }^{13} \mathrm{C}$ NMR Spectrum of Compound 11 & S64 & ${ }^{1} \mathrm{H}$ NMR Spectrum of Compound 26 \\
\hline S27 & ${ }^{31} \mathrm{P}$ NMR Spectrum of Compound 11 & S65 & ${ }^{13} \mathrm{C}$ NMR Spectrum of Compound 26 \\
\hline $\mathrm{S} 28$ & ${ }^{1} \mathrm{H}$ NMR Spectrum of Compound 12 & S66 & ${ }^{31} \mathrm{P}$ NMR Spectrum of Compound 26 \\
\hline S29 & ${ }^{13} \mathrm{C}$ NMR Spectrum of Compound 12 & S67 & ${ }^{1} \mathrm{H}$ NMR Spectrum of Compound 27 \\
\hline S30 & ${ }^{31} \mathrm{P}$ NMR Spectrum of Compound 12 & S68 & ${ }^{13} \mathrm{C}$ NMR Spectrum of Compound 27 \\
\hline S31 & ${ }^{1} \mathrm{H}$ NMR Spectrum of Compound 13 & S69 & ${ }^{1} \mathrm{H}$ NMR Spectrum of Compound 28 \\
\hline S32 & ${ }^{13} \mathrm{C}$ NMR Spectrum of Compound 13 & S70 & ${ }^{13} \mathrm{C}$ NMR Spectrum of Compound 28 \\
\hline S33 & ${ }^{31} \mathrm{P}$ NMR Spectrum of Compound 13 & S71 & ${ }^{31} \mathrm{P}$ NMR Spectrum of Compound $\mathbf{2 8}$ \\
\hline S34 & ${ }^{1} \mathrm{H}$ NMR Spectrum of Compound 14 & S72 & ${ }^{1} \mathrm{H}$ NMR Spectrum of Compound 29 \\
\hline S35 & ${ }^{13} \mathrm{C}$ NMR Spectrum of Compound 14 & S73 & ${ }^{13} \mathrm{C}$ NMR Spectrum of Compound 29 \\
\hline S36 & ${ }^{31} \mathrm{P}$ NMR Spectrum of Compound 14 & & \\
\hline S37 & ${ }^{1} \mathrm{H}$ NMR Spectrum of Compound 15 & & \\
\hline S38 & ${ }^{13} \mathrm{C}$ NMR Spectrum of Compound 15 & & \\
\hline
\end{tabular}



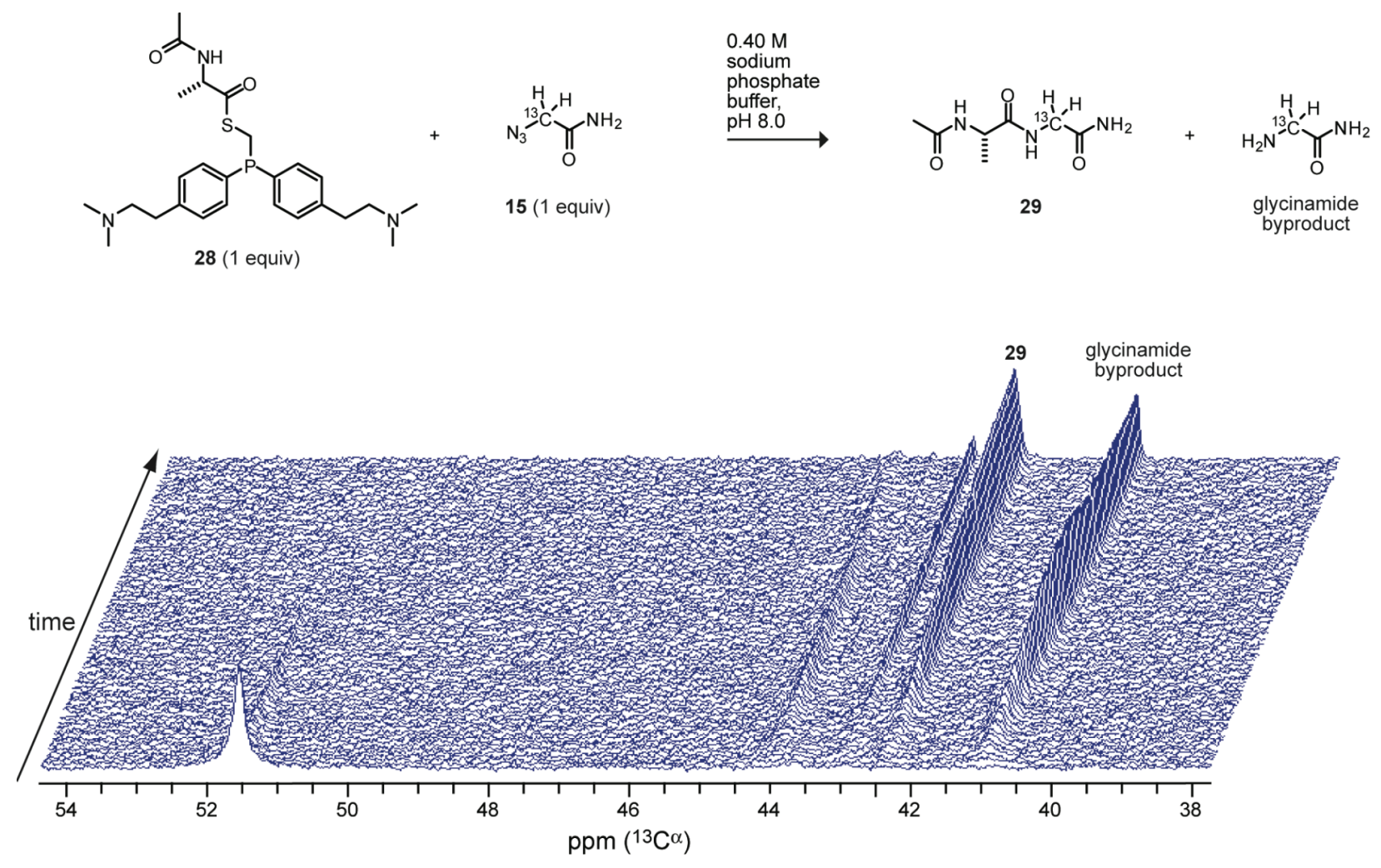

Figure S1. ${ }^{13} \mathrm{C}$ NMR assay of a traceless Staudinger ligation mediated by phosphinothiol $\mathbf{1 7}$. The reaction between phosphinothioester 28 and ${ }^{13} \mathrm{C}$-labeled azide 15 was performed at room temperature with reactant concentrations of $0.16 \mathrm{M}$ in $0.40 \mathrm{M}$ sodium phosphate buffer at $\mathrm{pH}$ 8.0. Ninety ${ }^{13} \mathrm{C}$ NMR spectra were acquired over a 16 -h time course. Yields were determined from peak integrations on the final spectrum. The second-order rate constant for the appearance of amide 29 was $k_{2}=7.4 \times 10^{-3} \mathrm{M}^{-1} \mathrm{~s}^{-1}$. 
A

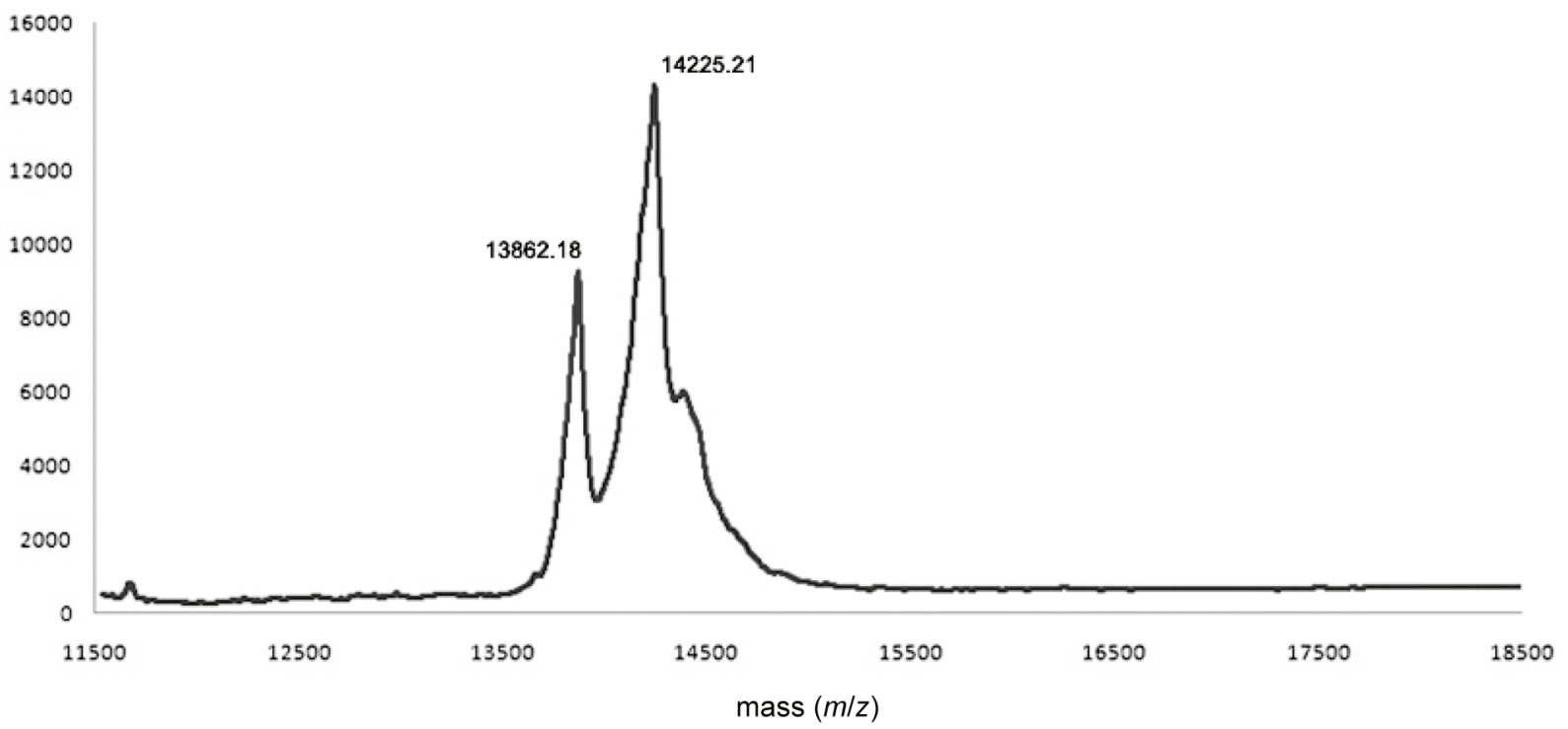

B

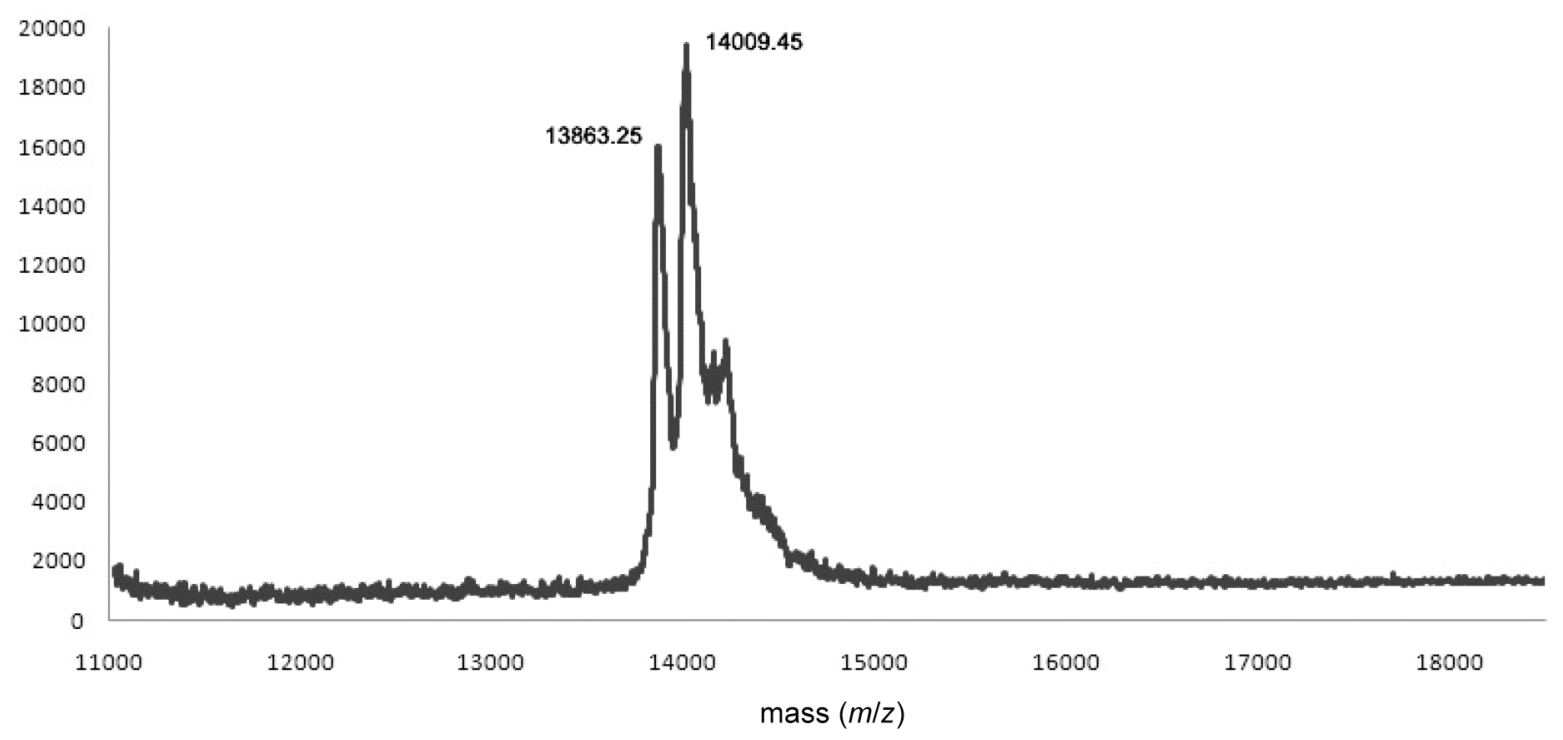

Figure S2. MALDI-TOF mass spectra of protein thioesters. (A) Protein phosphinothioester 32 $\left(m / z\right.$ 14225, expected for Met(-1)RNase A-Gly- $\mathrm{SCH}_{2}\left(\mathrm{P}\left(\mathrm{C}_{6} \mathrm{H}_{4}-p-\mathrm{CH}_{2} \mathrm{CH}_{2} \mathrm{NMe}_{2}\right)_{2}\right)$, $\mathrm{C}_{603} \mathrm{H}_{950} \mathrm{~N}_{175} \mathrm{O}_{194} \mathrm{PS}_{14}$, 14224). (B) Control: protein phosphinothioester with 2-mercaptoethanesulfonic acid (MESNA; $\mathrm{m} / \mathrm{z}$ 14009, expected for Met(-1)RNase A-Gly$\left.\mathrm{SCH}_{2} \mathrm{CH}_{2} \mathrm{SO}_{3} \mathrm{H}, \mathrm{C}_{584} \mathrm{H}_{925} \mathrm{~N}_{173} \mathrm{O}_{197} \mathrm{~S}_{15}, 14002\right)$. The yield of protein phosphinothioester 32 was $70 \%$ that of the MESNA control, as determined by ultraviolet absorbance of the two samples. 
Tam et al.

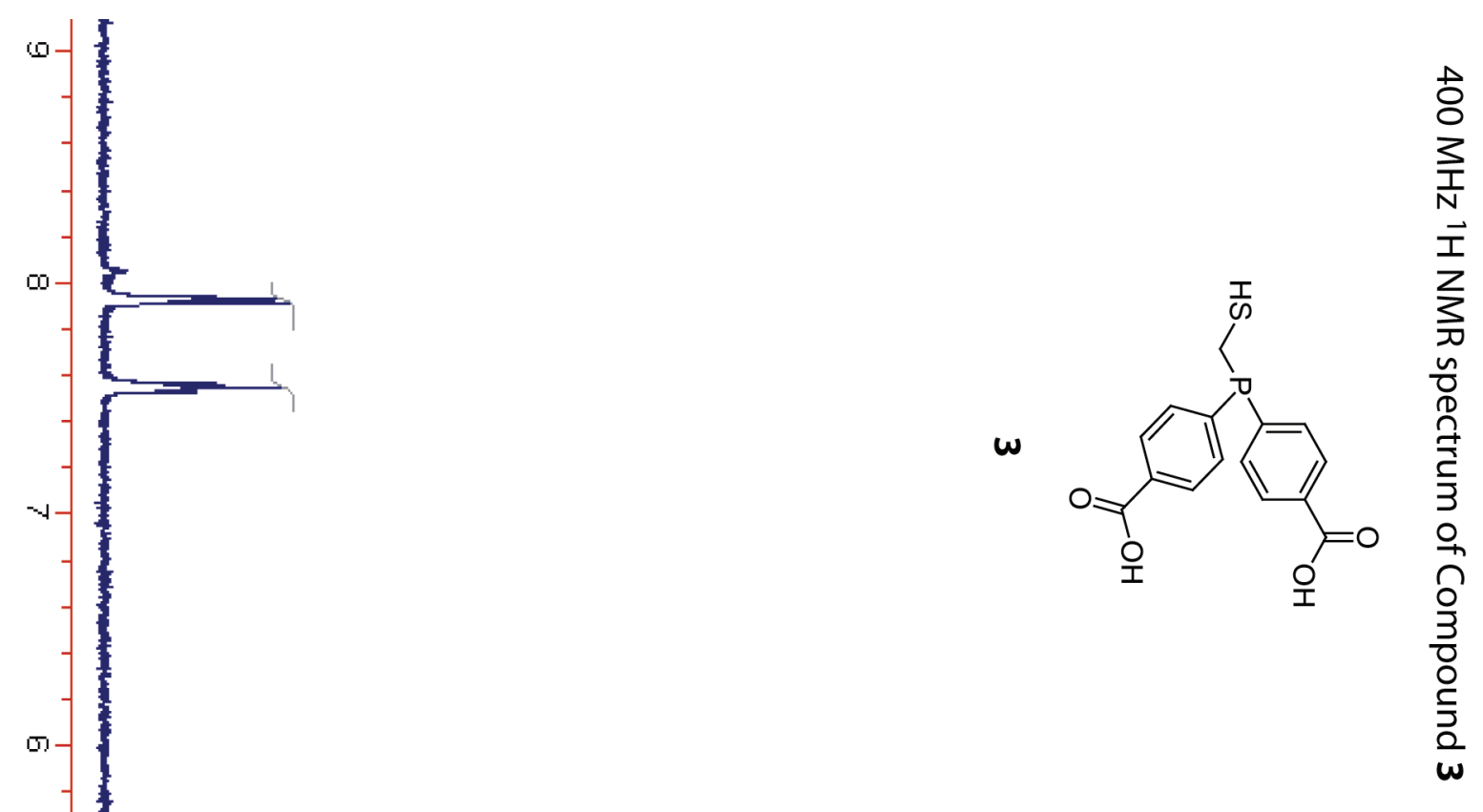

Supporting Information

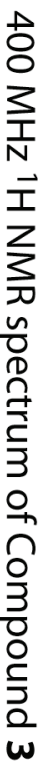

-SH- 
3

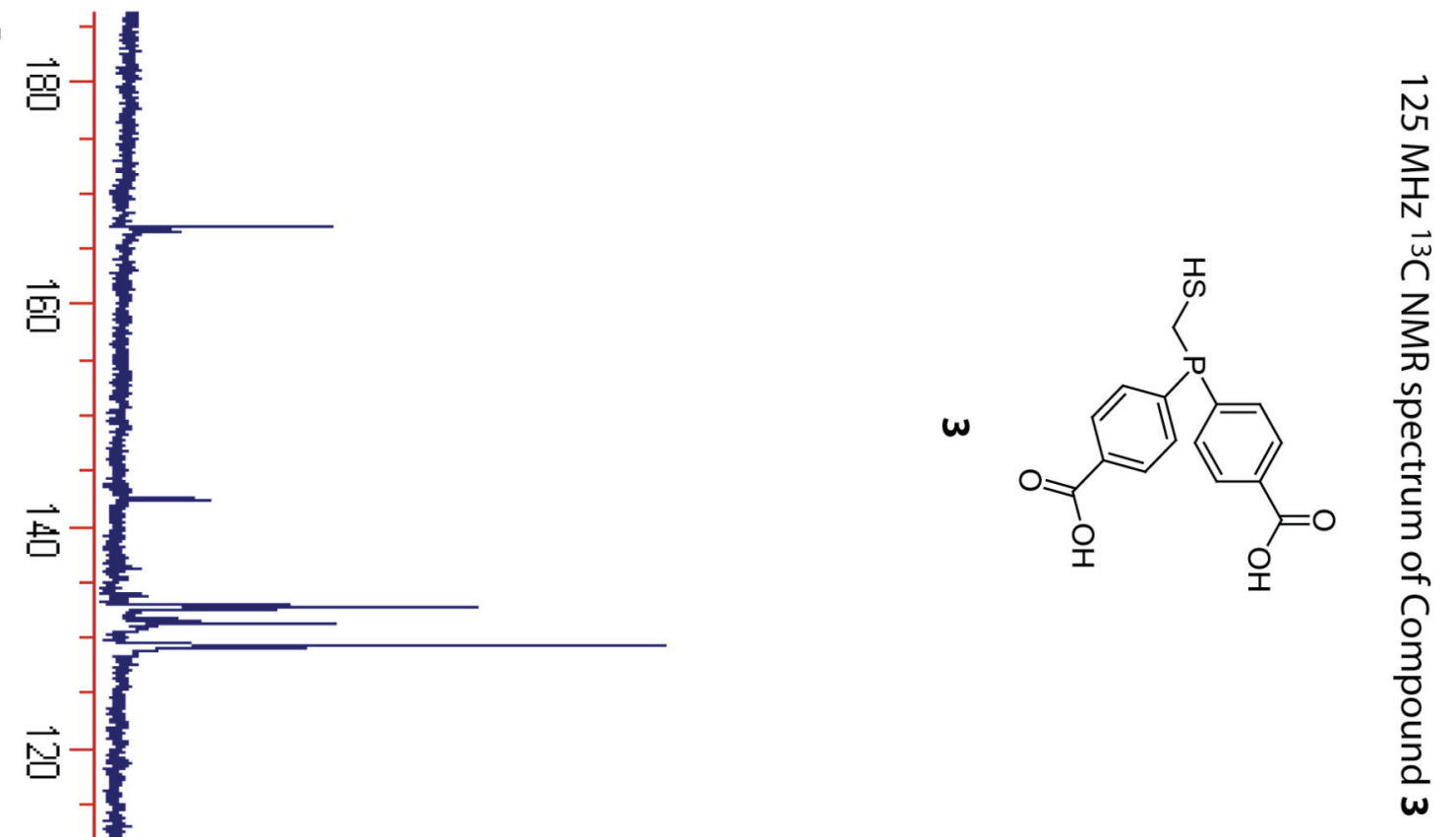


Tam et al.

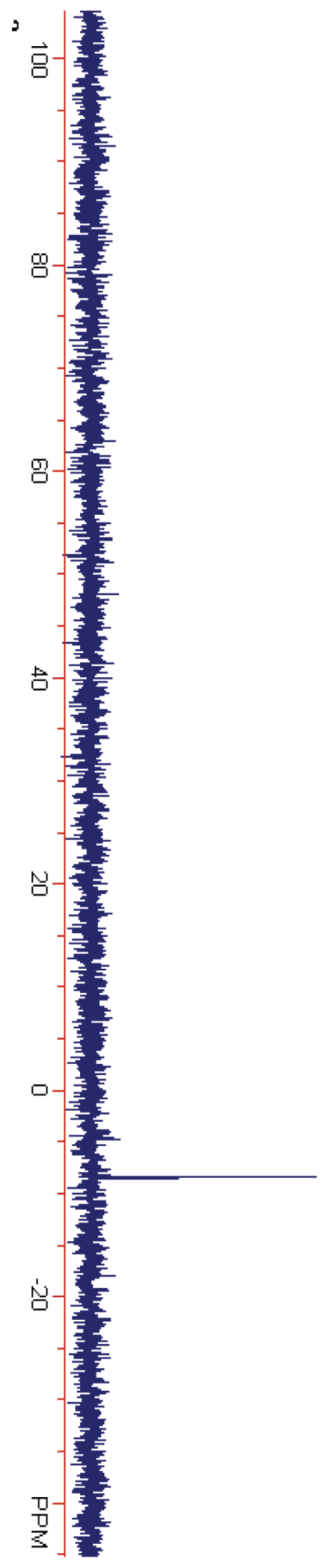

Supporting Information

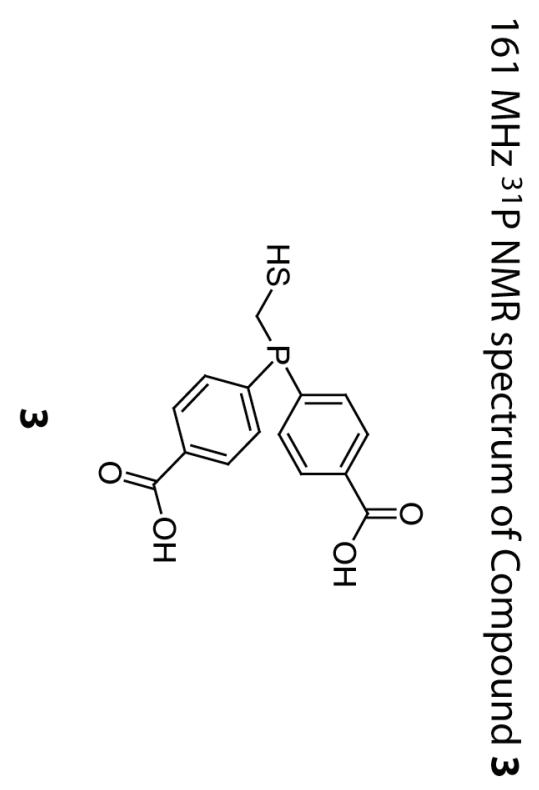

-Sb- 
Tam et al.

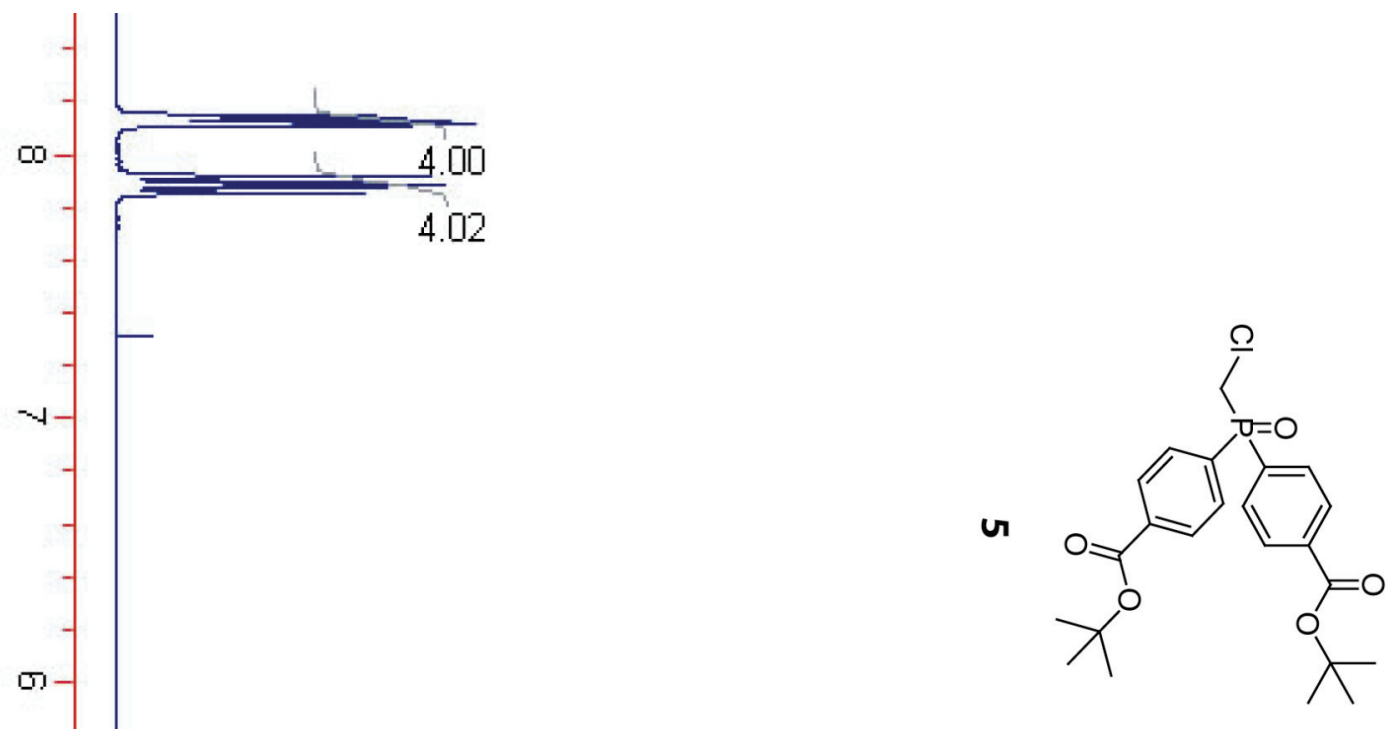

Supporting Information

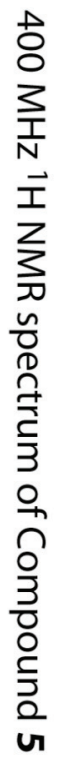


3

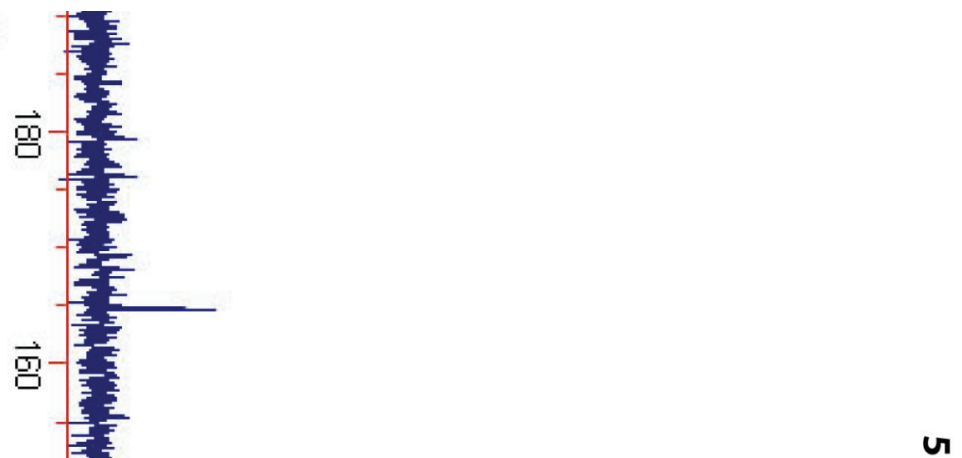

点

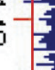

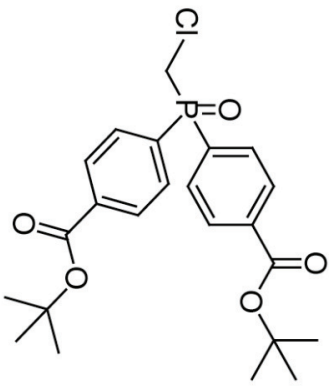

$\vec{N}$

$\underset{N}{3}$

กั

方

员

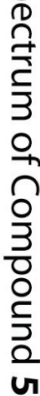

븜

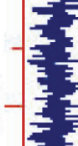

宫
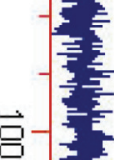

몸

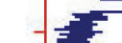

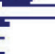

g

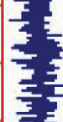

点

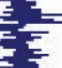

ㄱ-

믈

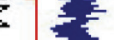




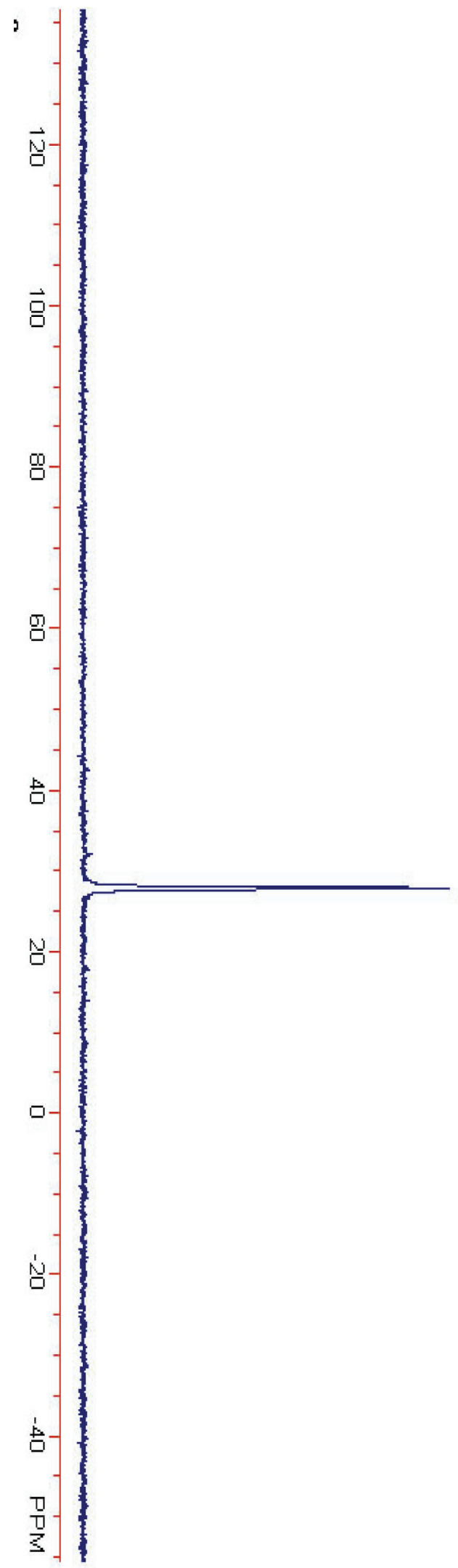


Tam et al.

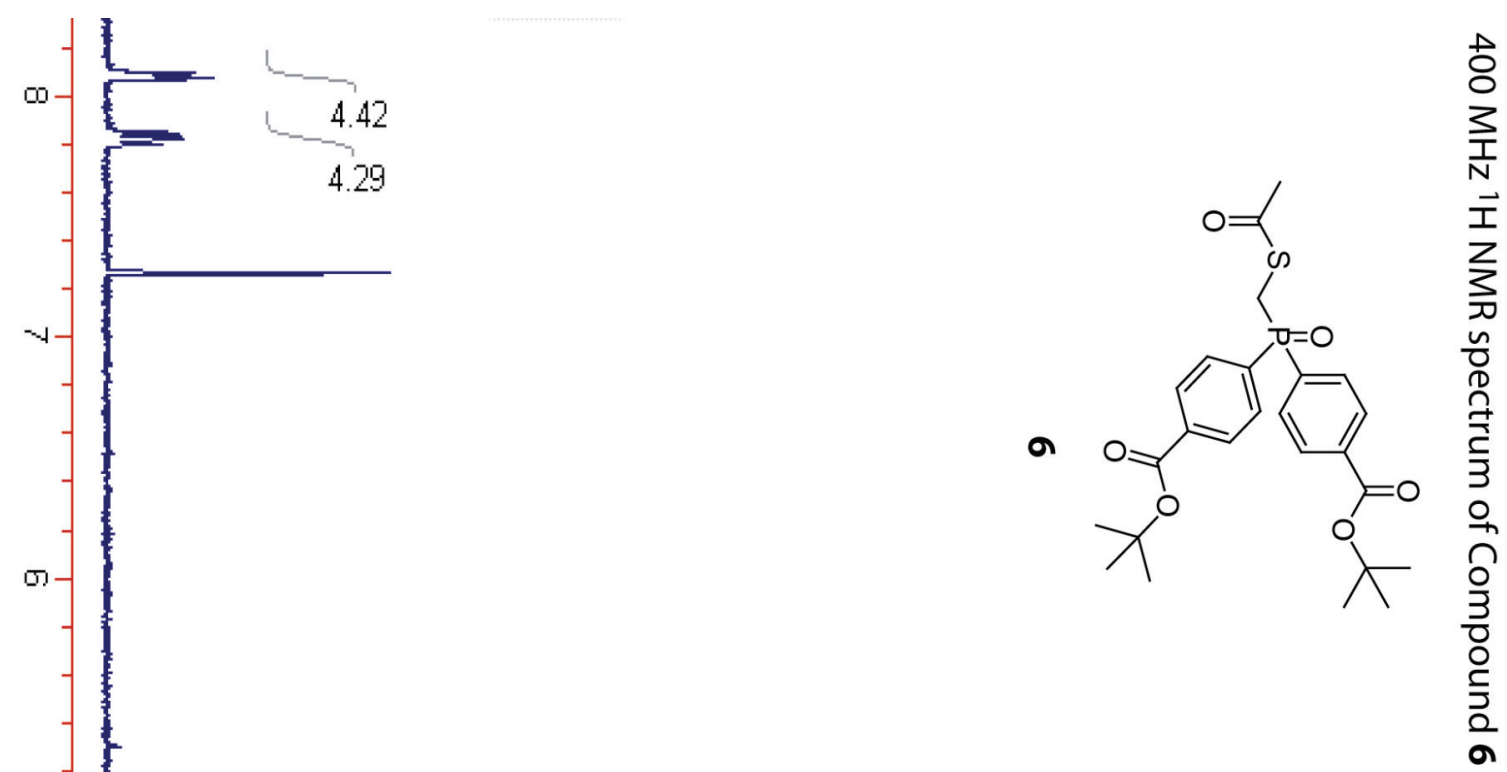

Supporting Information

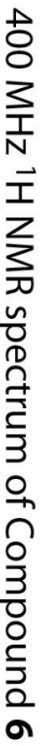

$$
\text { - }
$$

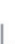

2.07

$\omega-$
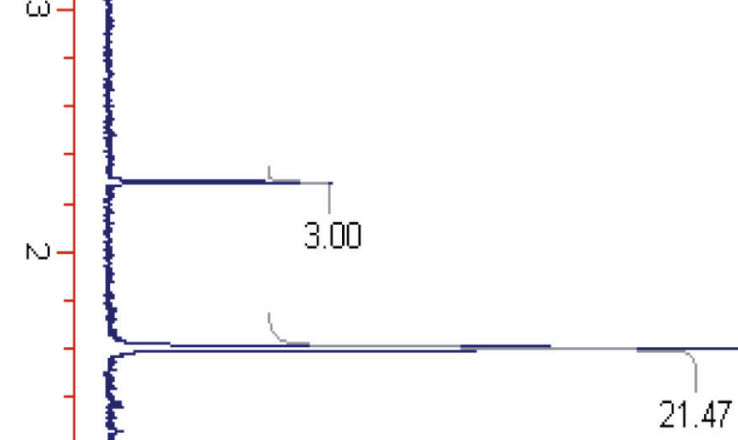


$$
E
$$




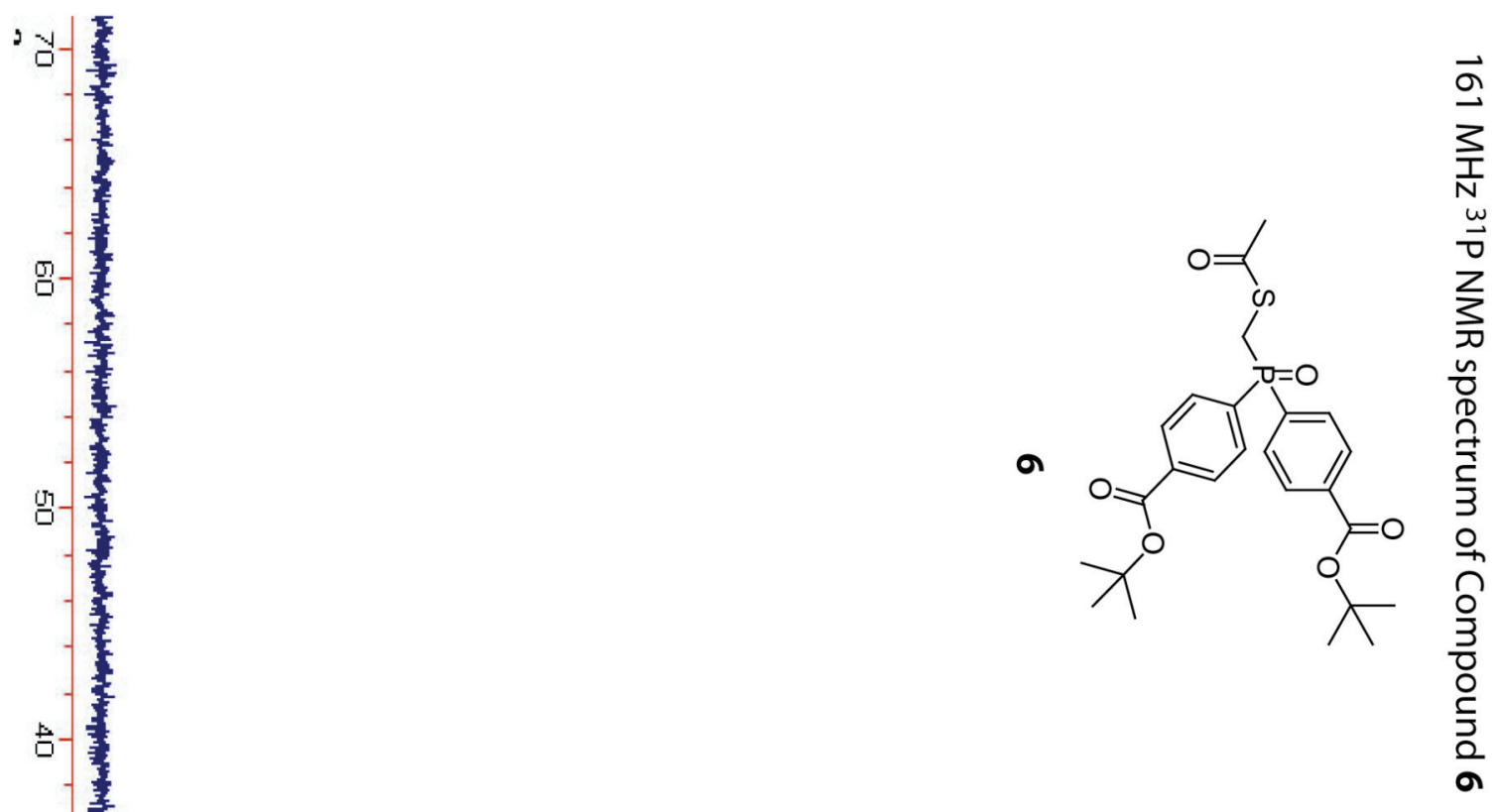

岁-

ㅁ.

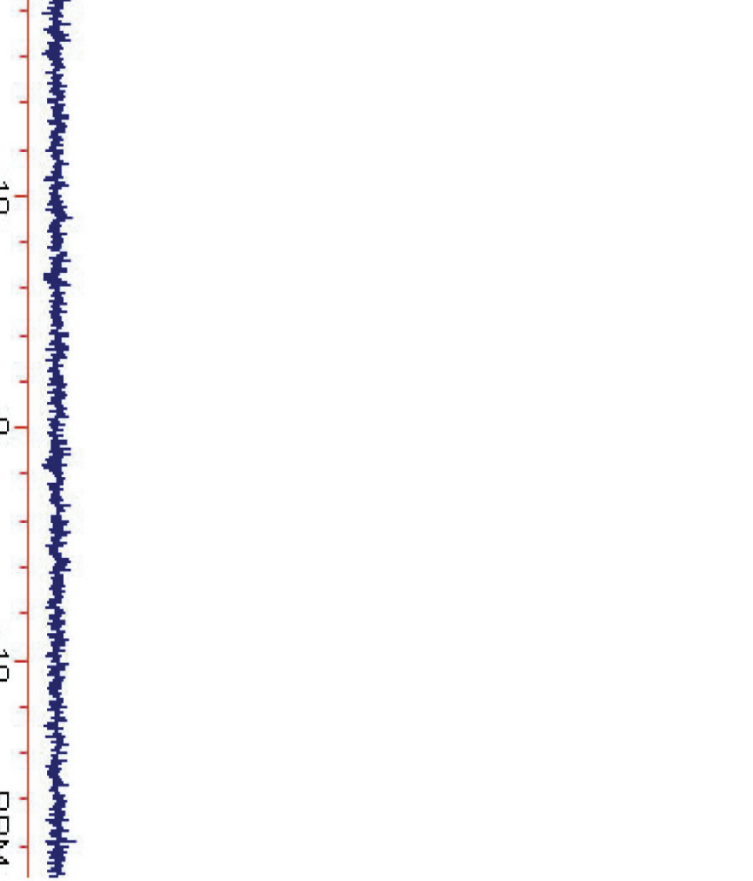


Tam et al.

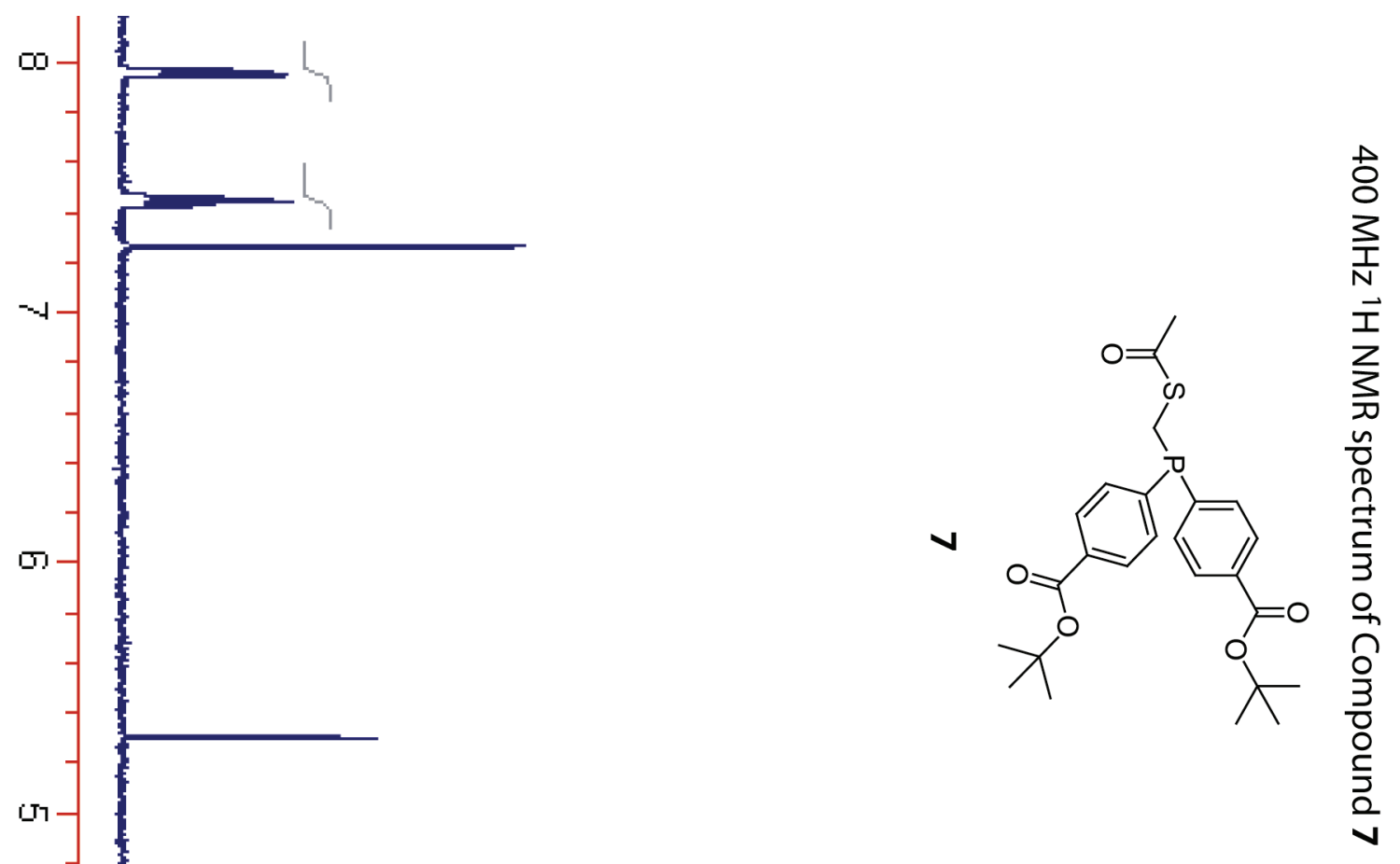

Supporting Information

$-\mathrm{S} 13-$ 

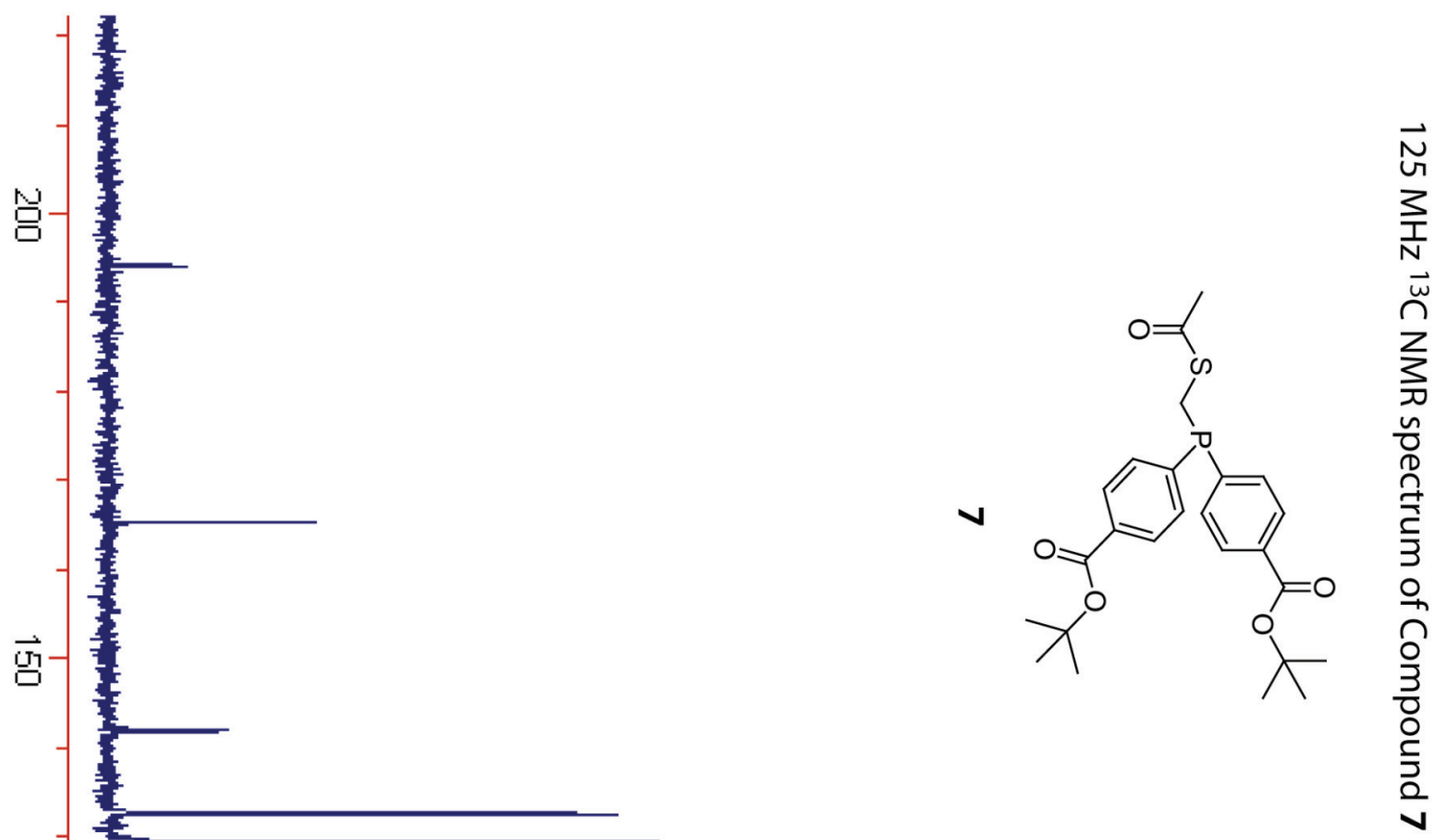

宣

佥

G

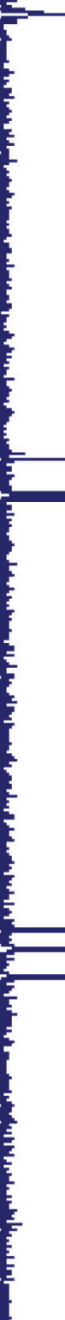



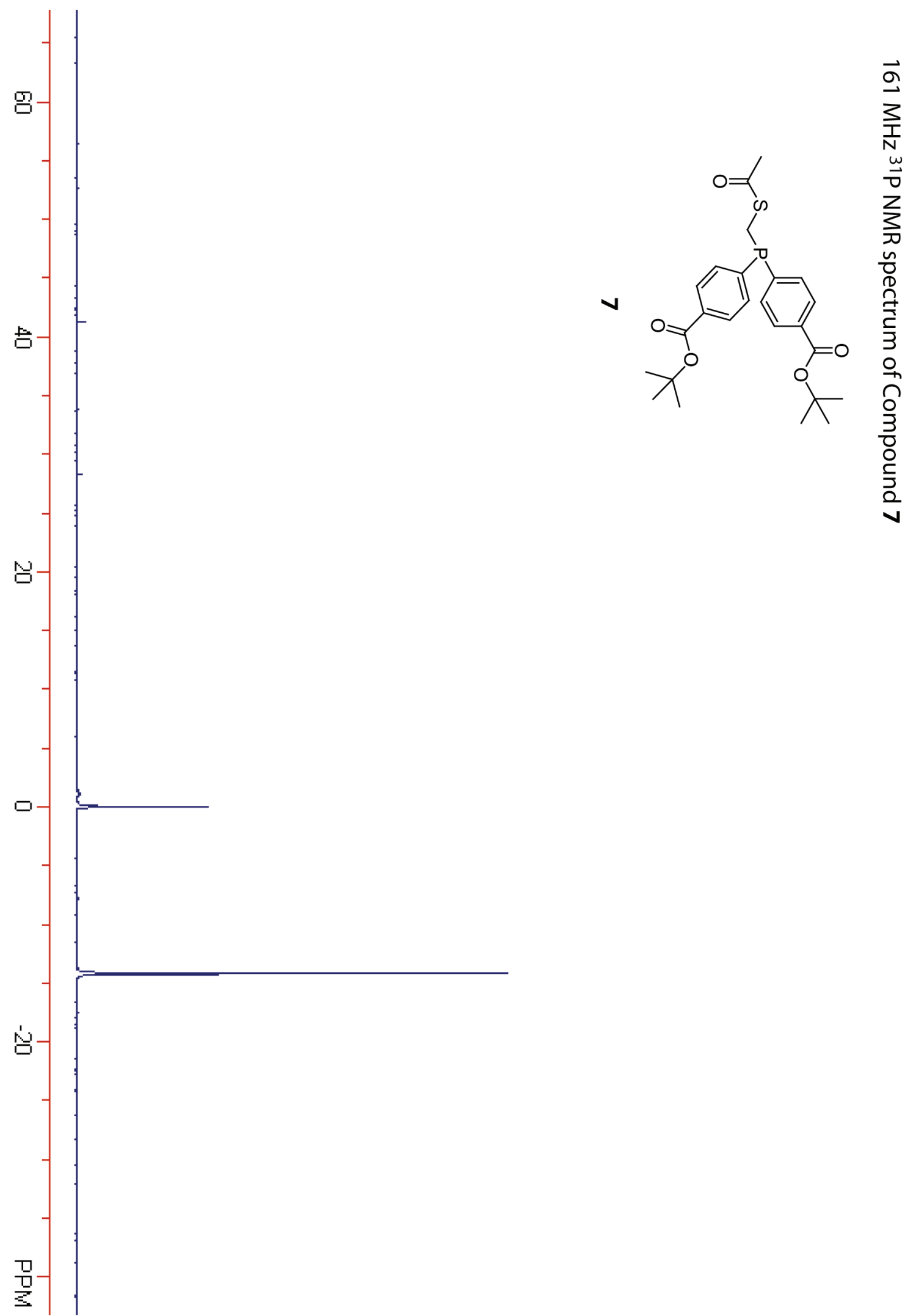
Tam et al.

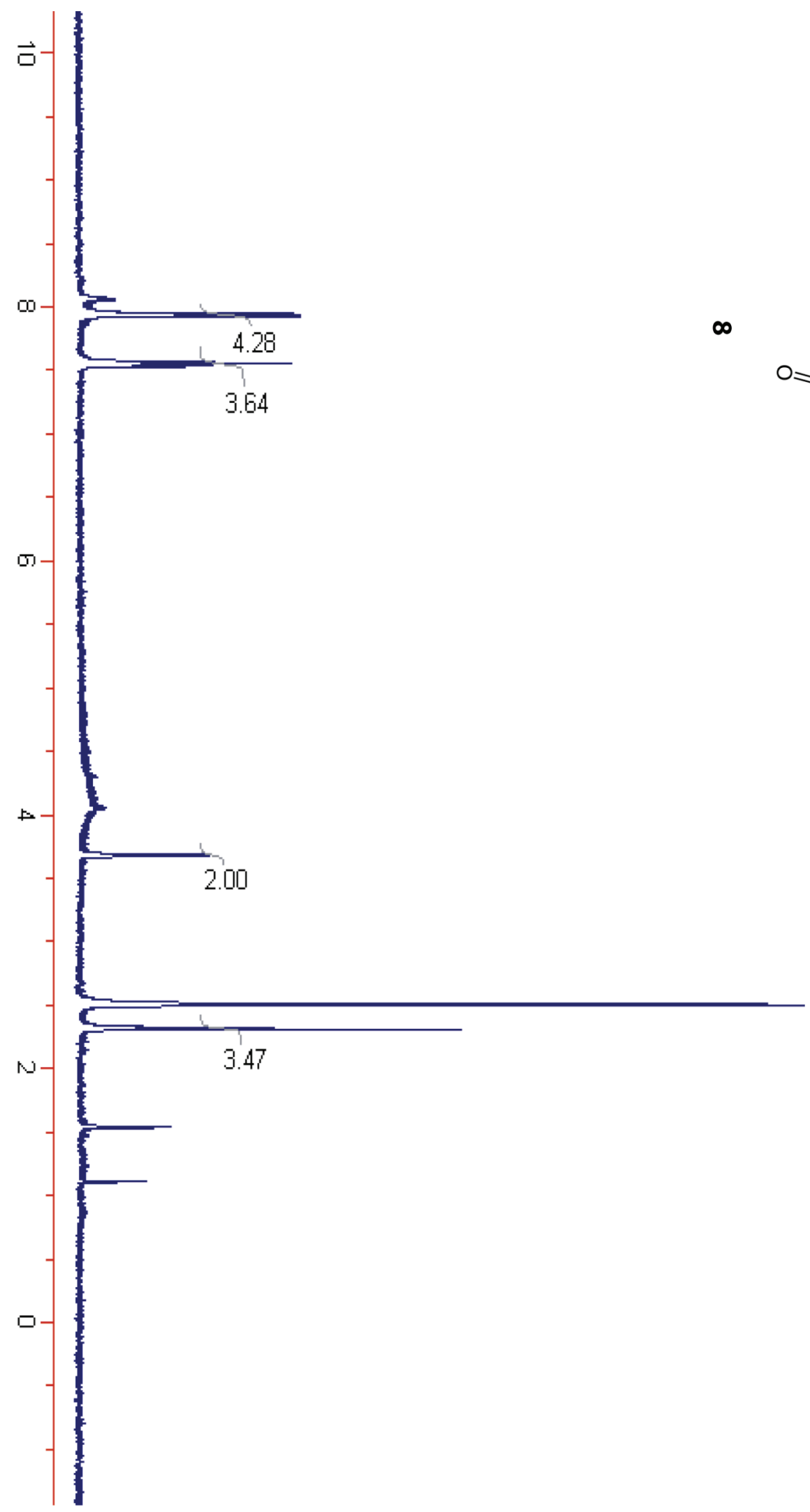

Supporting Information

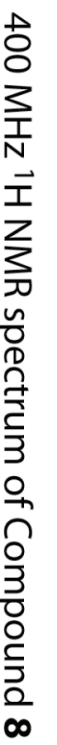


Tam et al.

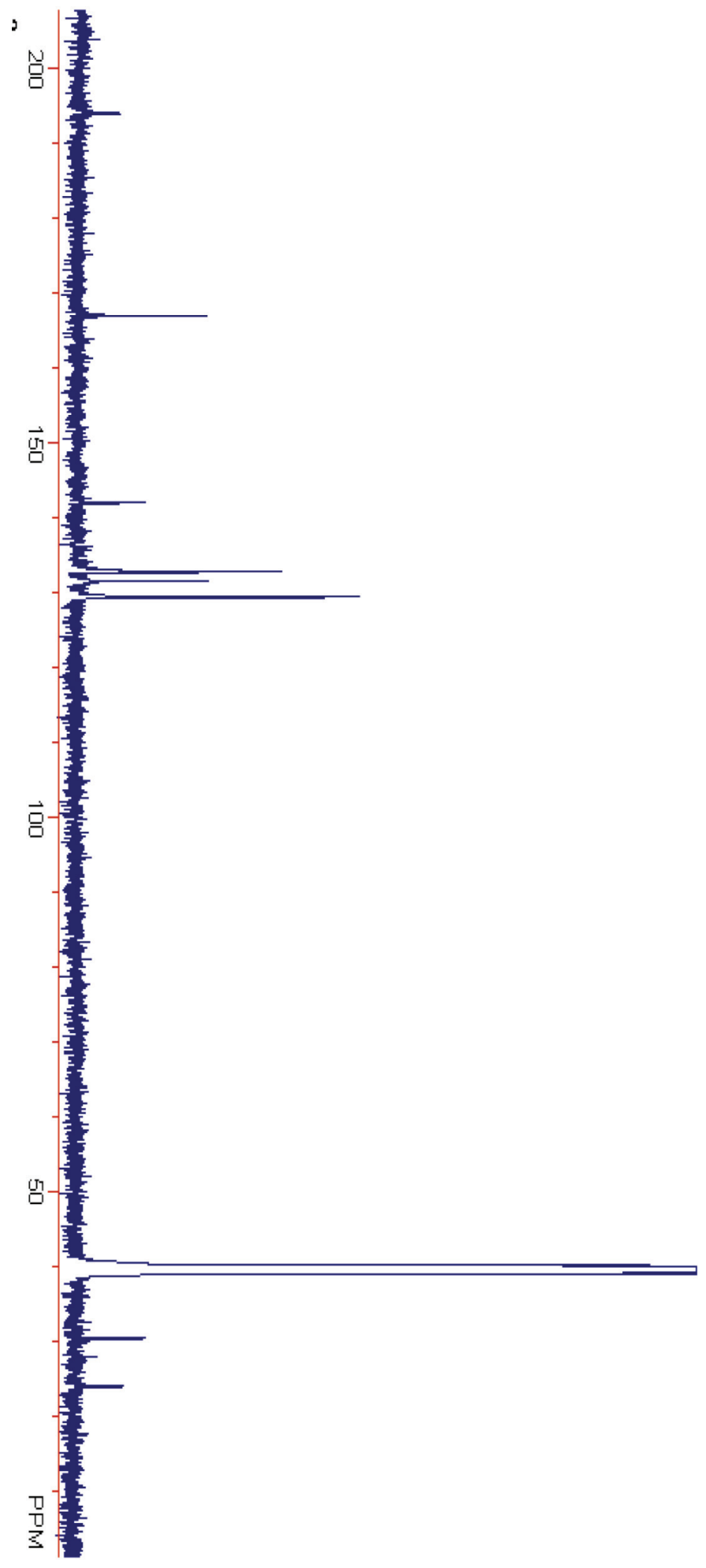

Supporting Information

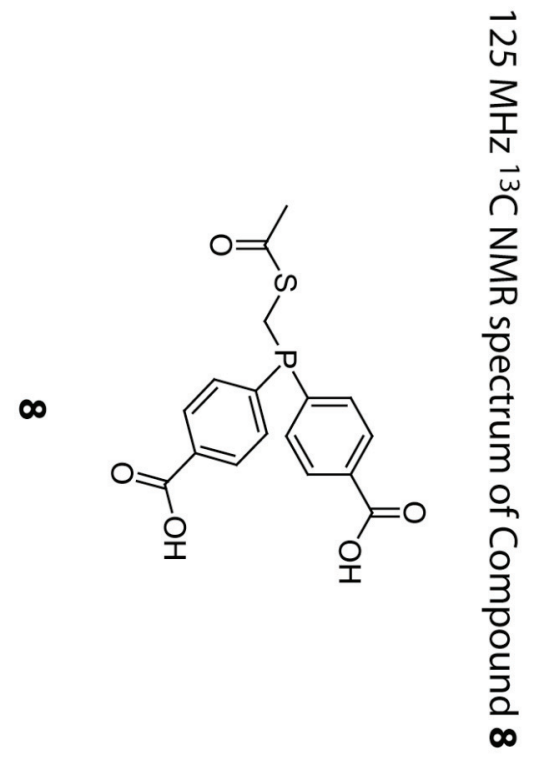

-S17- 


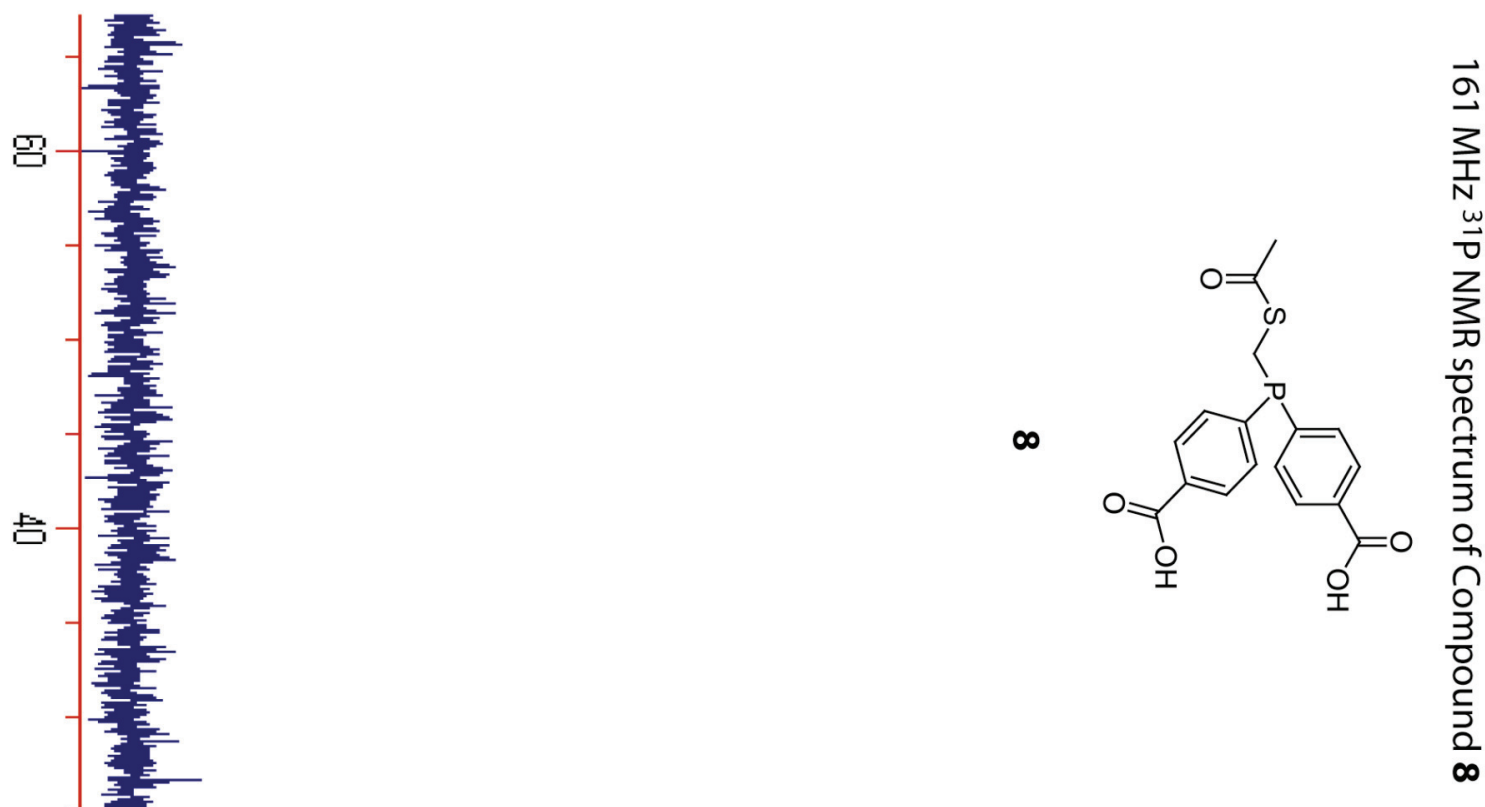

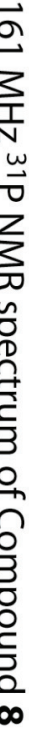

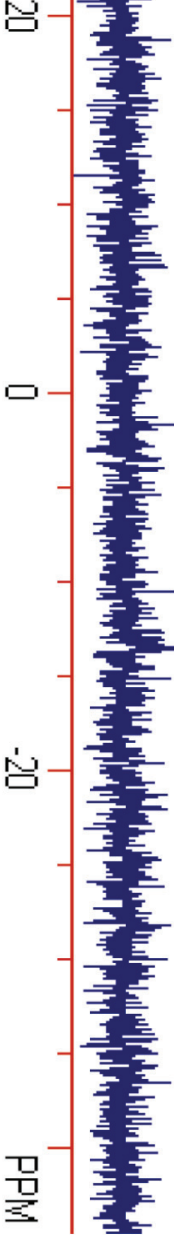




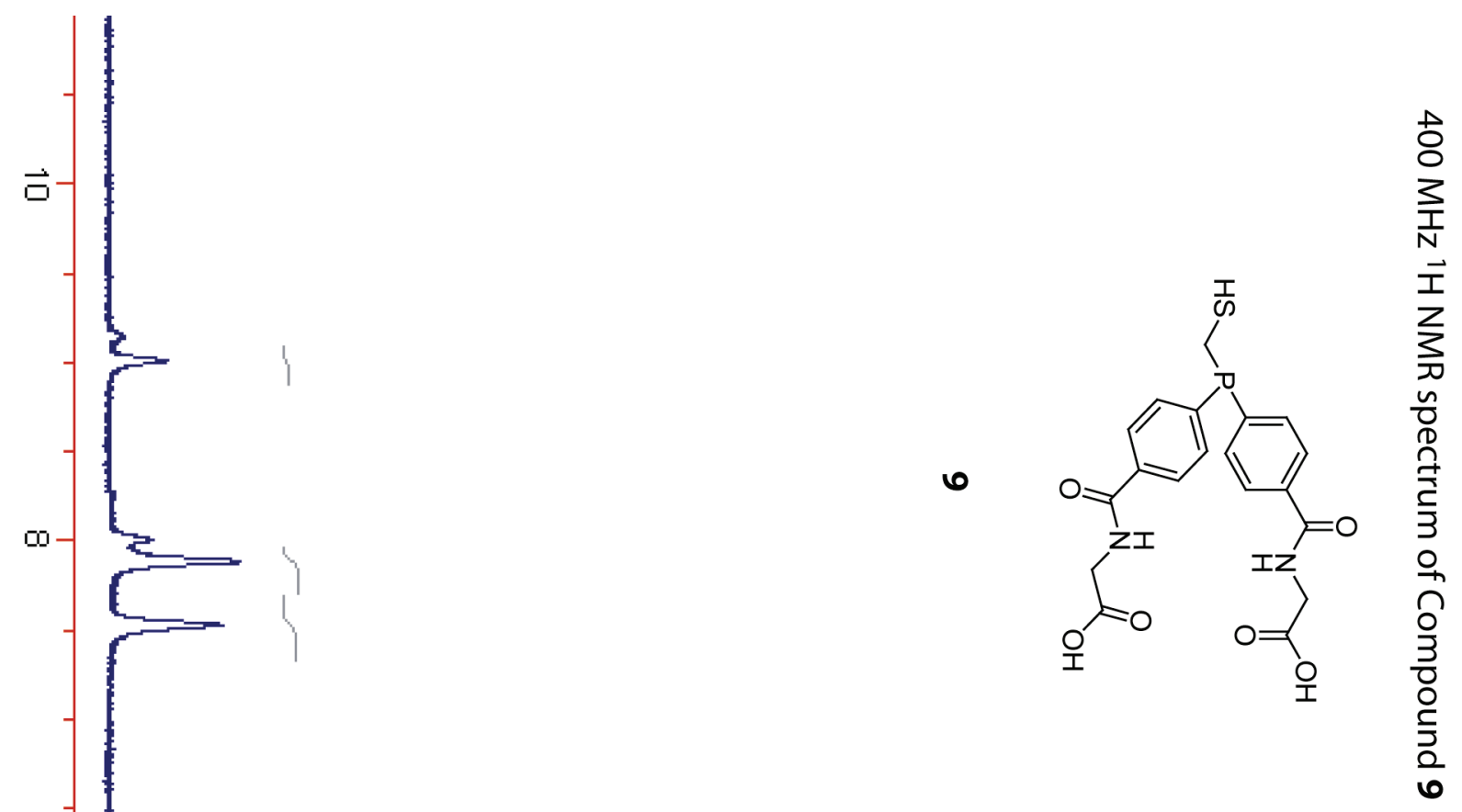

$\square$
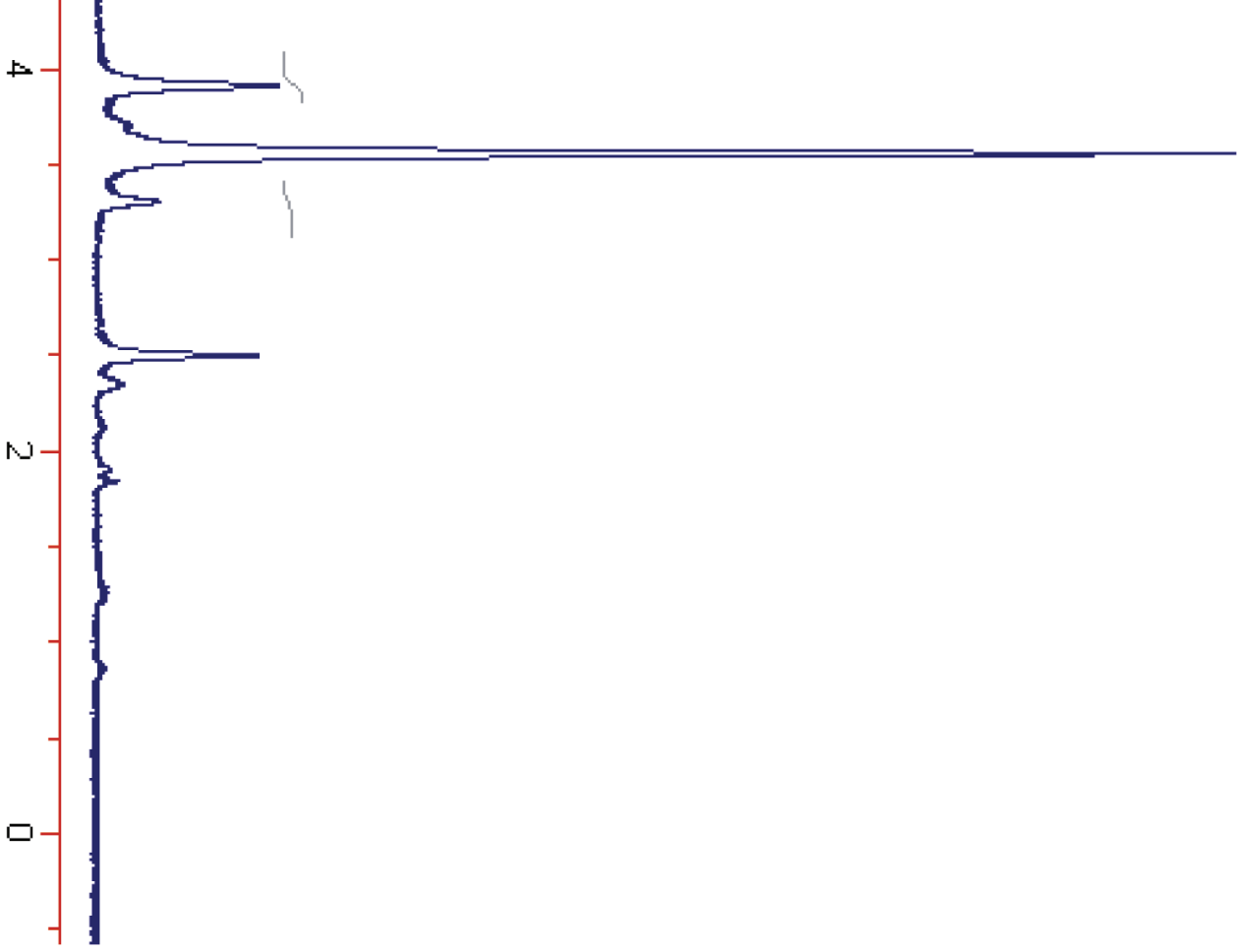


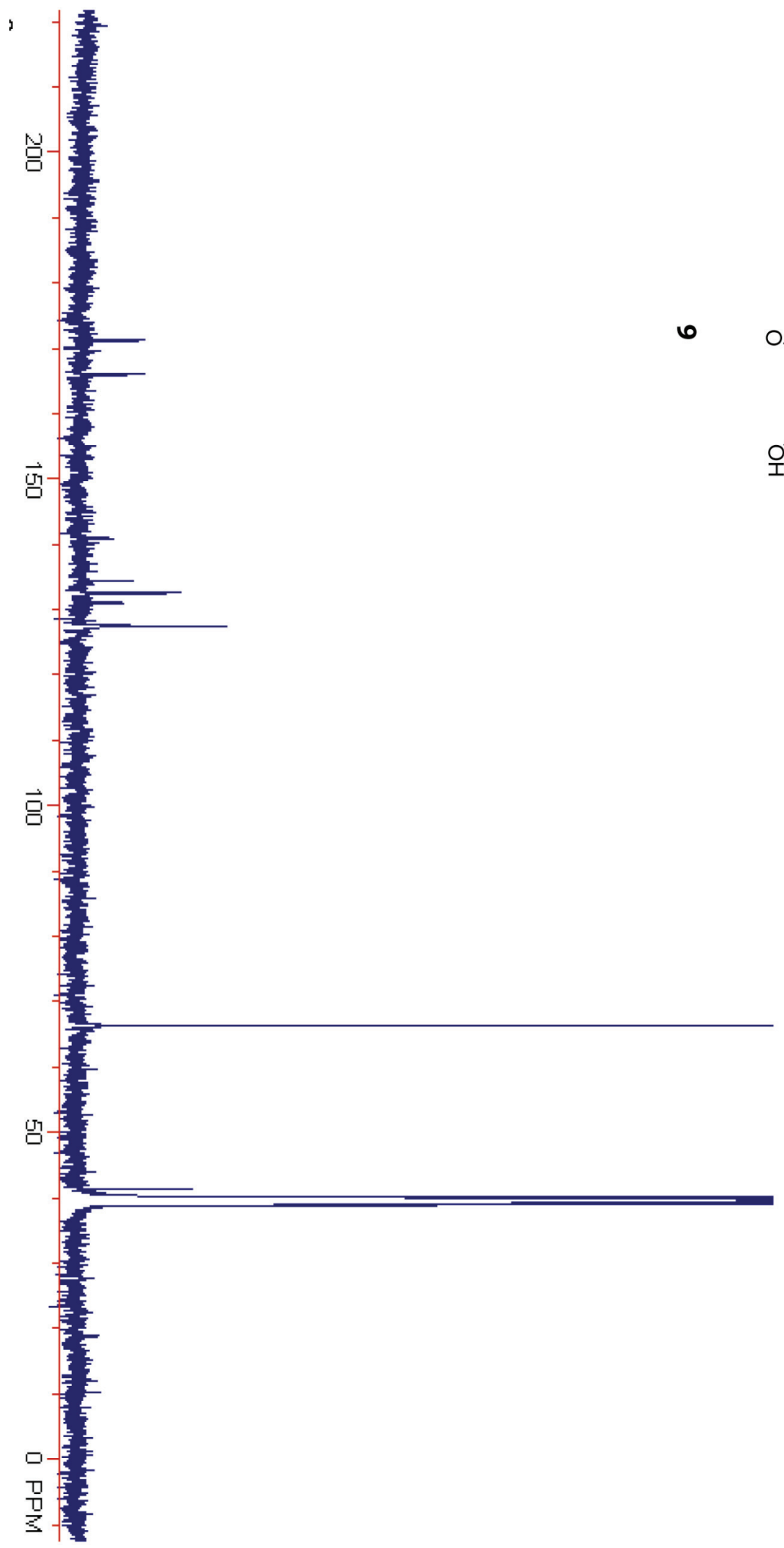



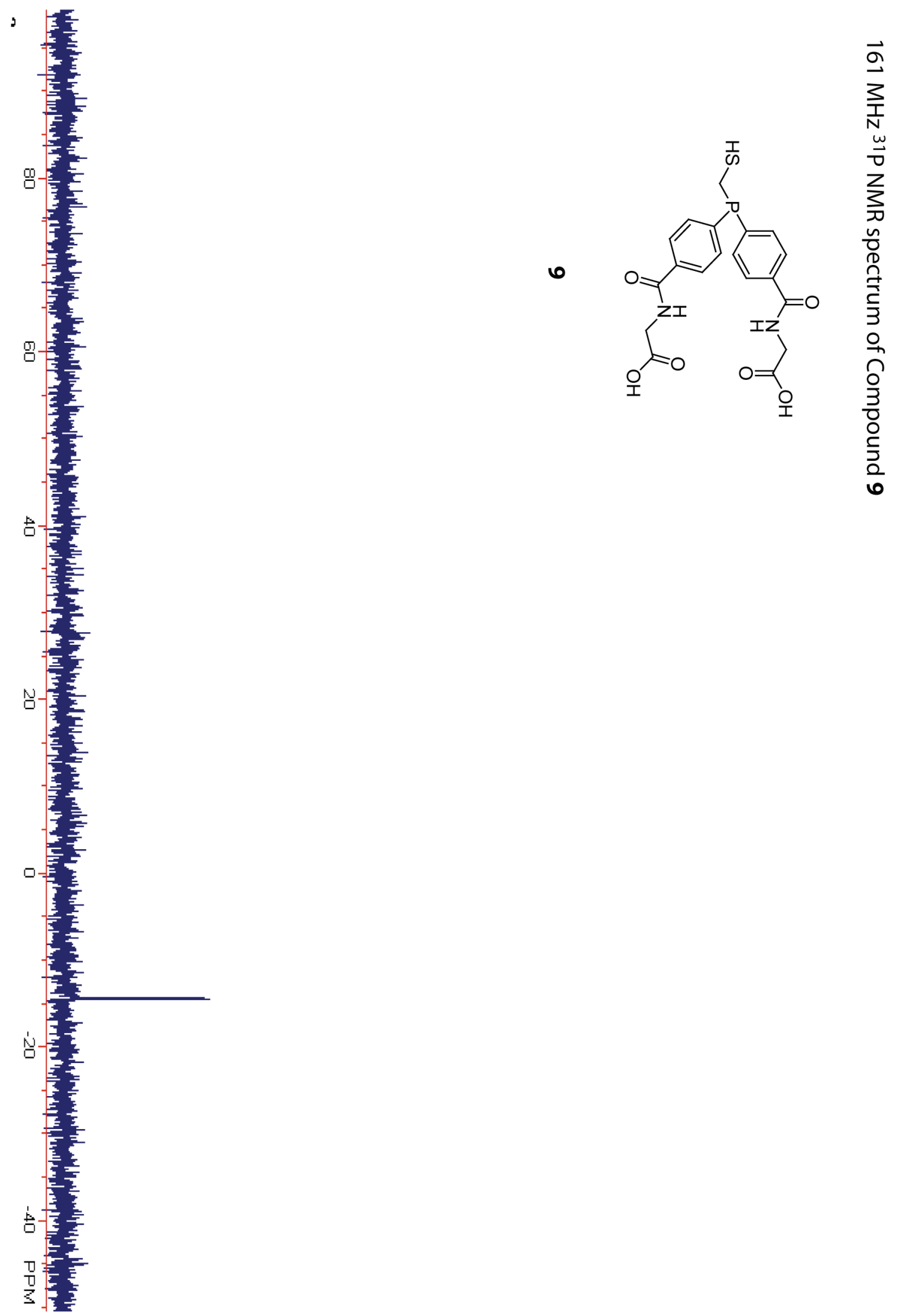

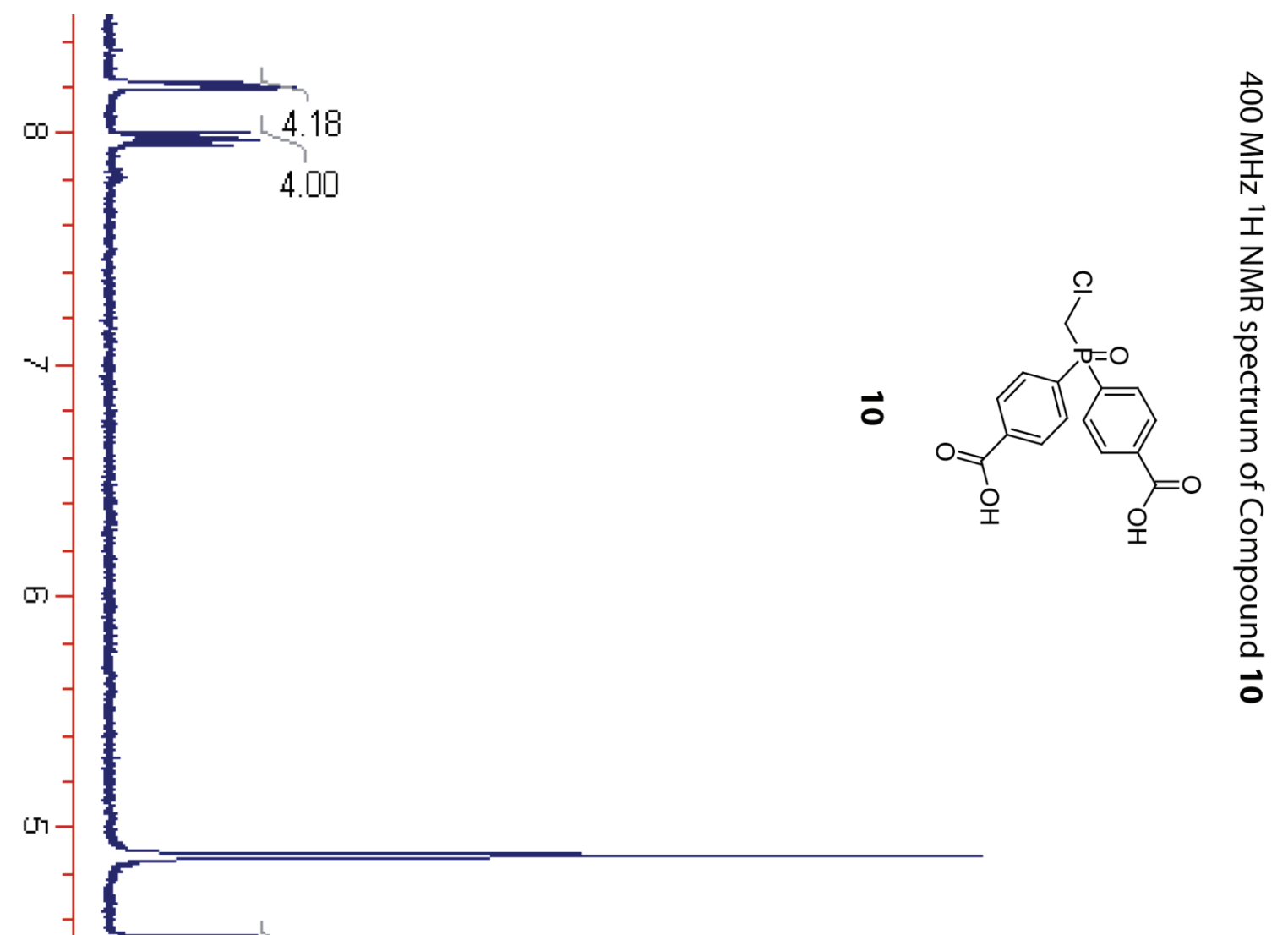

$\omega$

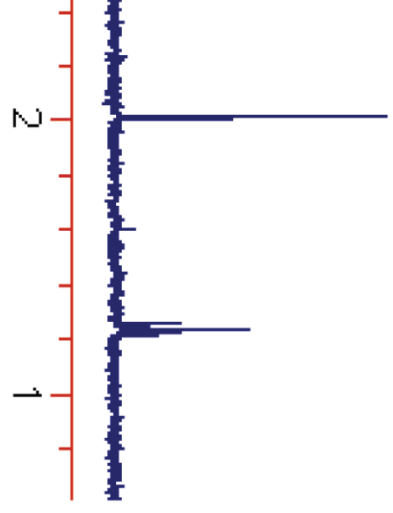




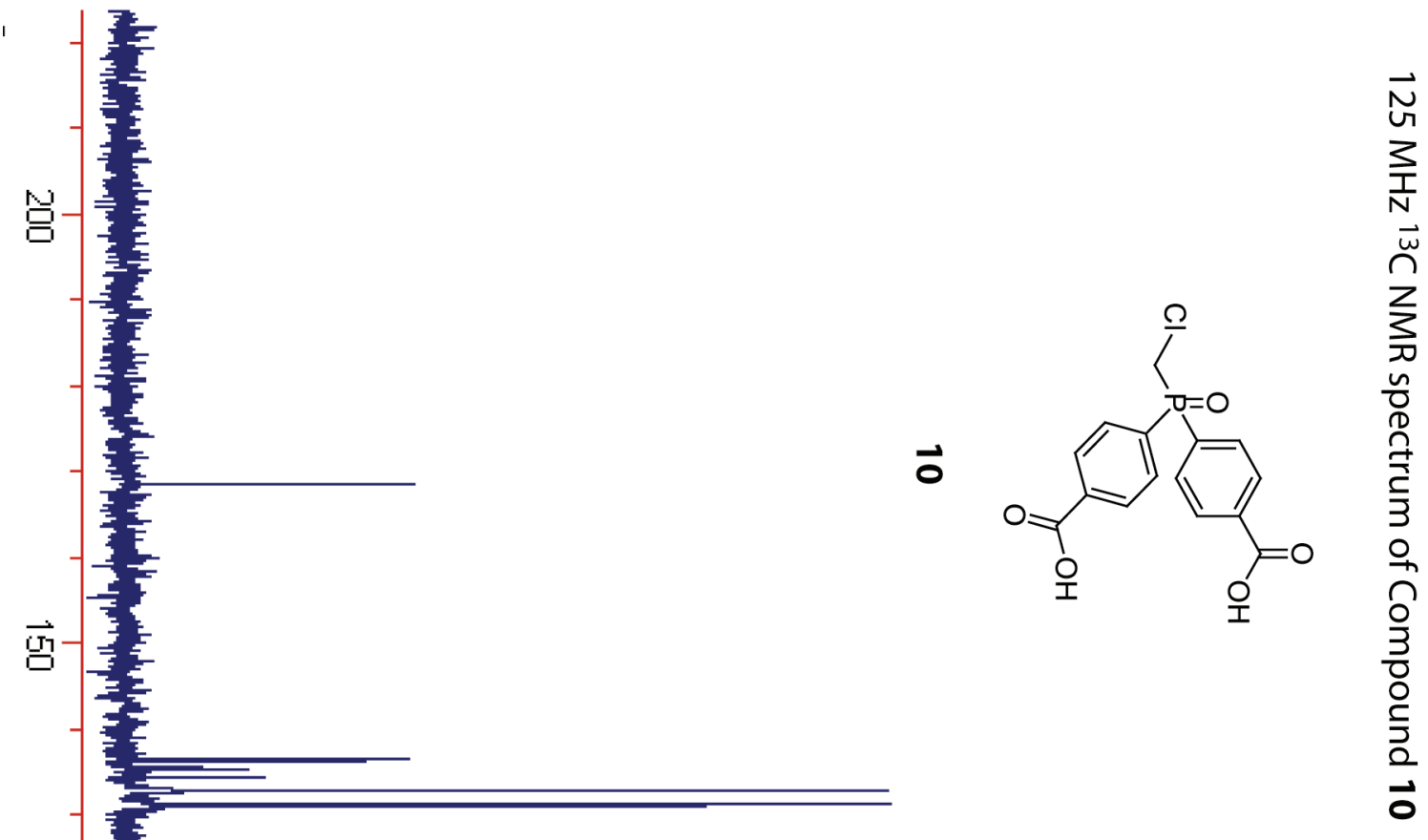

甼

言
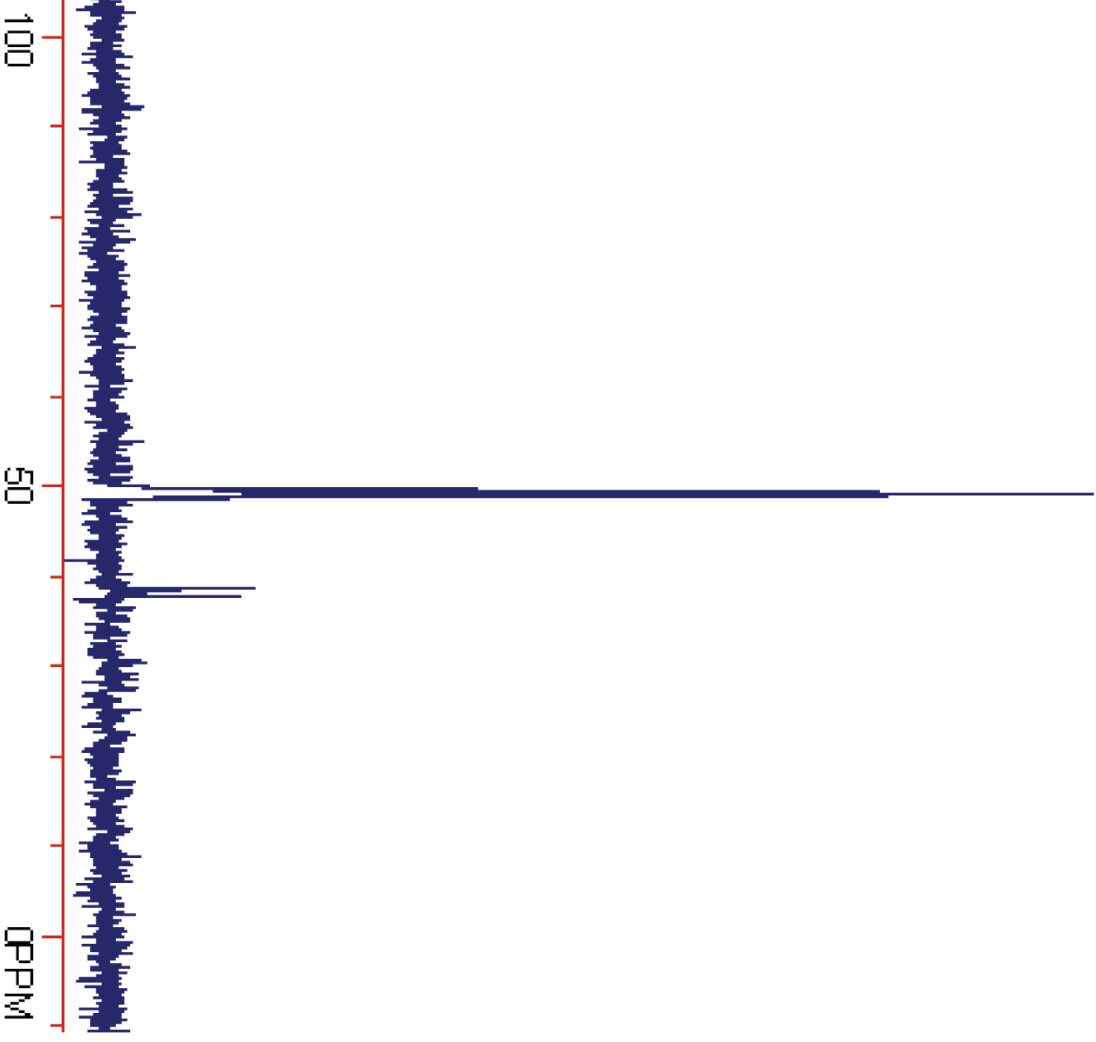


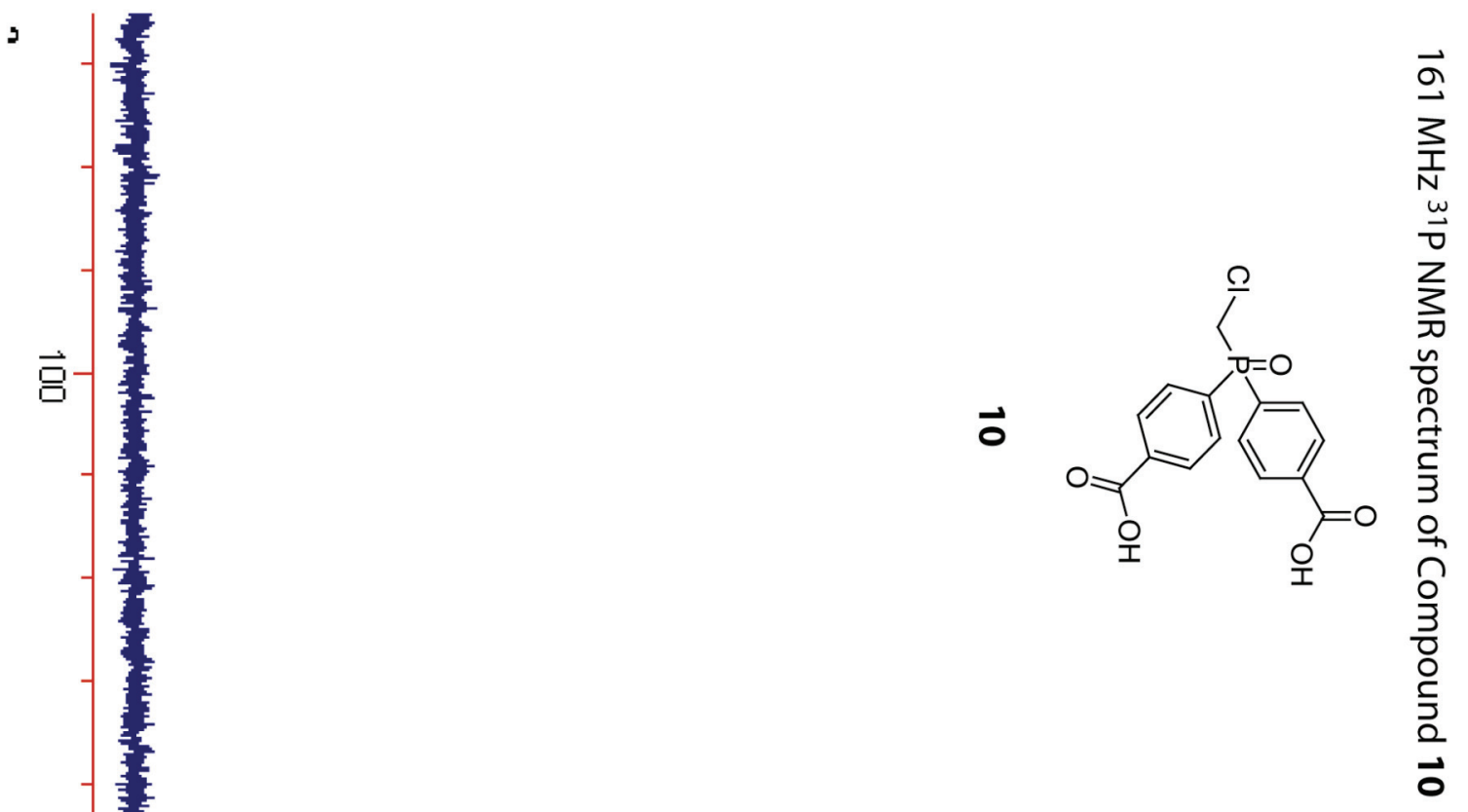

밈-

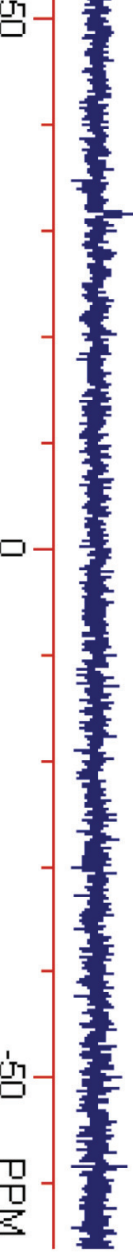

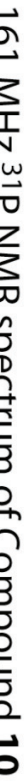




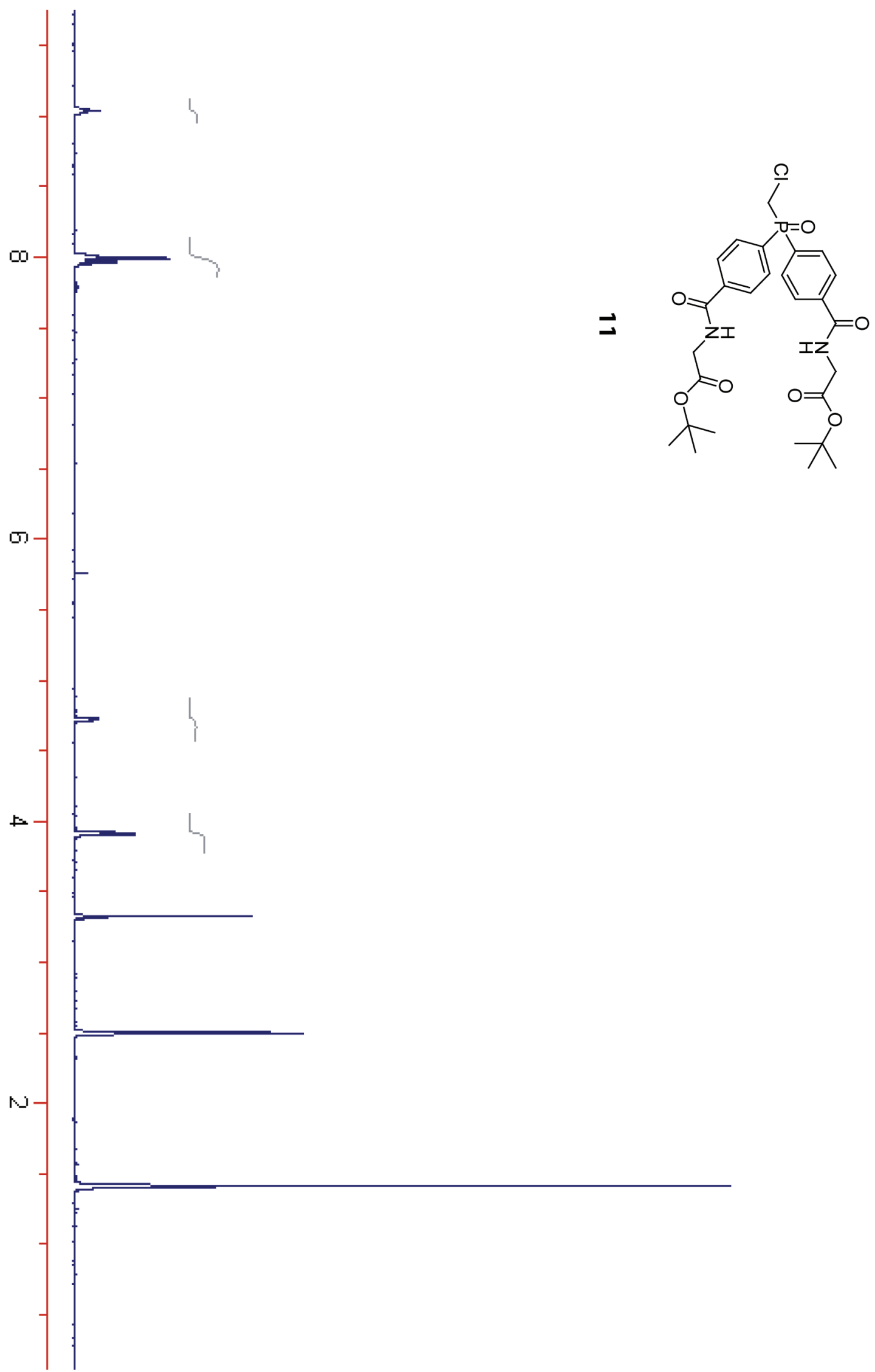

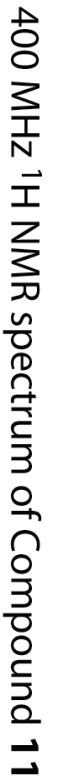




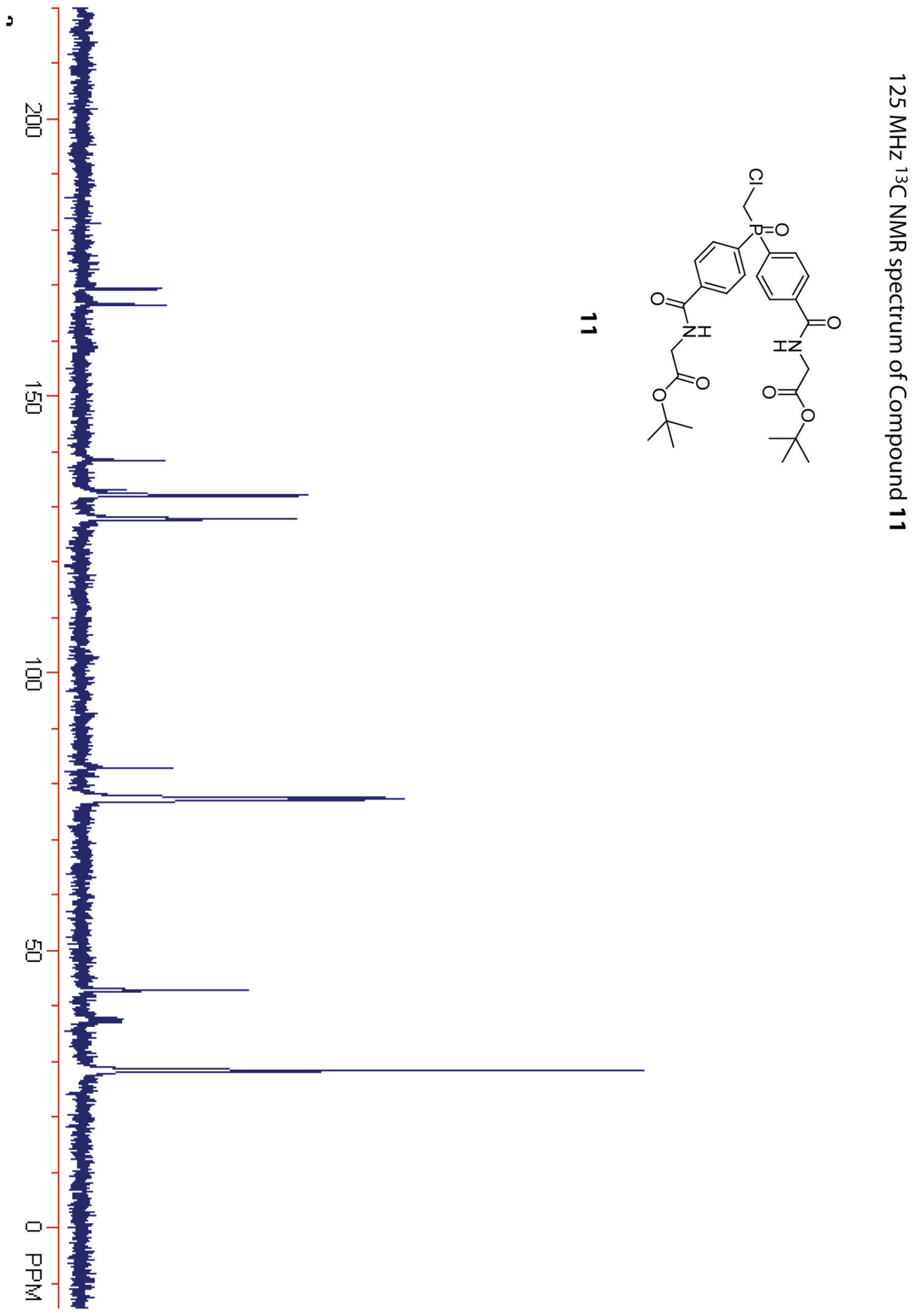


Tam et al.

Supporting Information
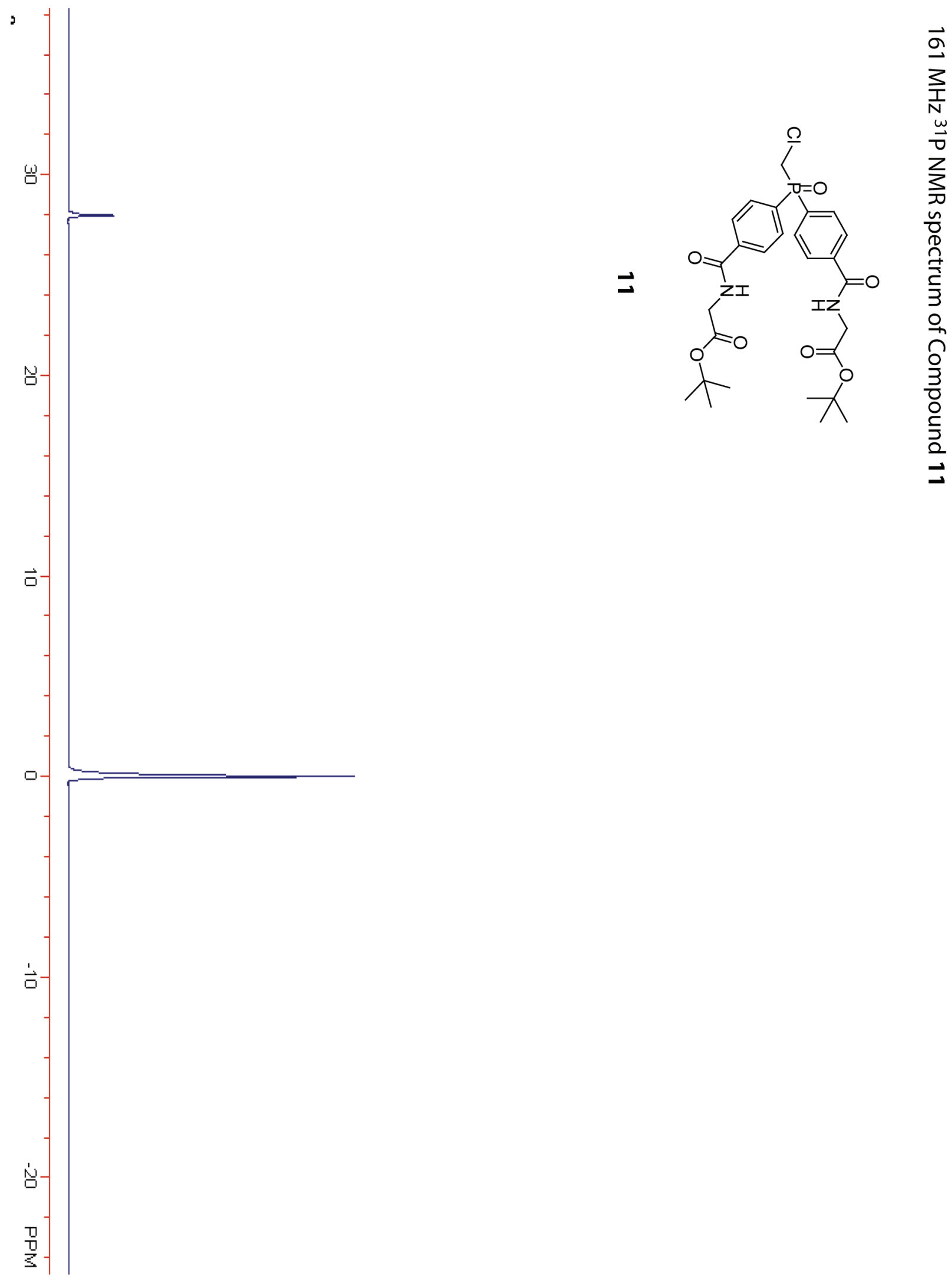

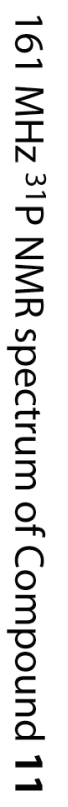


Tam et al.

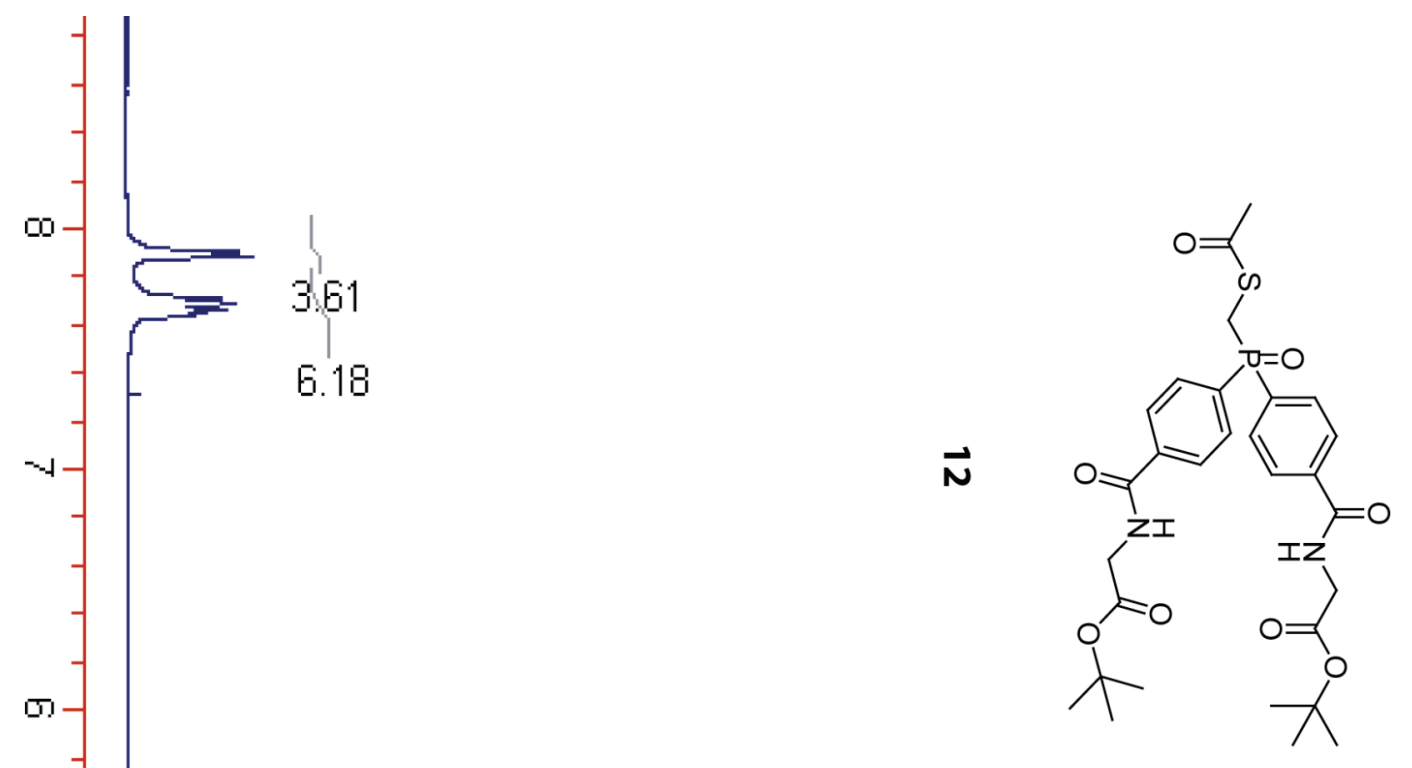

Supporting Information

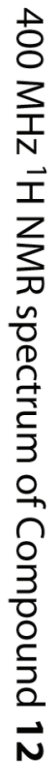

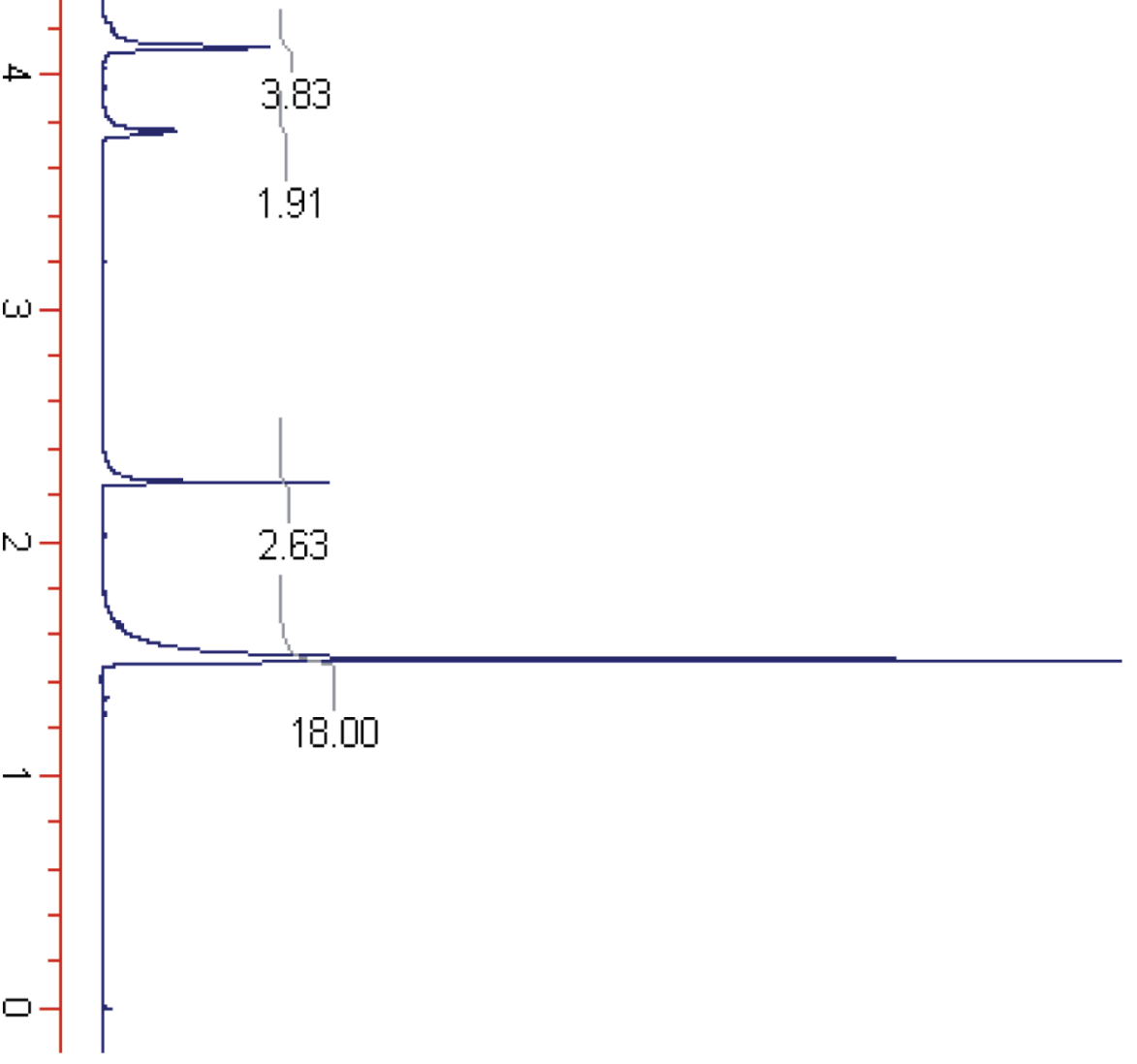


2

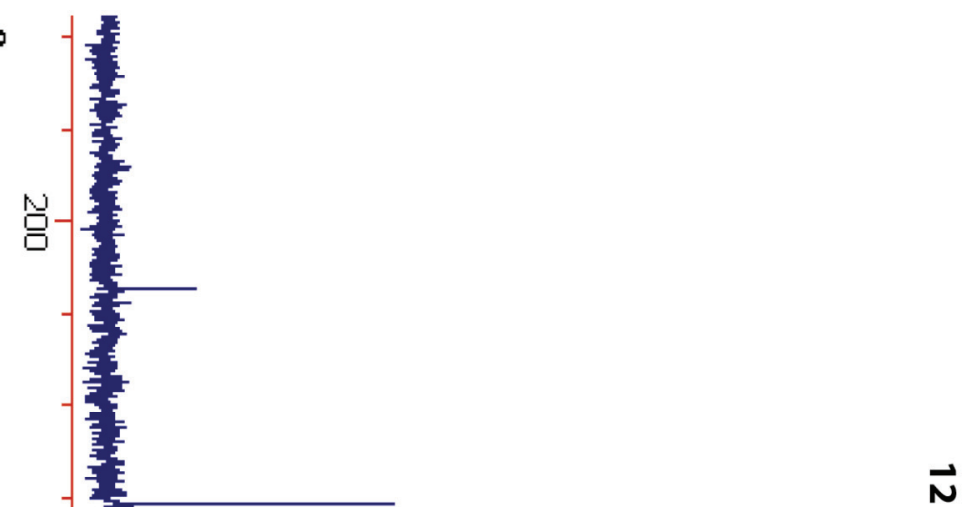

号

可
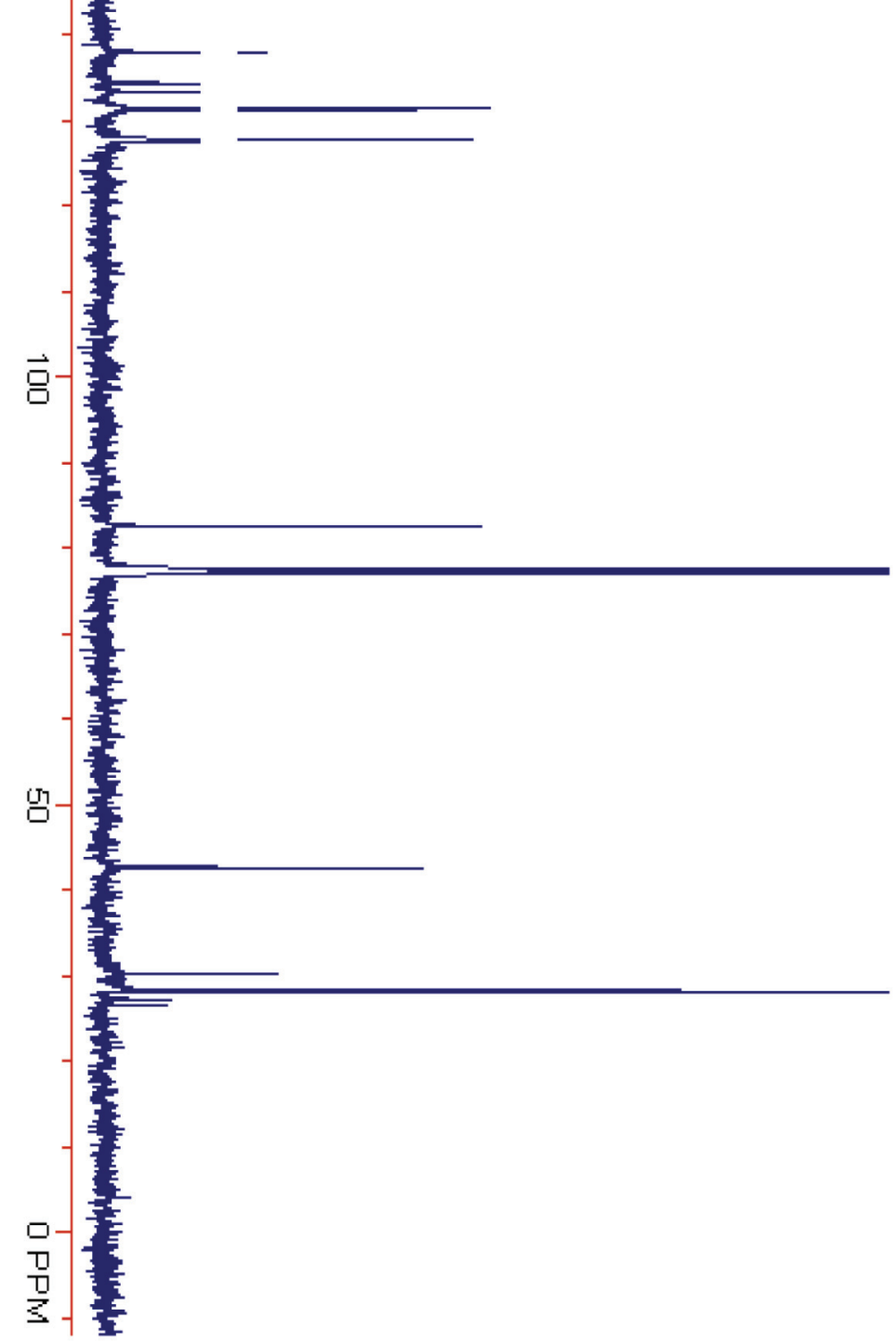

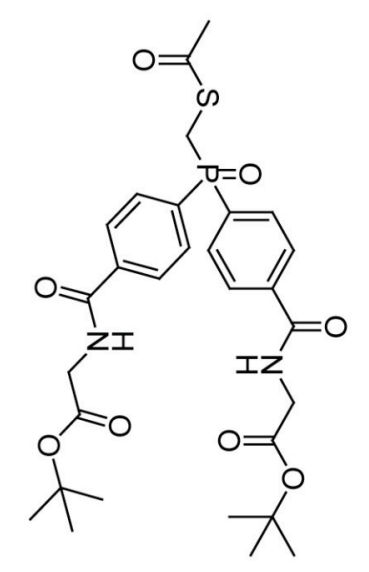

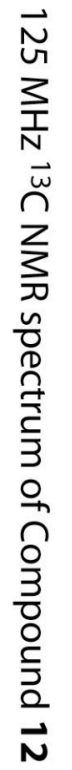




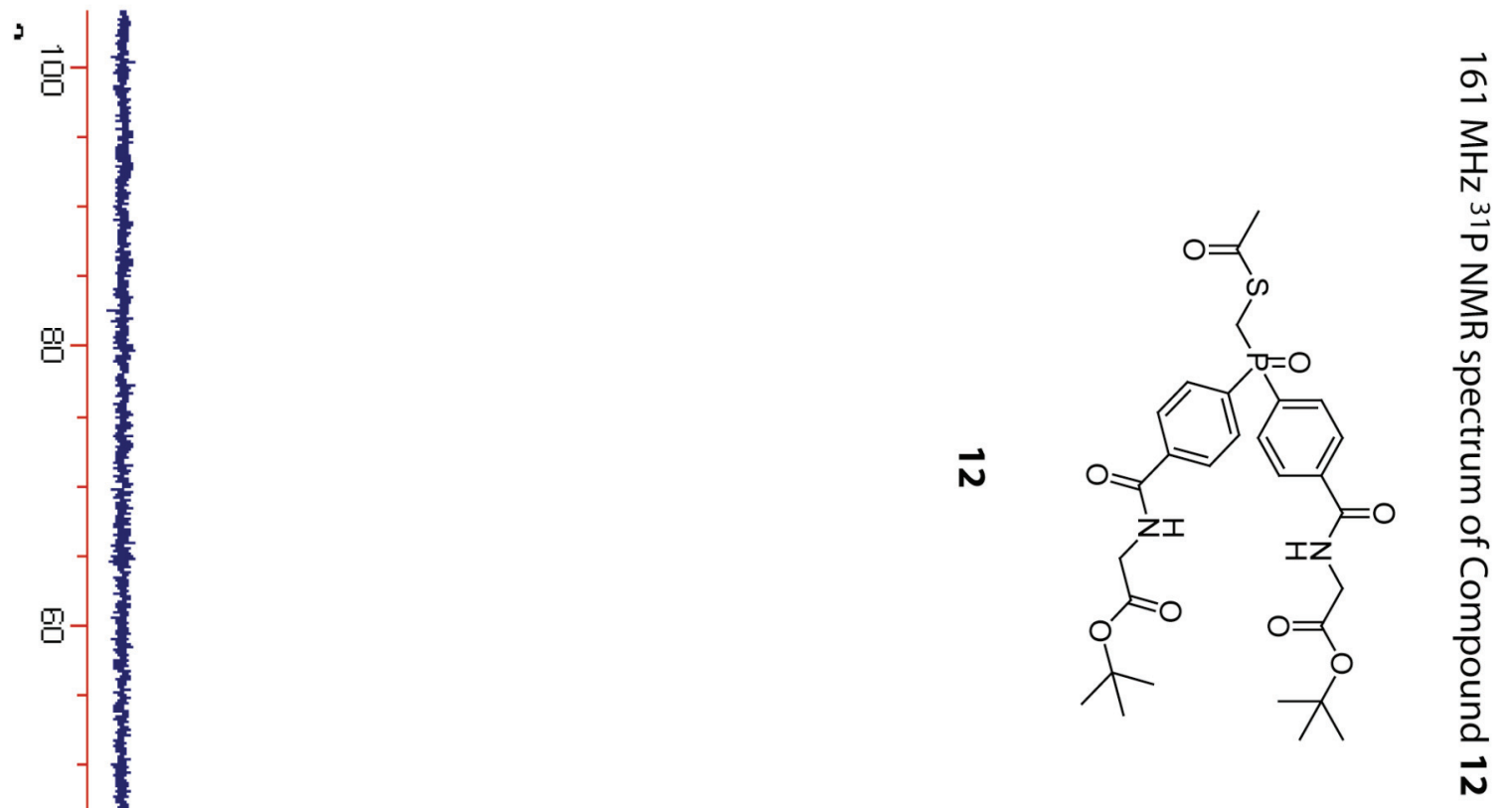

吉

븜

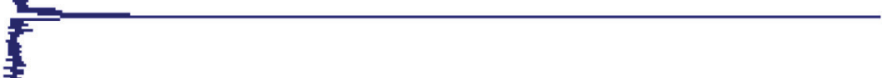

品

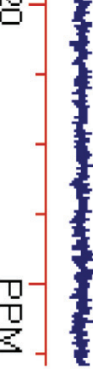




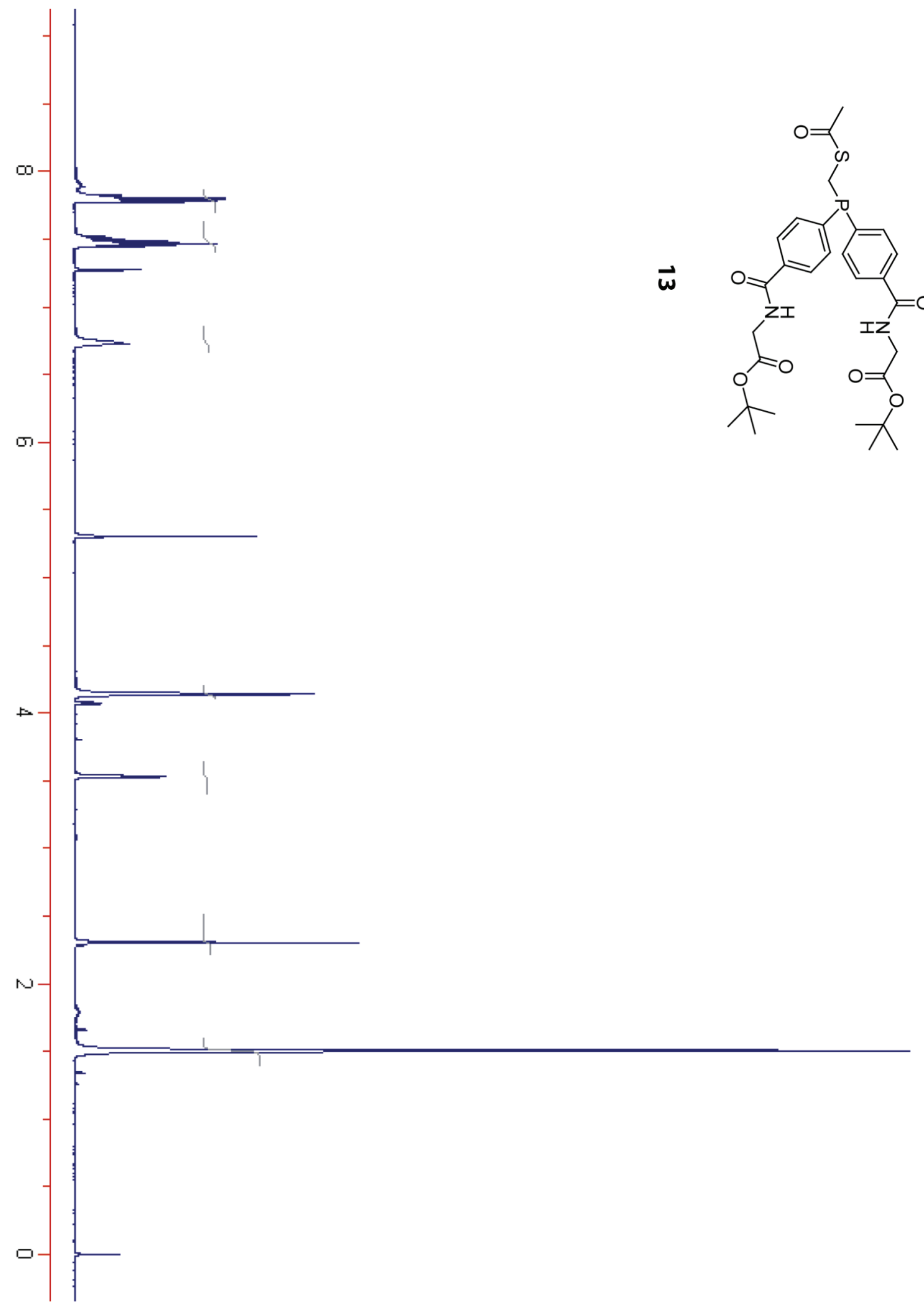

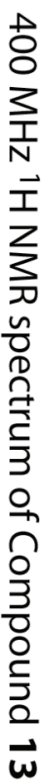


Tam et al.

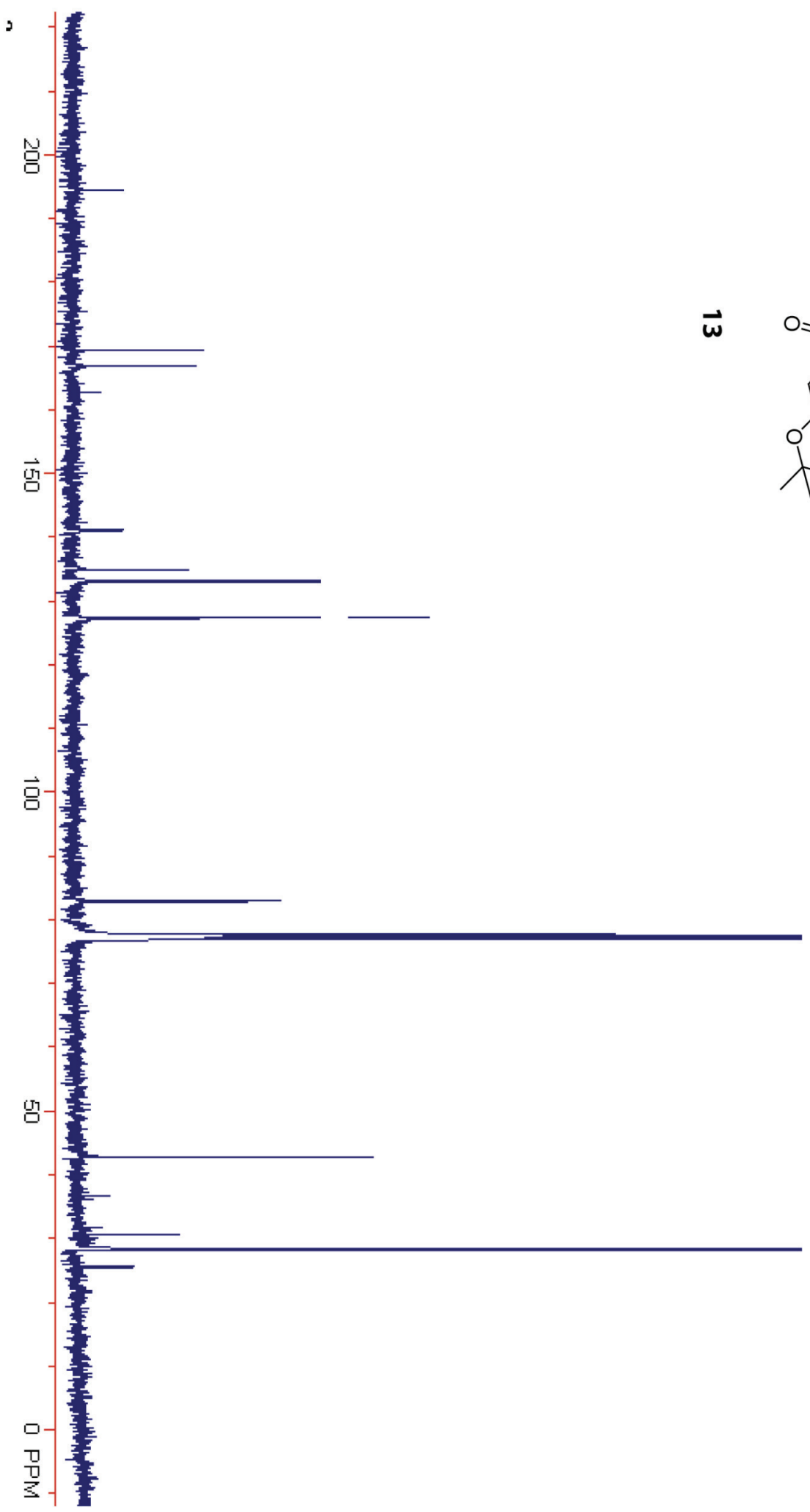

Supporting Information
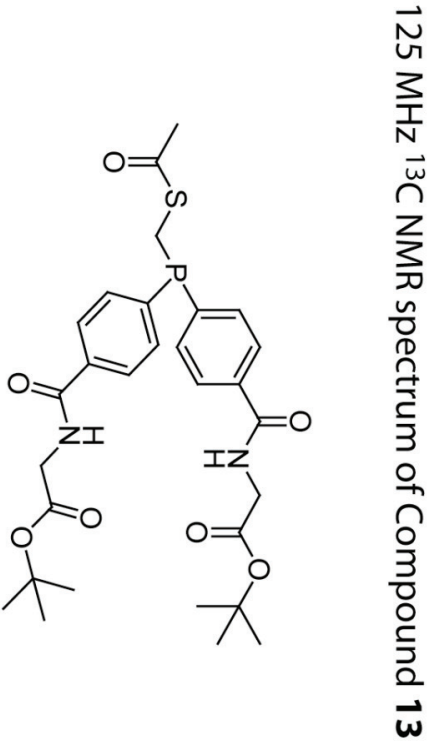

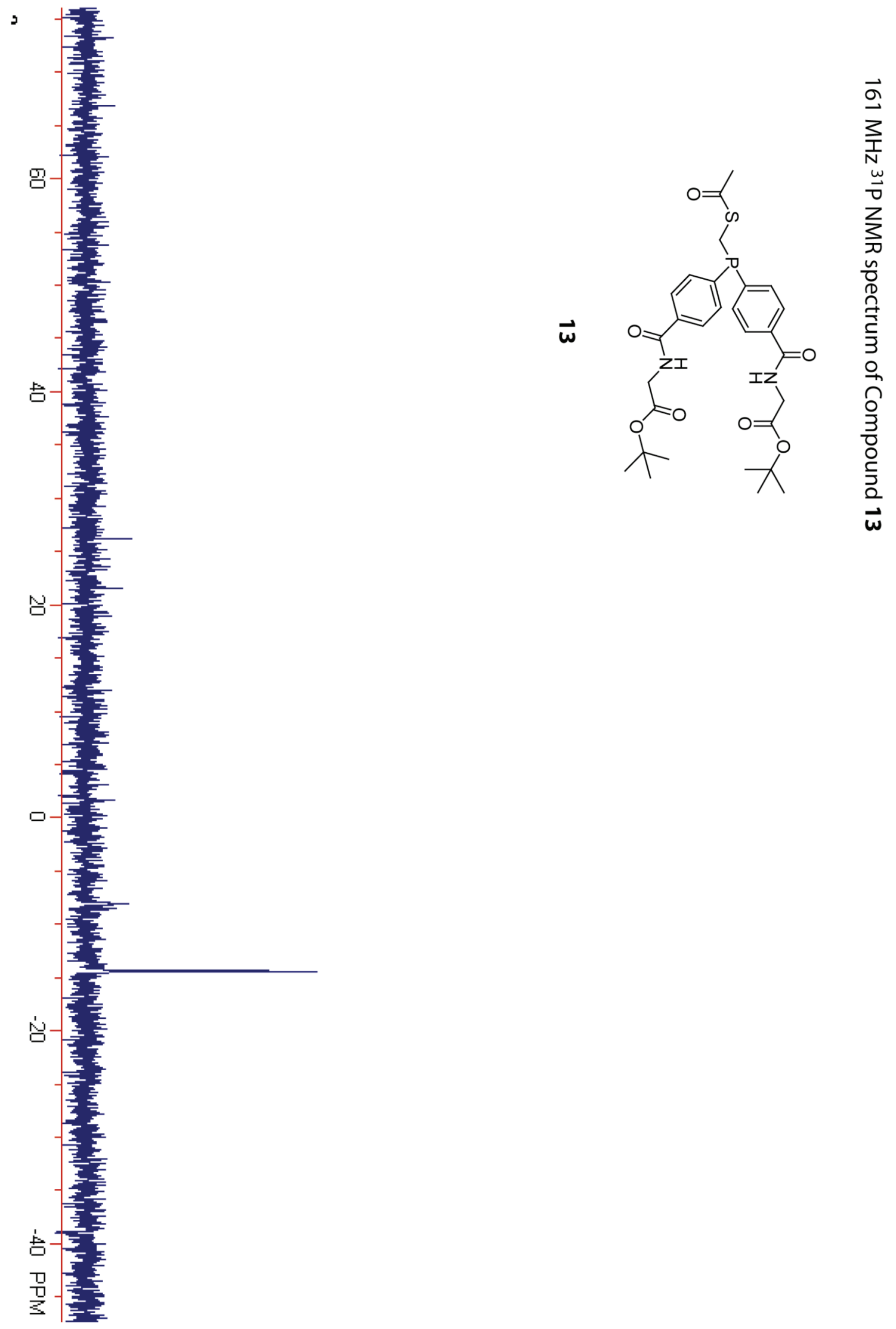

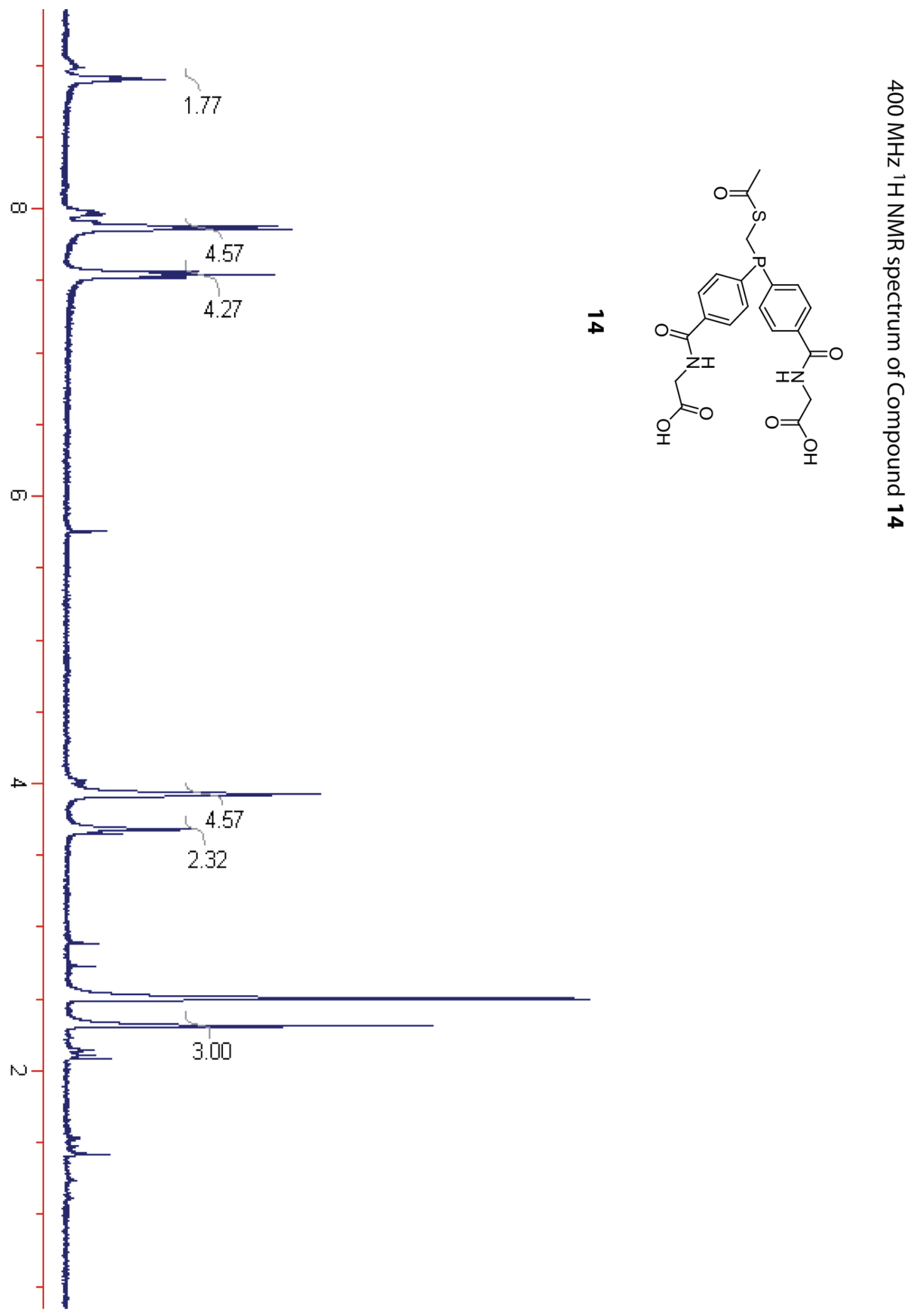


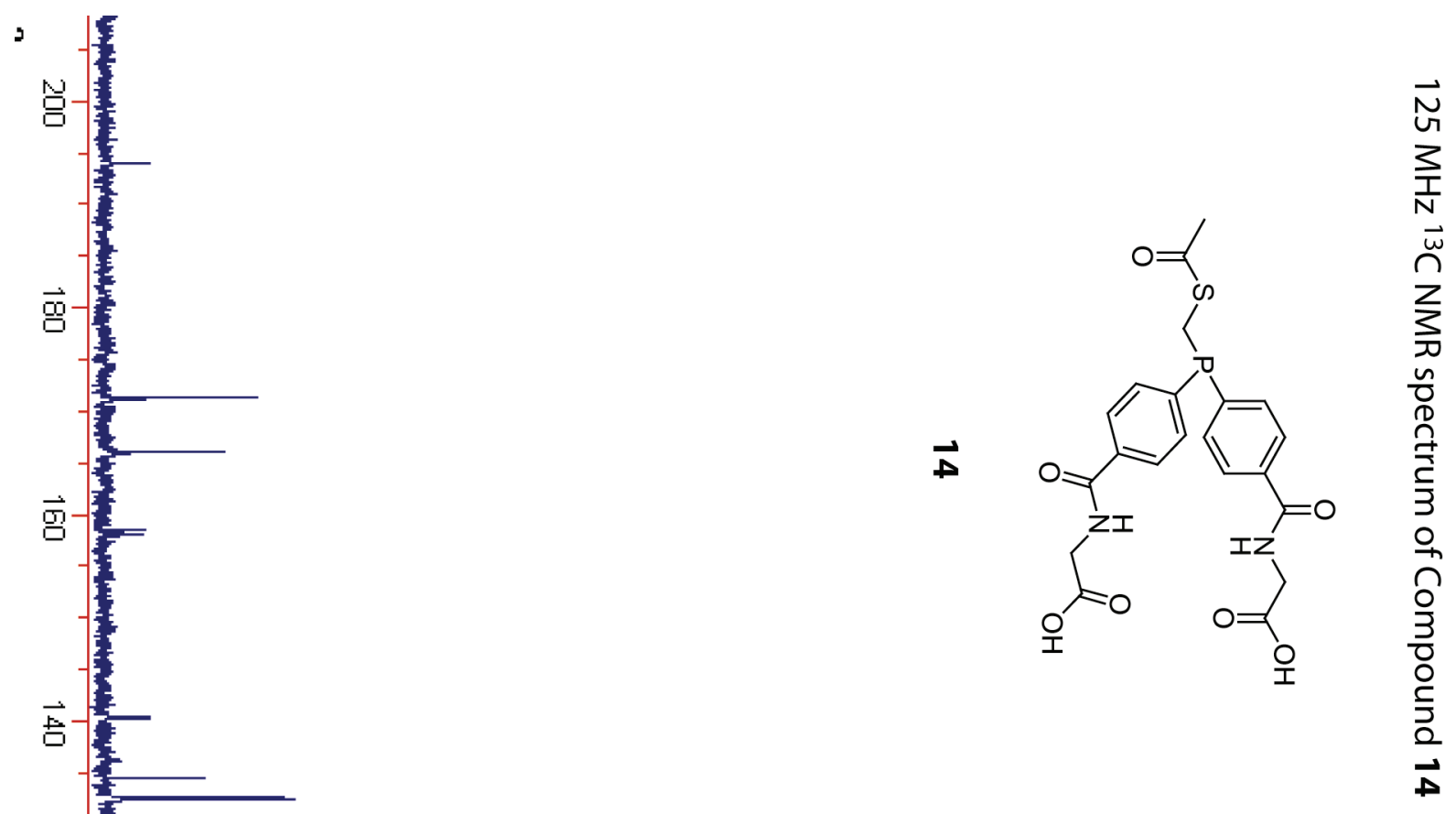

g-

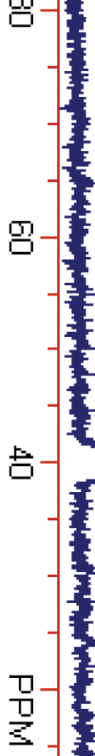

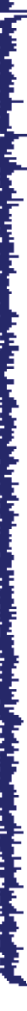

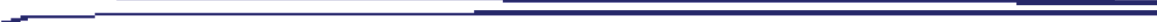

F

$-$

믄

$\Xi$ 
Tam et al.

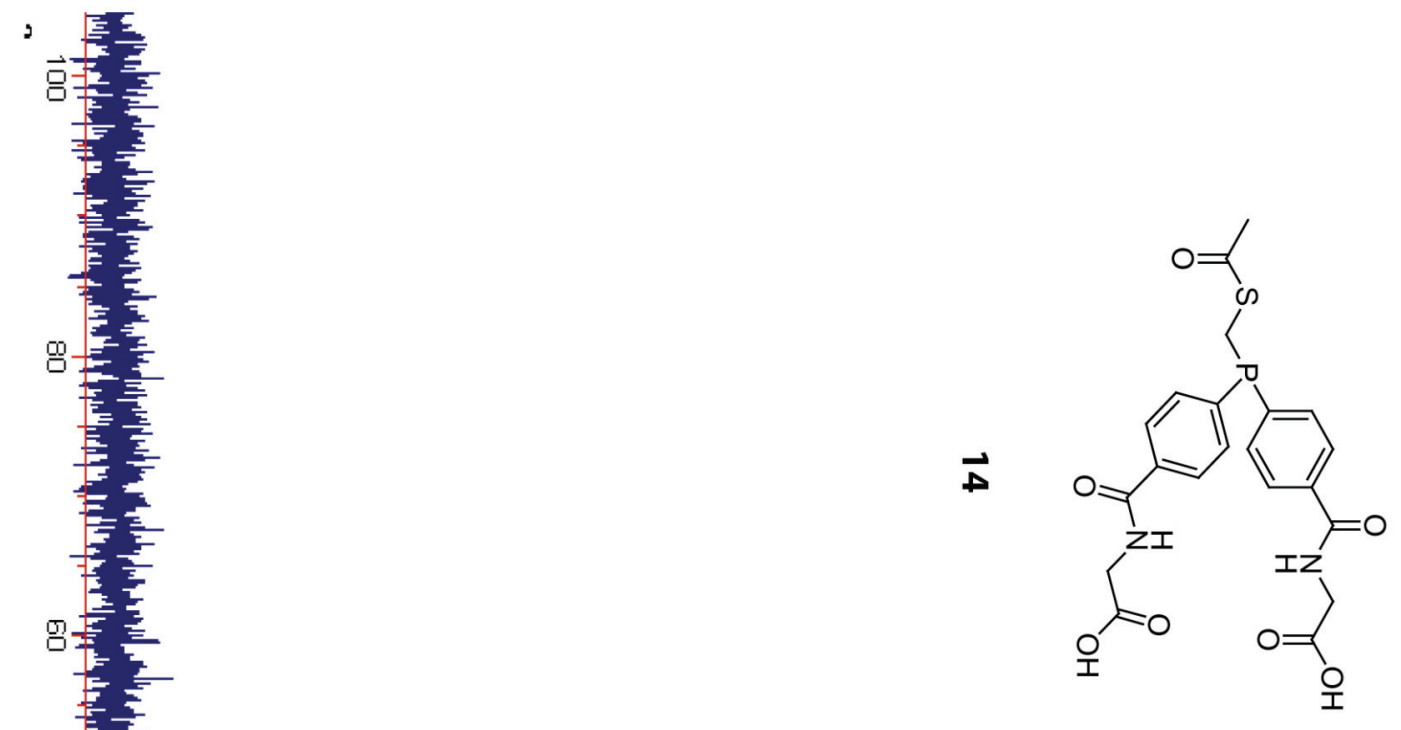

Supporting Information

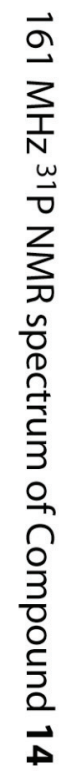

$-\mathrm{S} 36-$ 


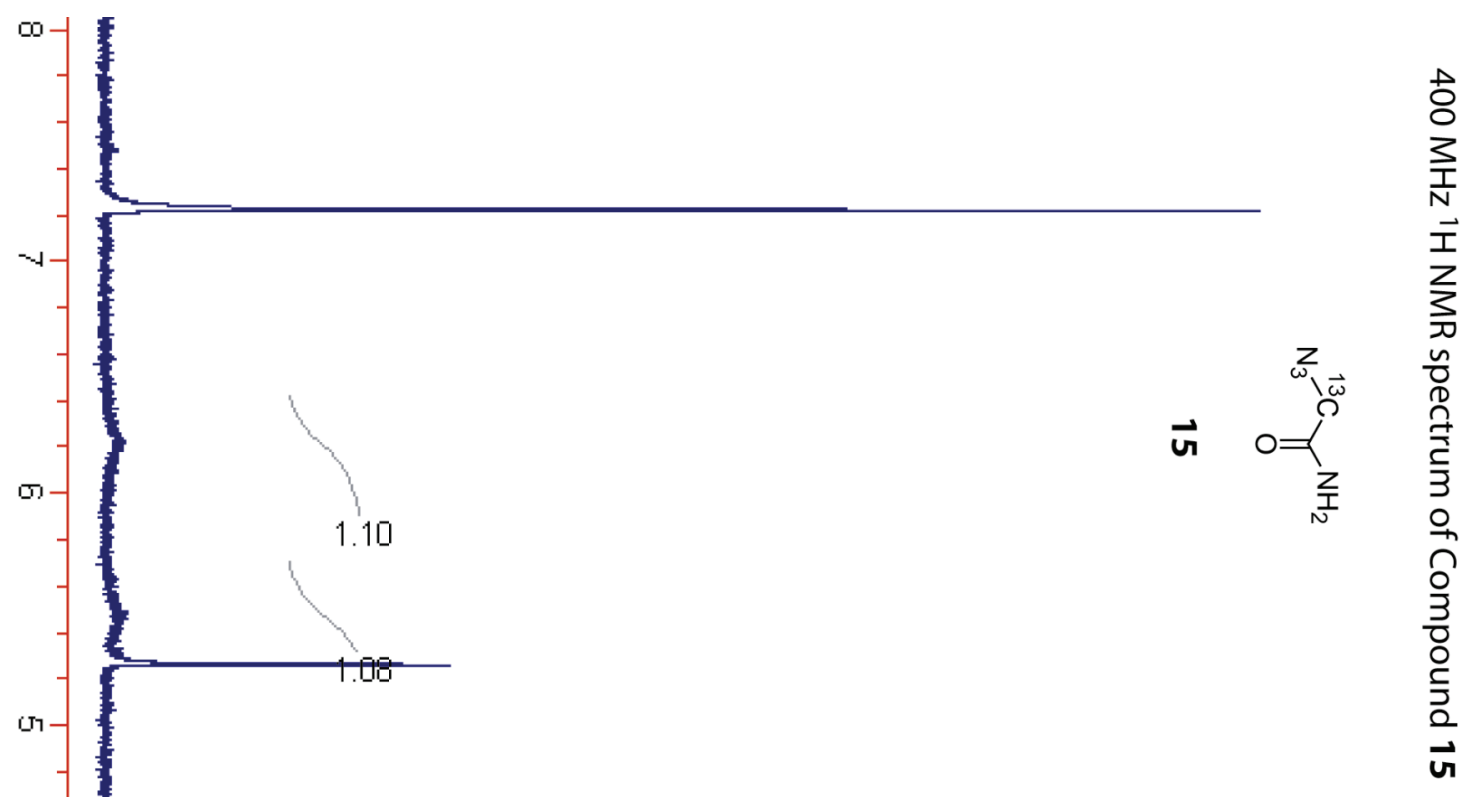

$\omega$

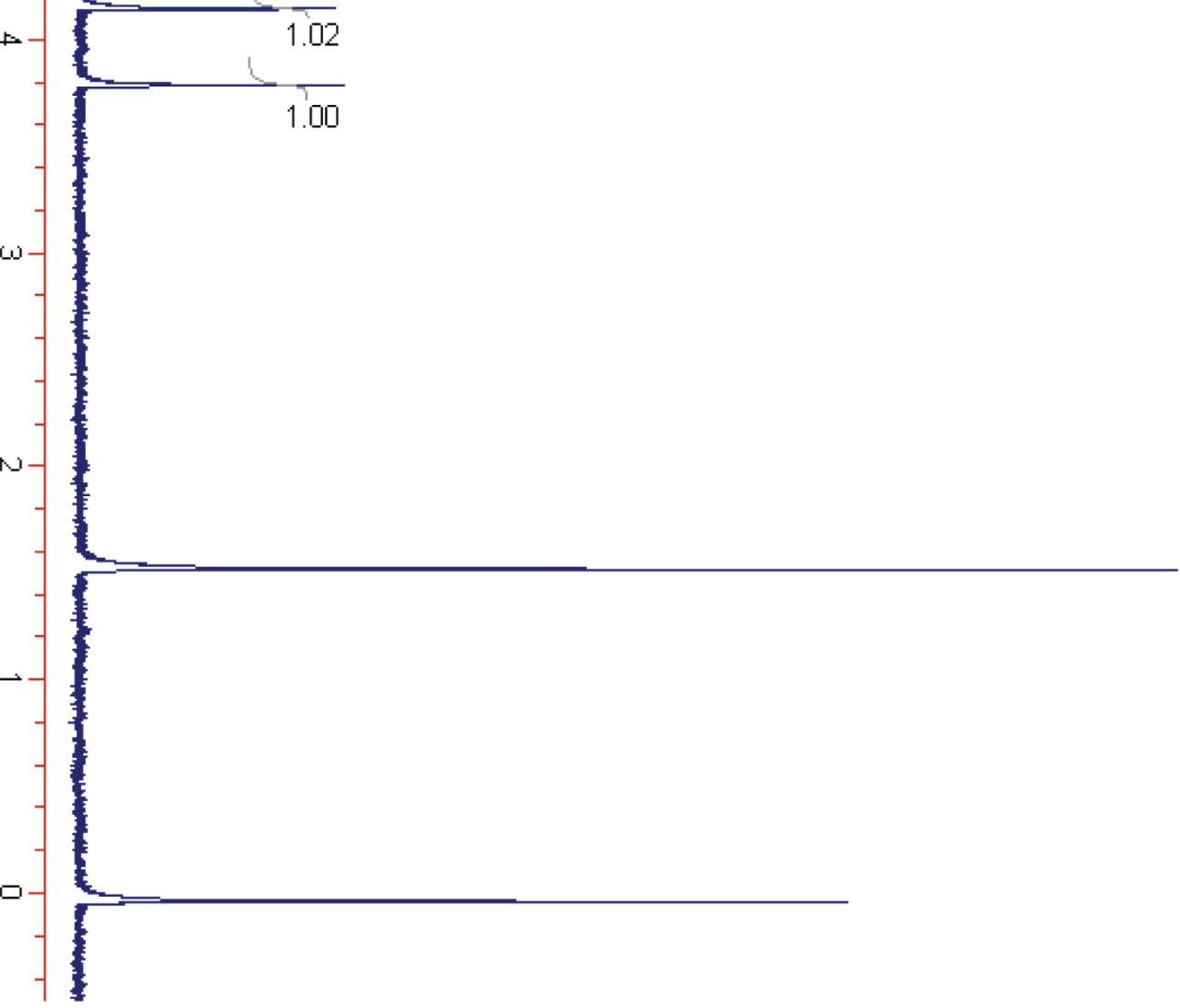


Tam et al.

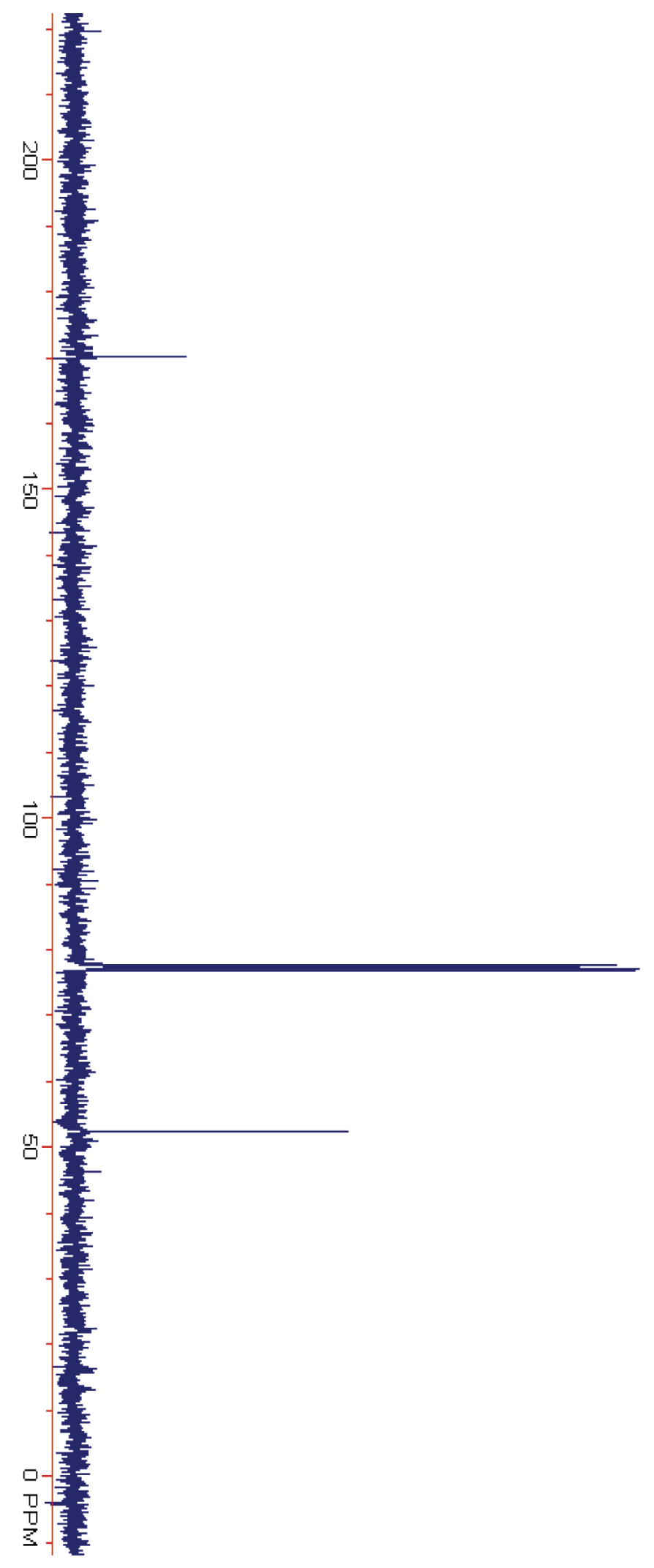

Supporting Information

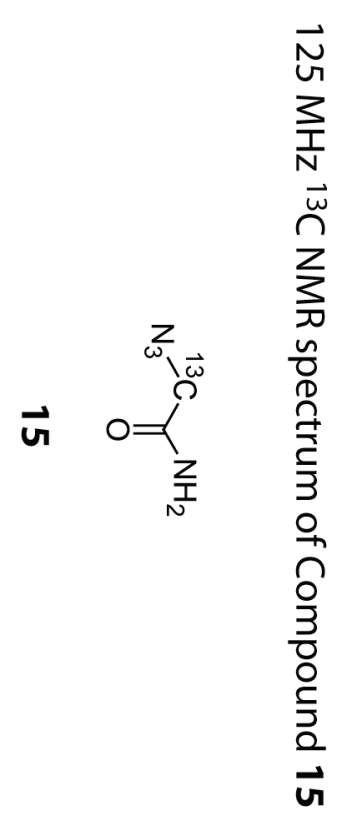

-S38- 
Tam et al.

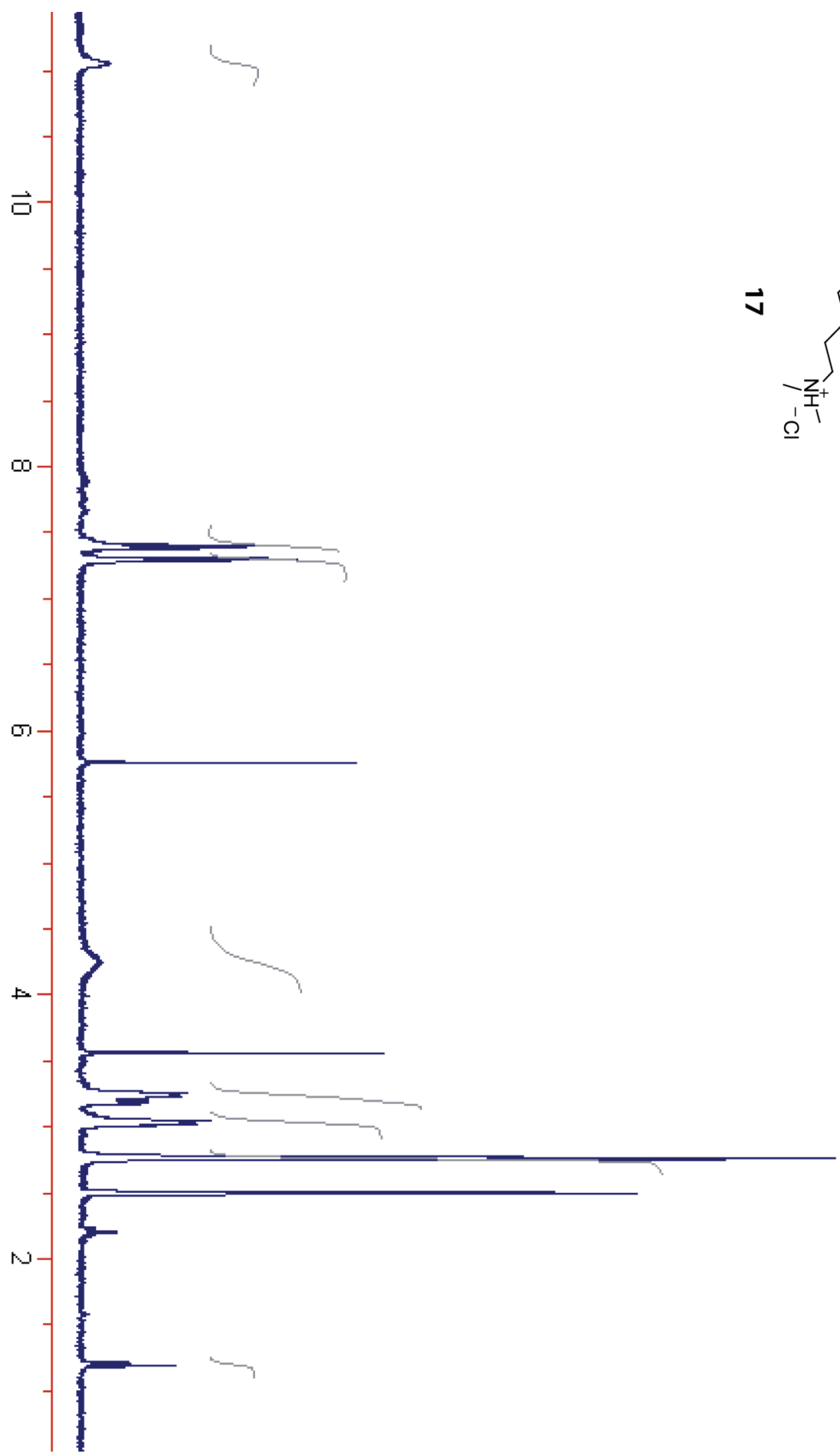

Supporting Information

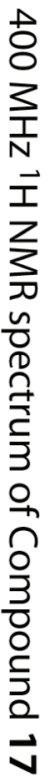




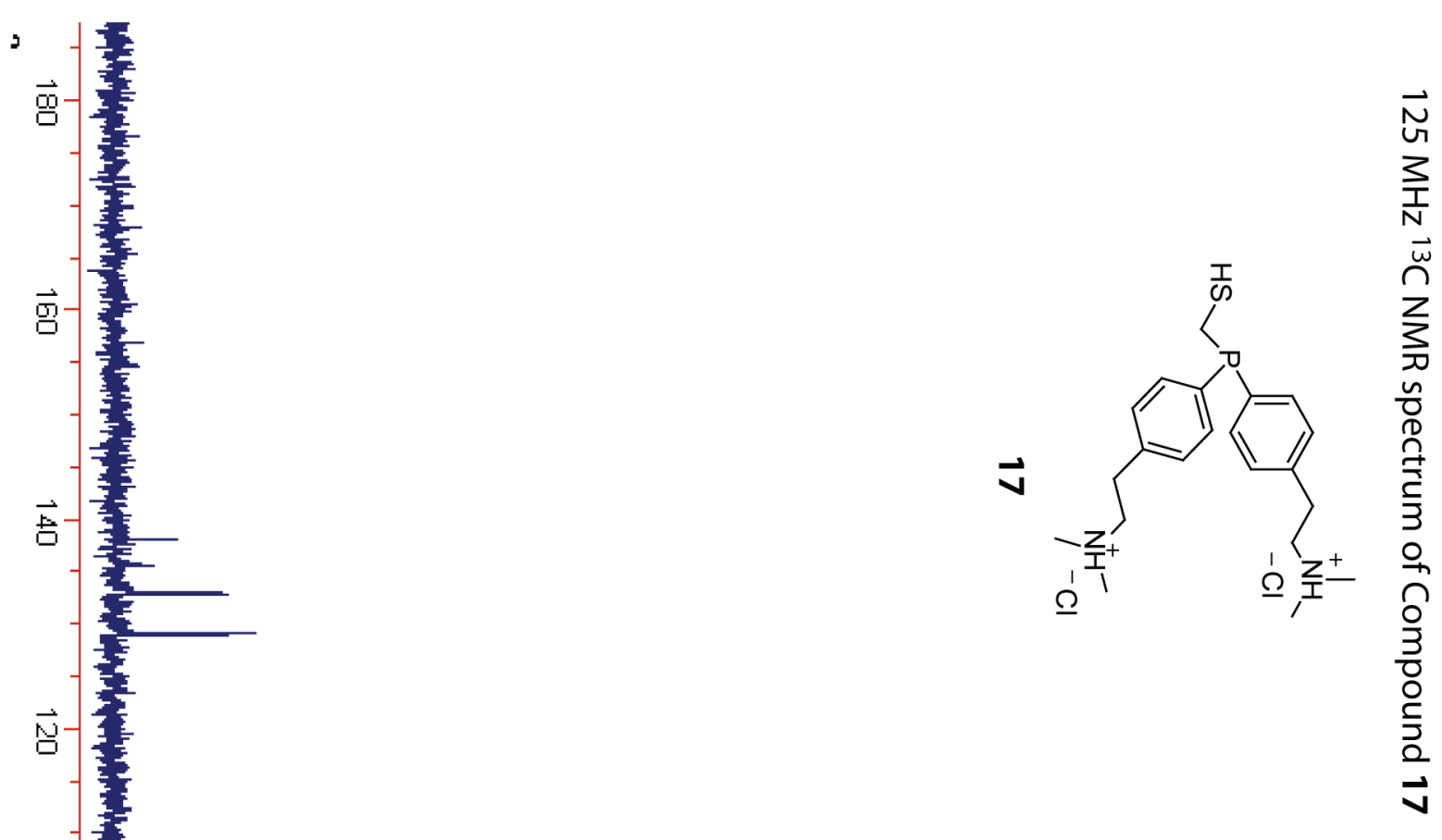

呂

g

㝘

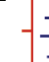

-

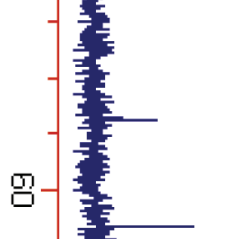

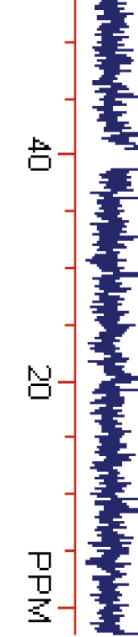

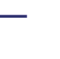

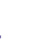
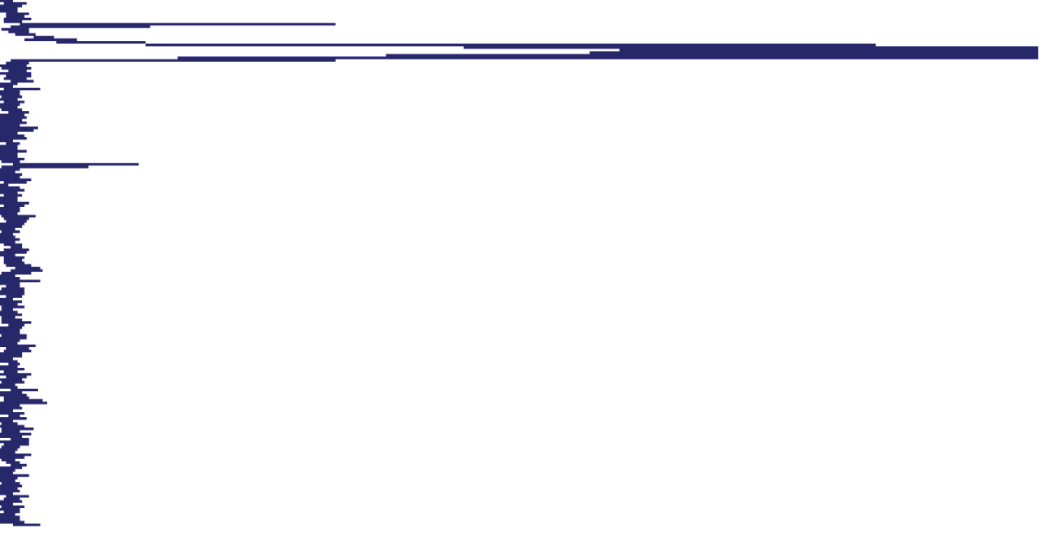

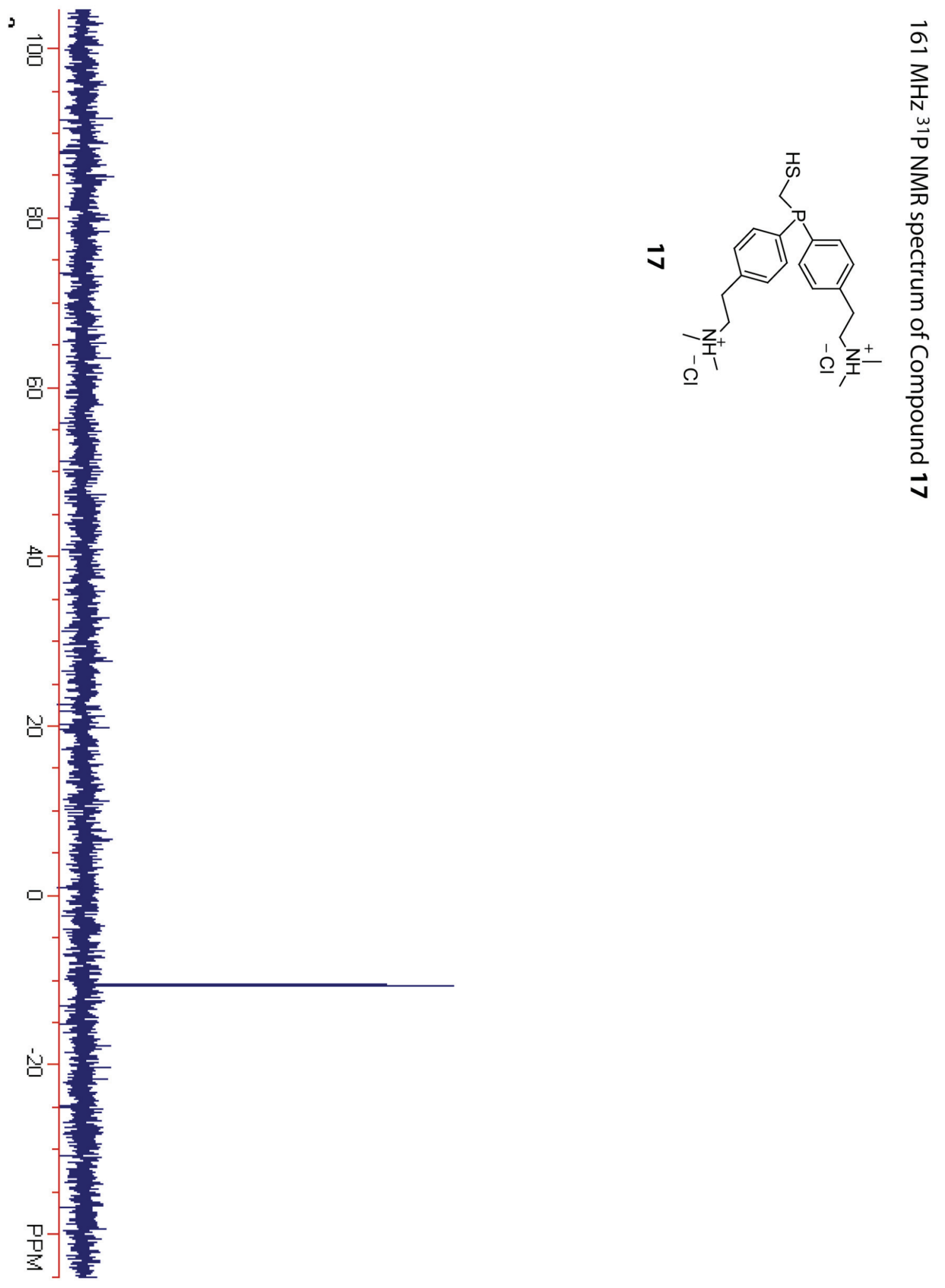
Tam et al.

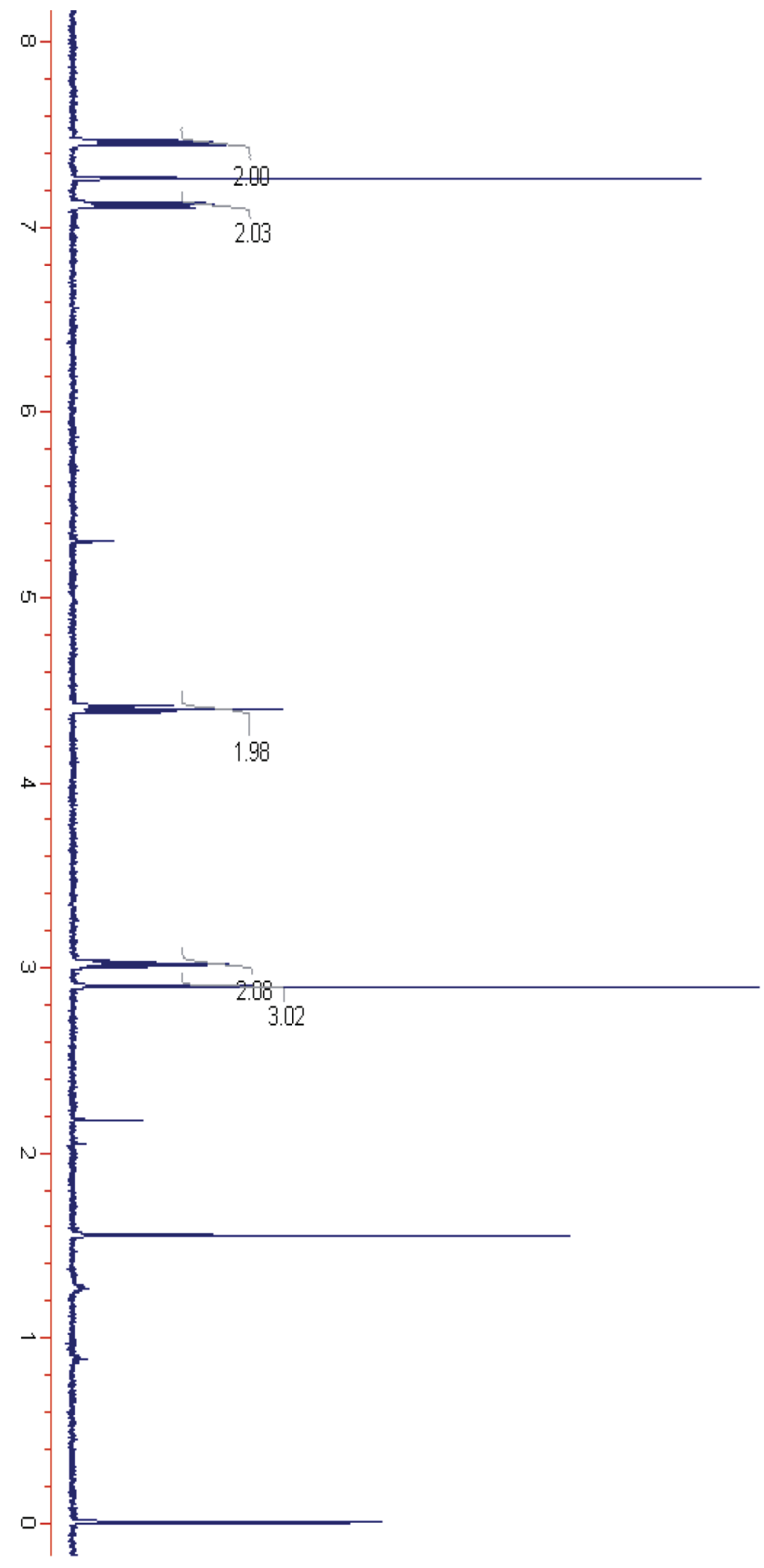

Supporting Information

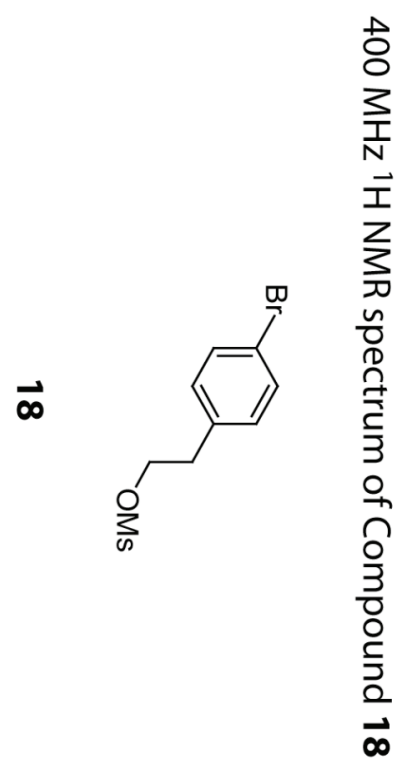




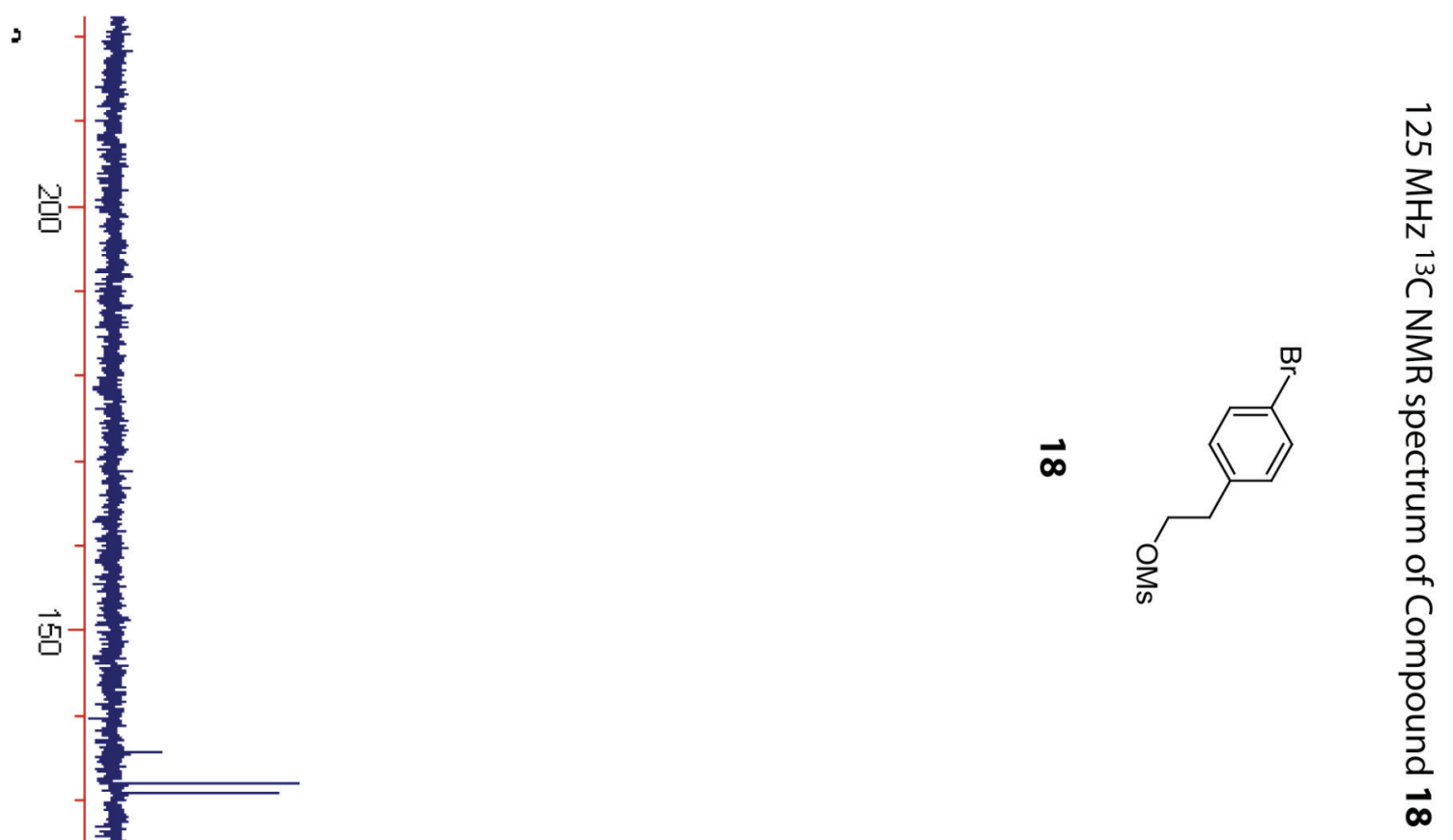

$\square-$

믐

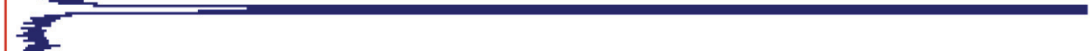

g1

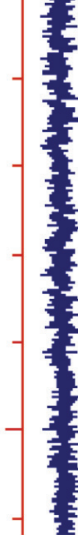


Tam et al.

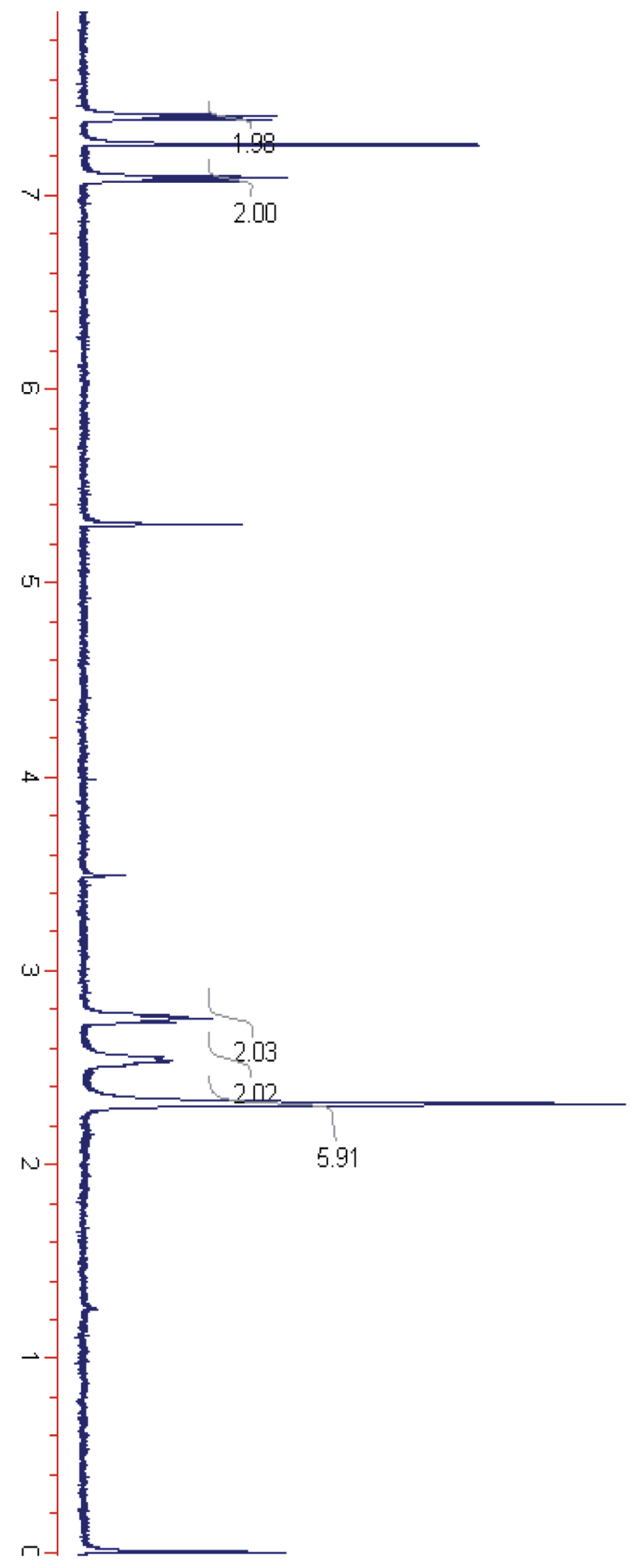

Supporting Information

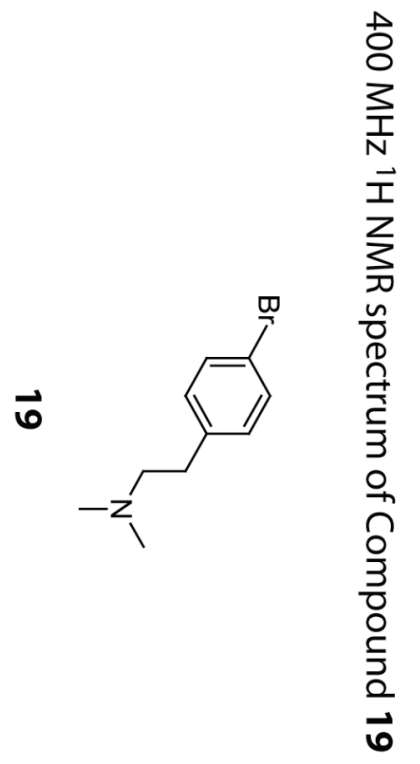




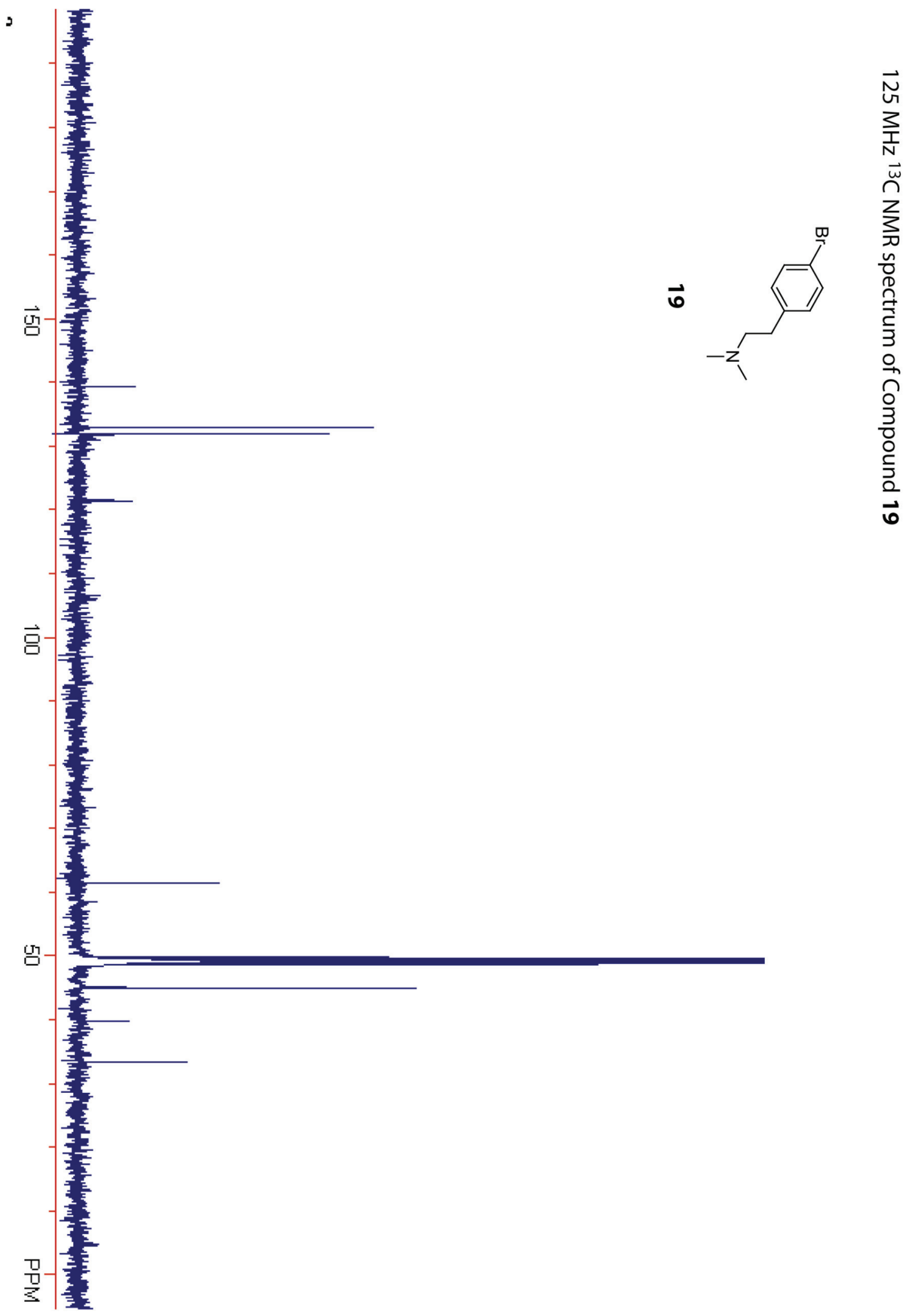




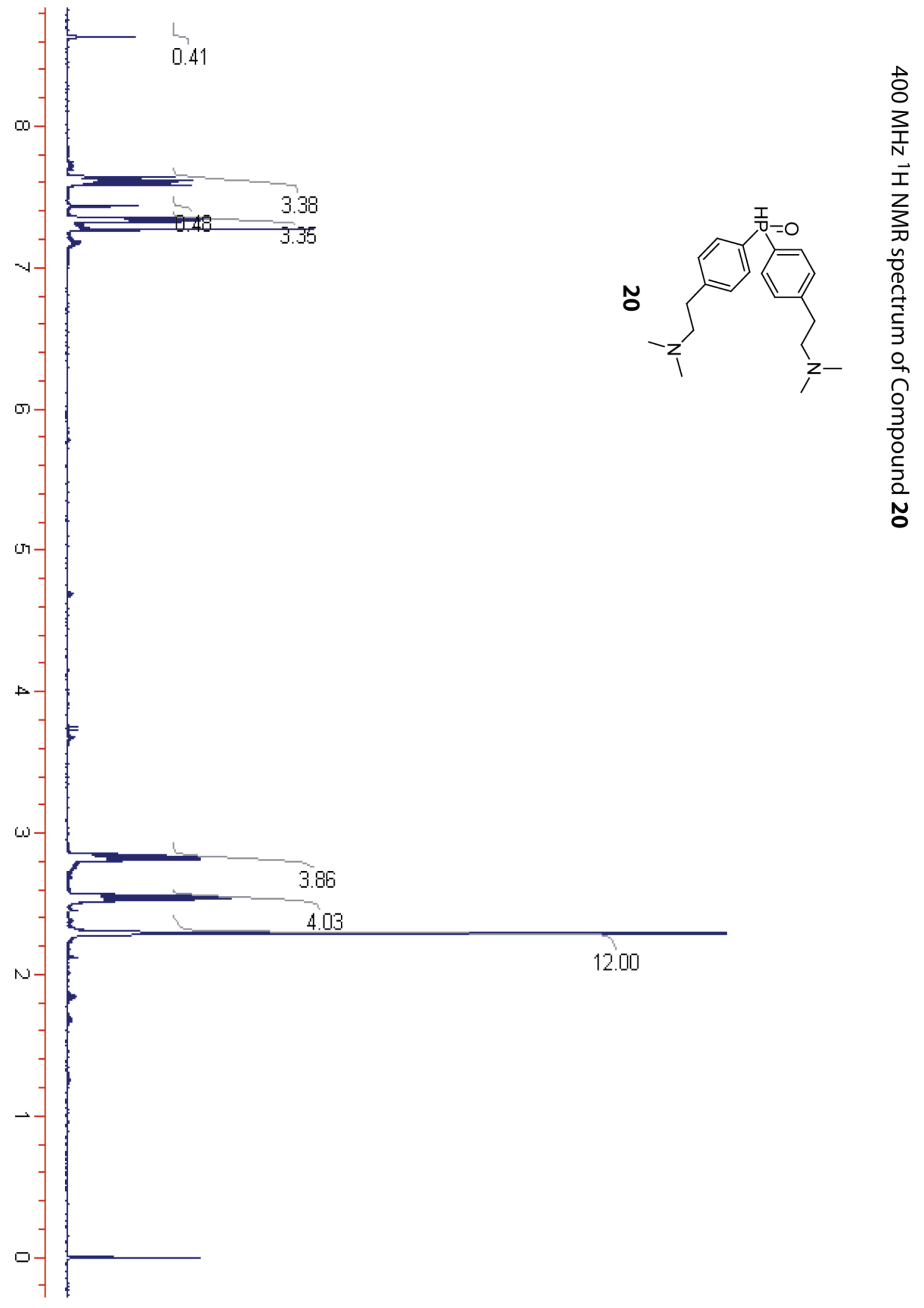




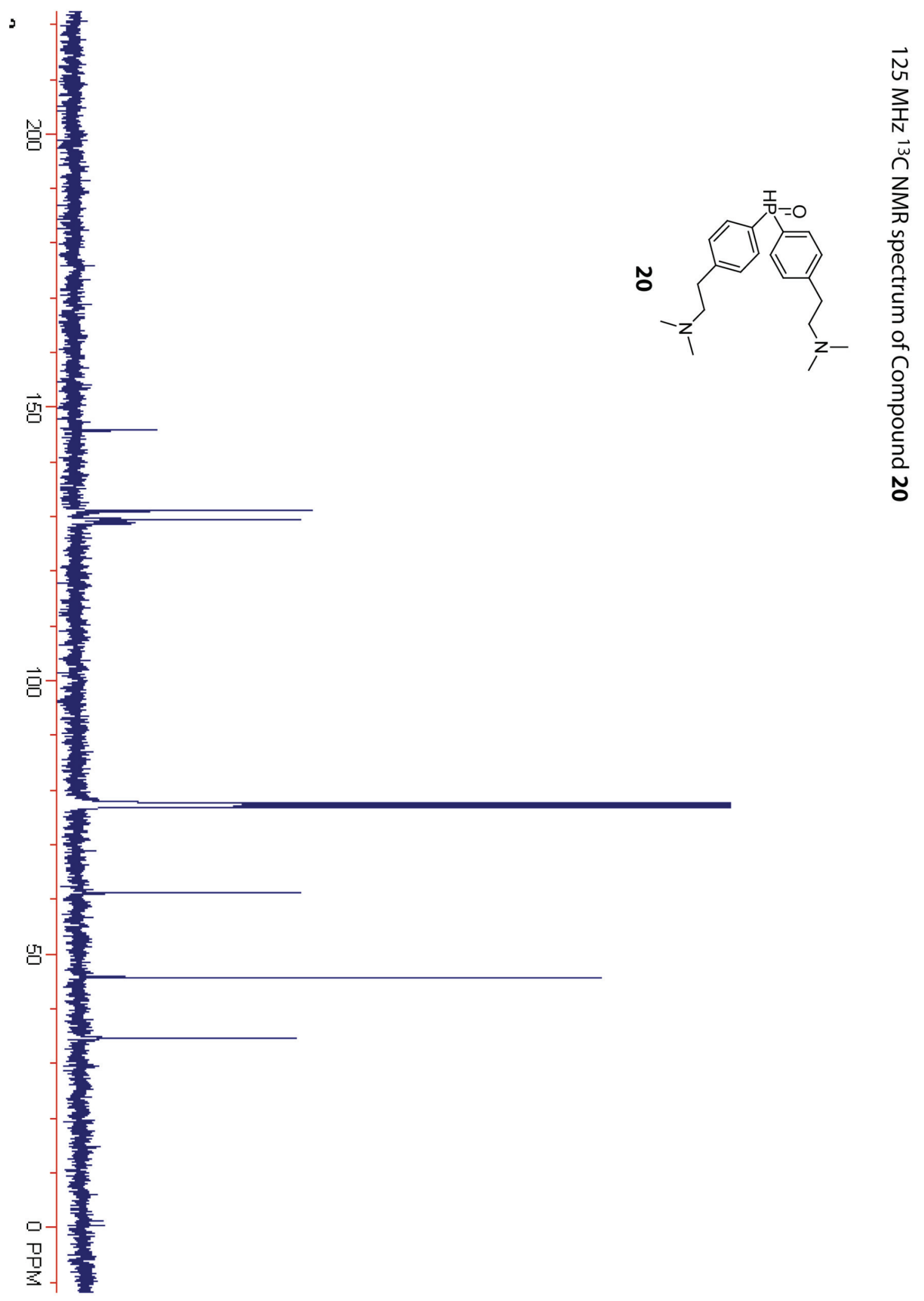



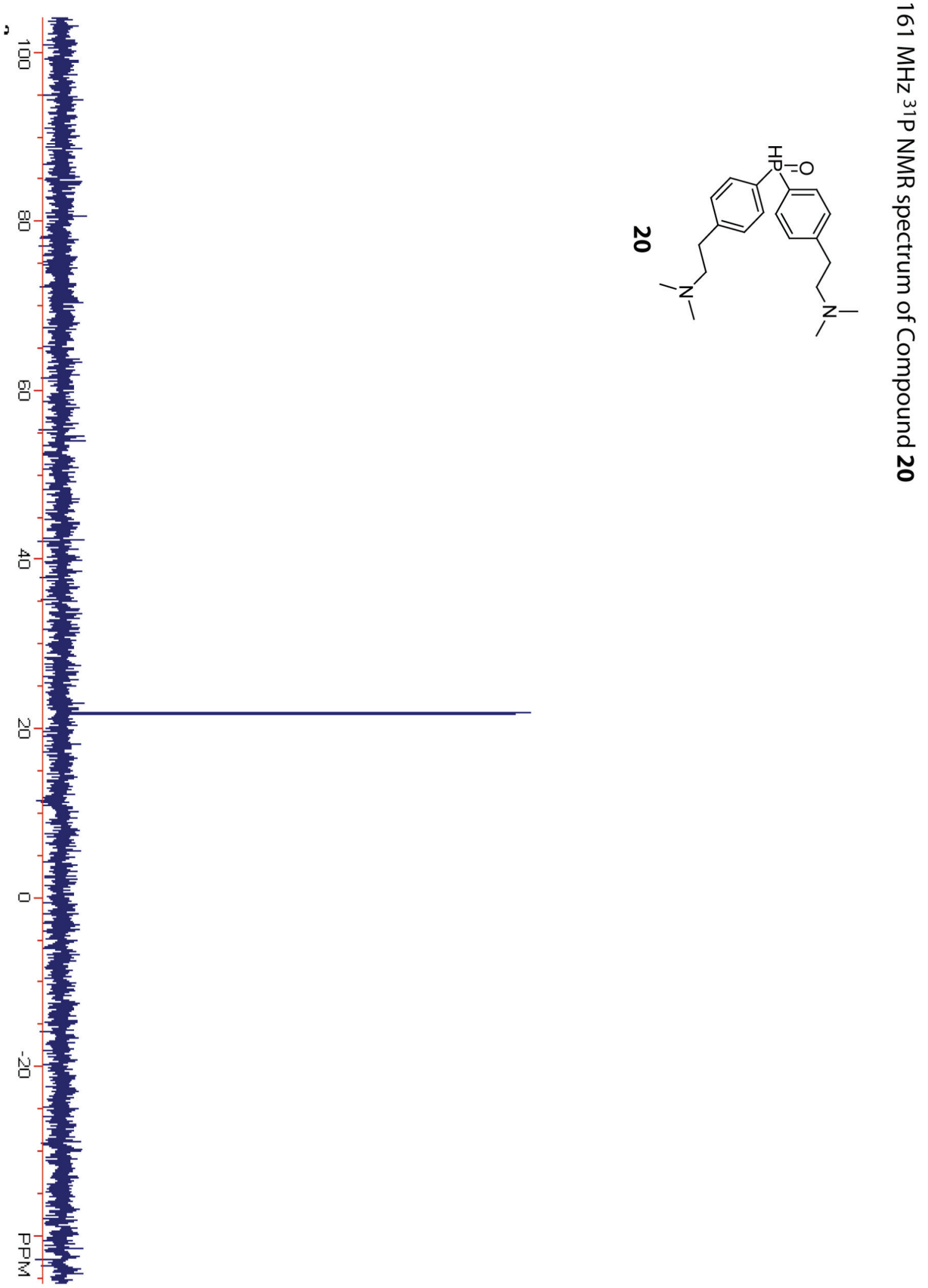
Tam et al.

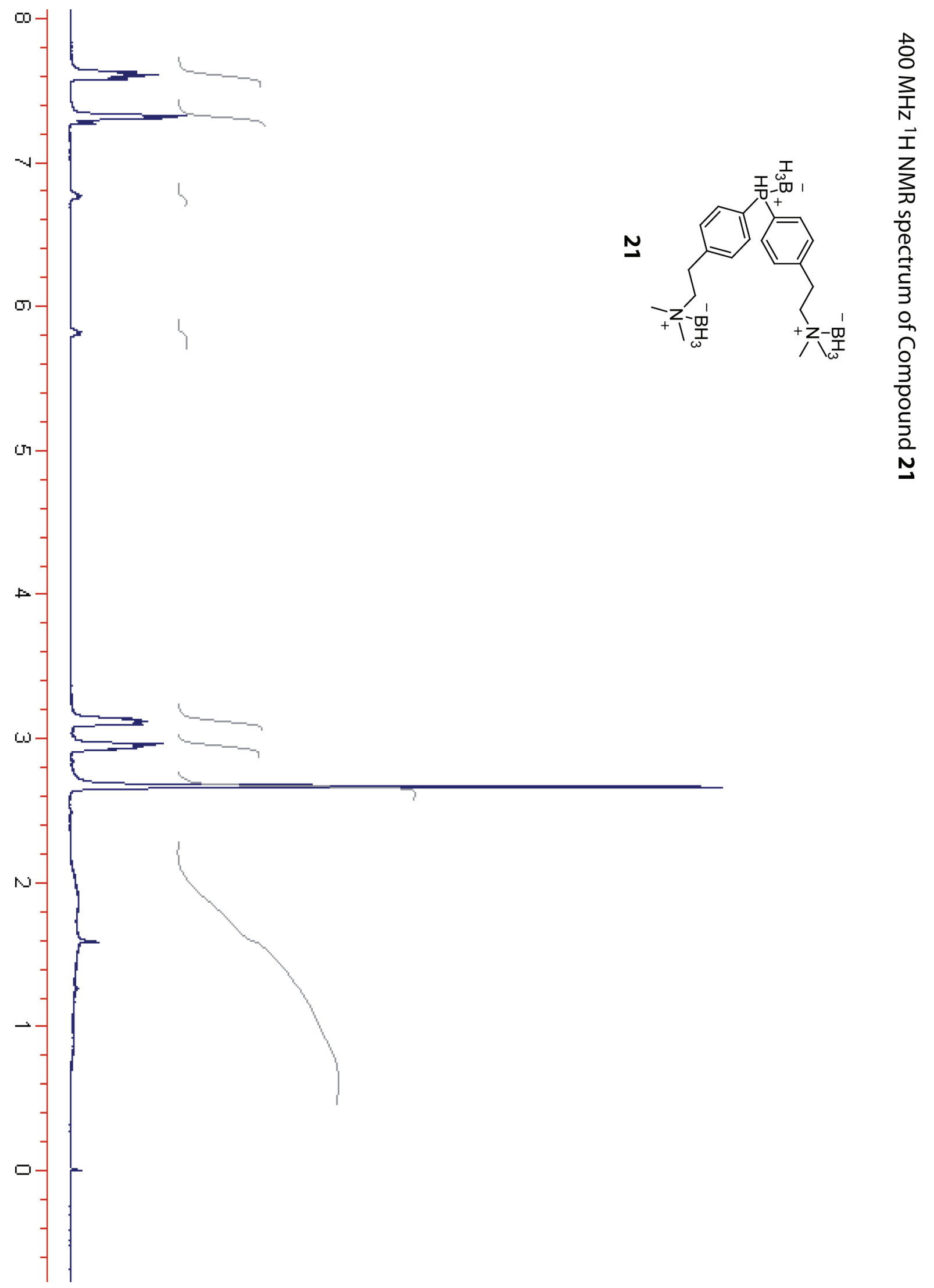

Supporting Information

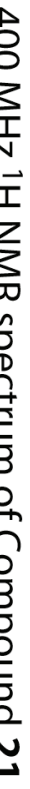



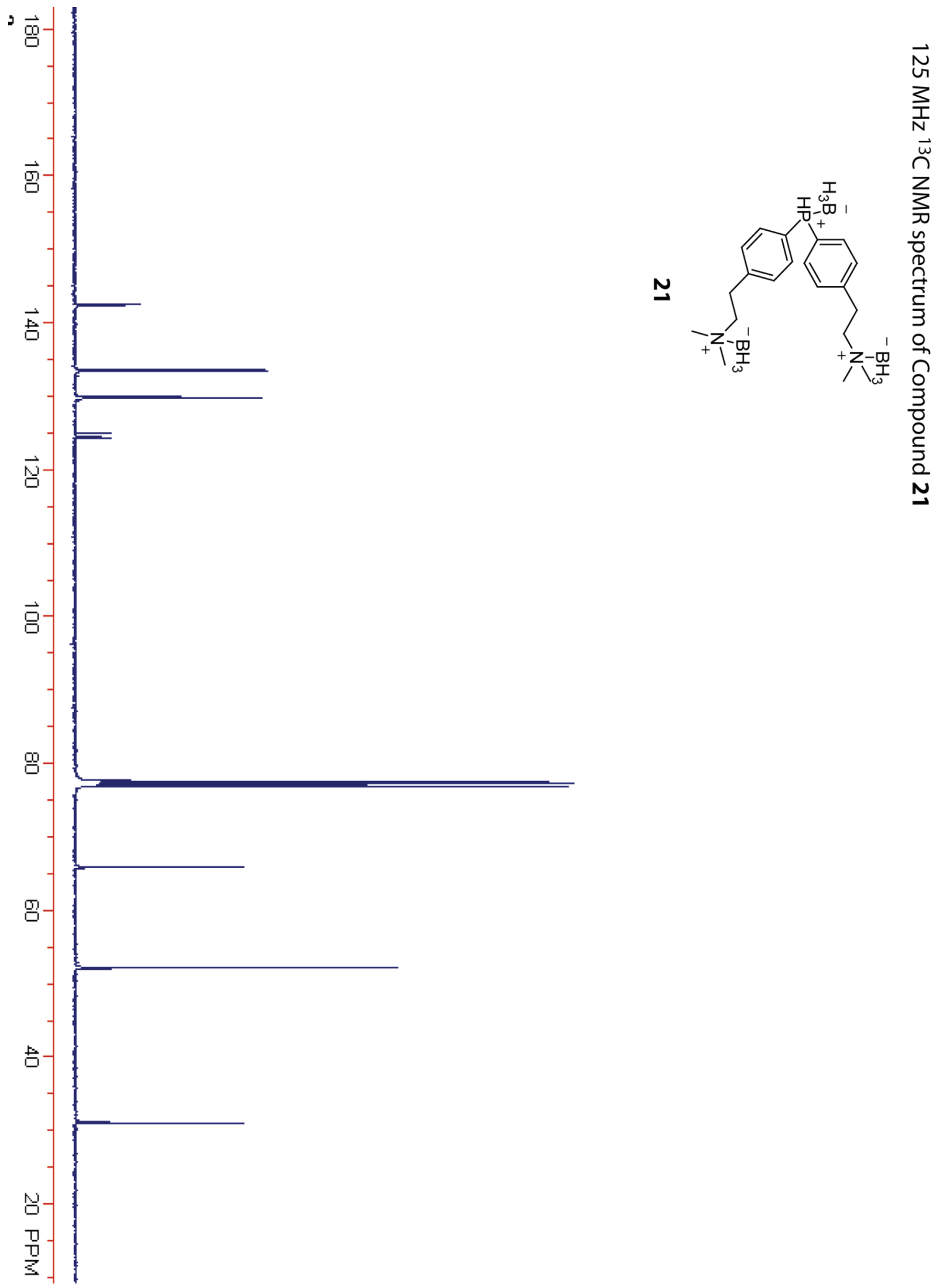

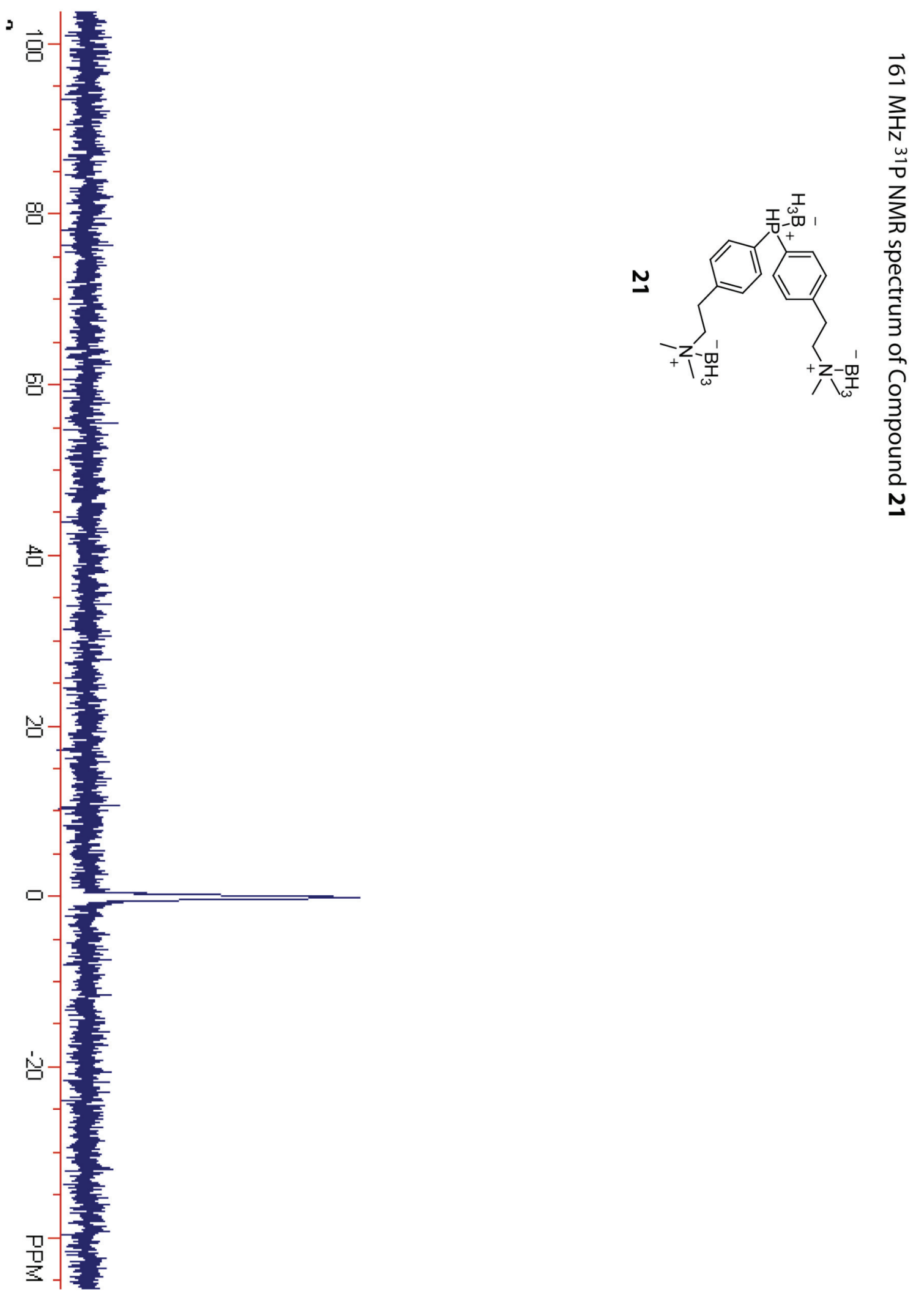
Tam et al.

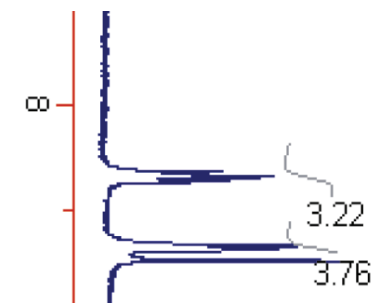

m-

\llcorner

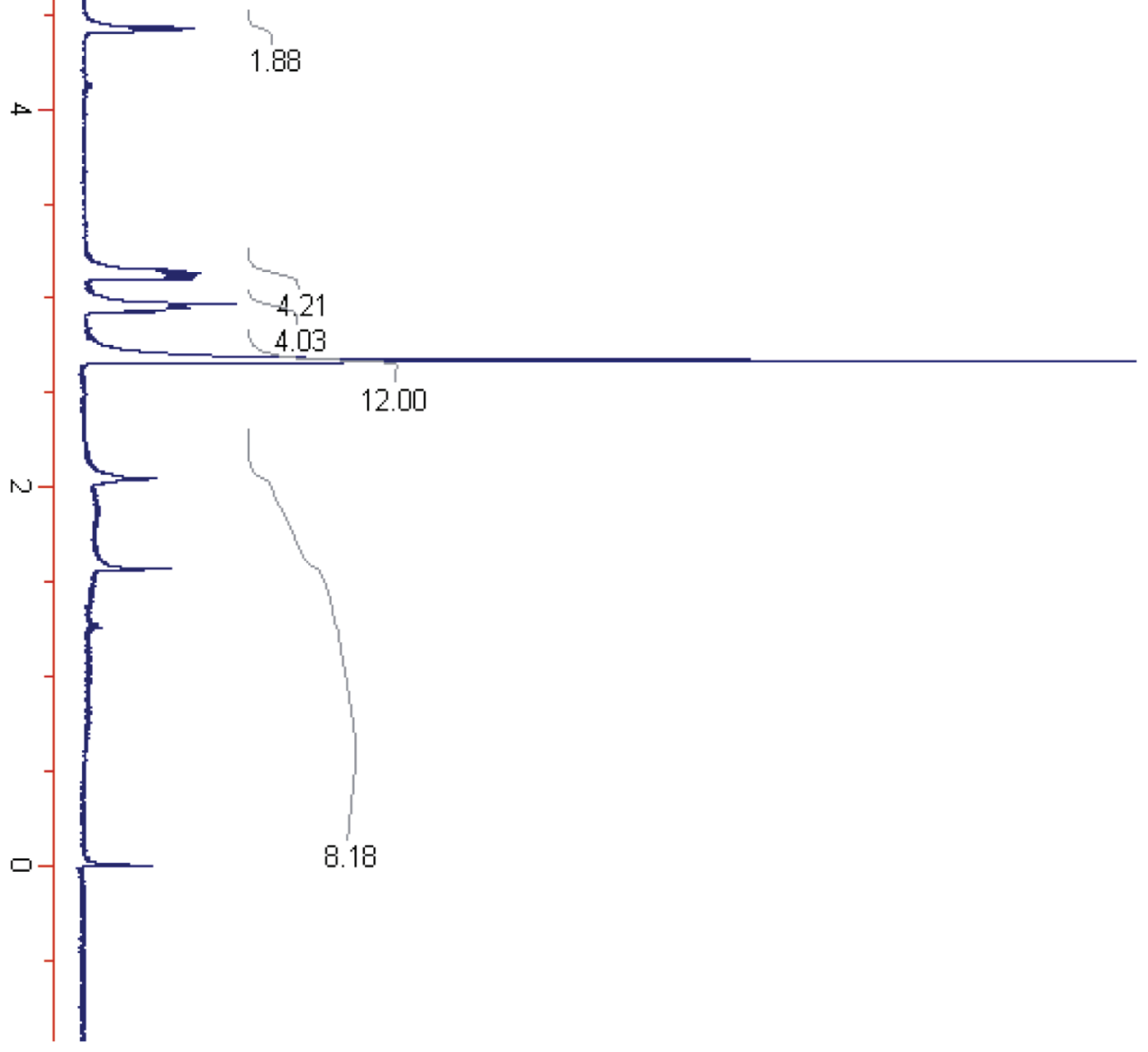

Supporting Information

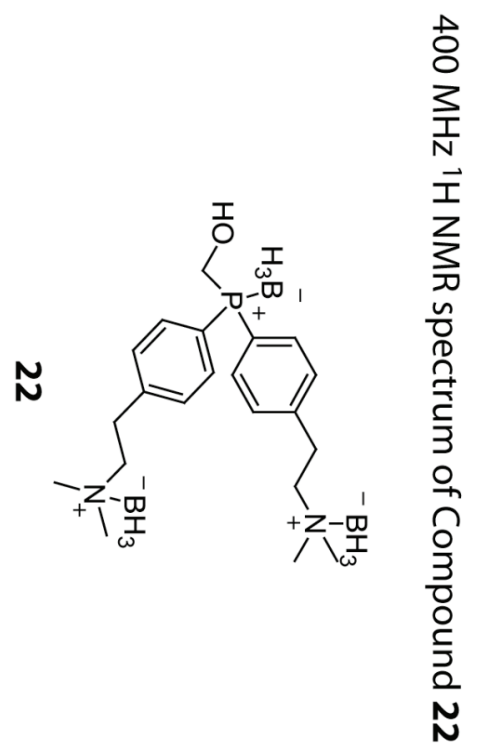



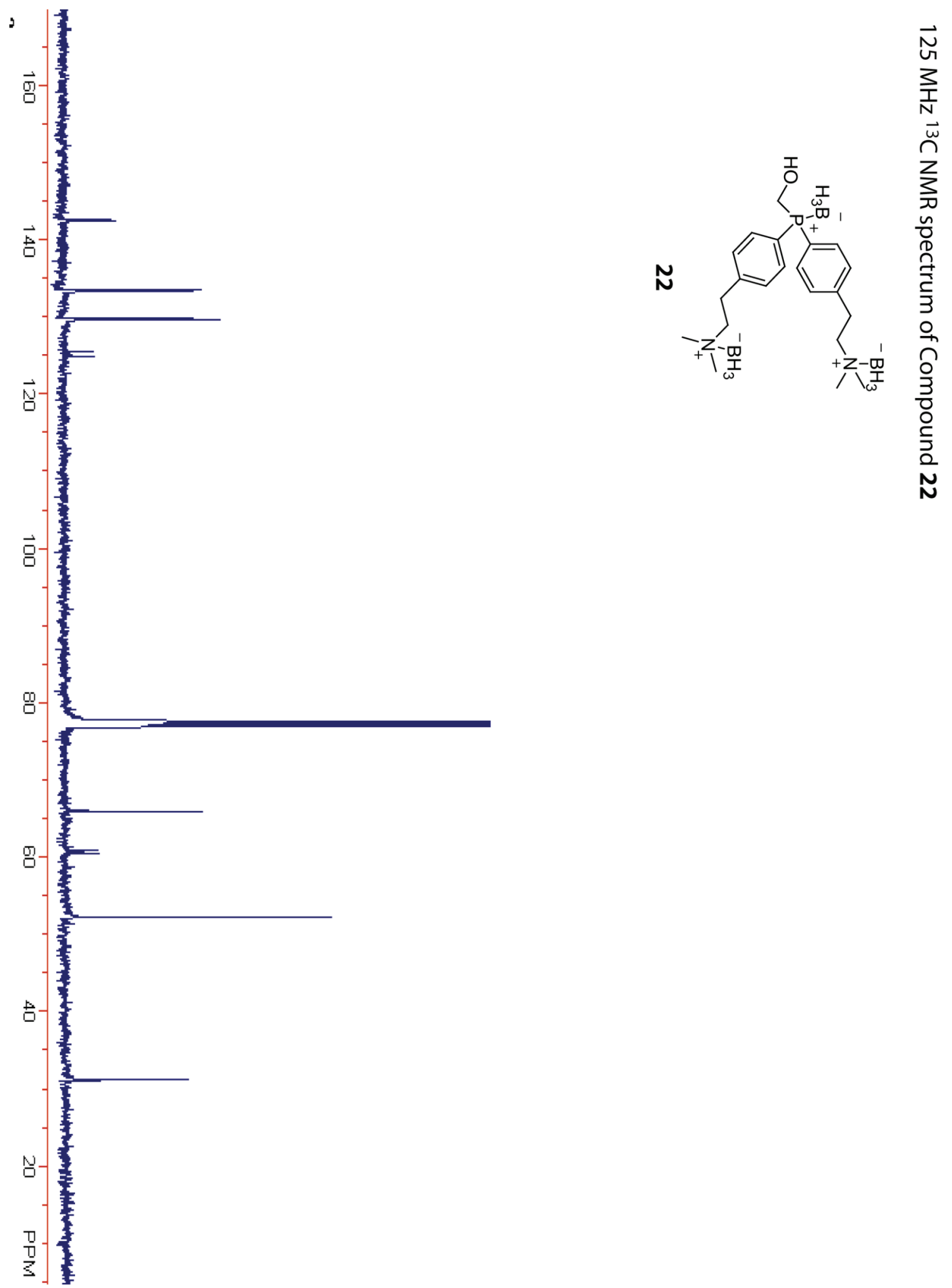

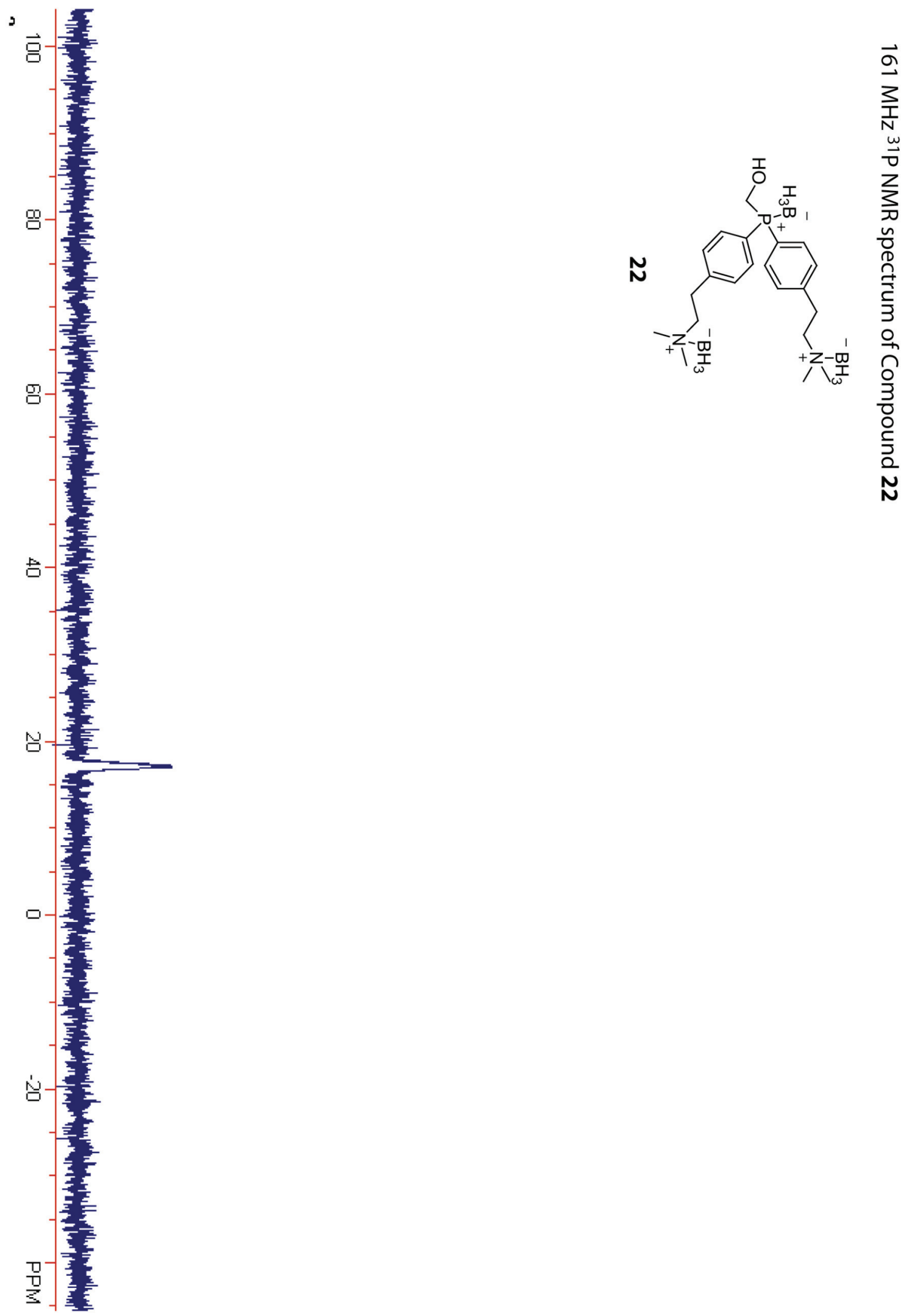
Tam et al.

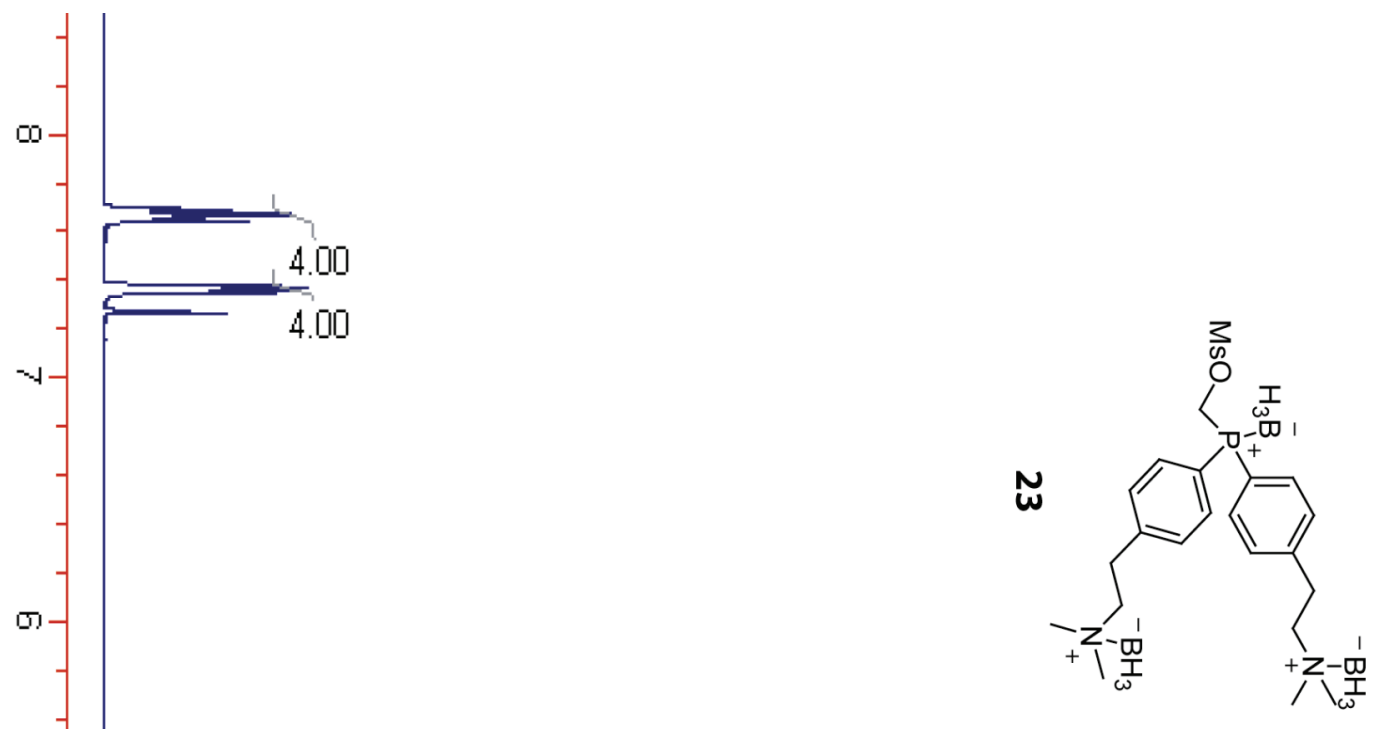

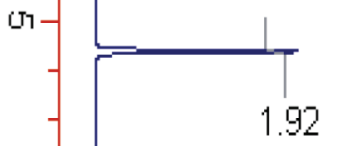

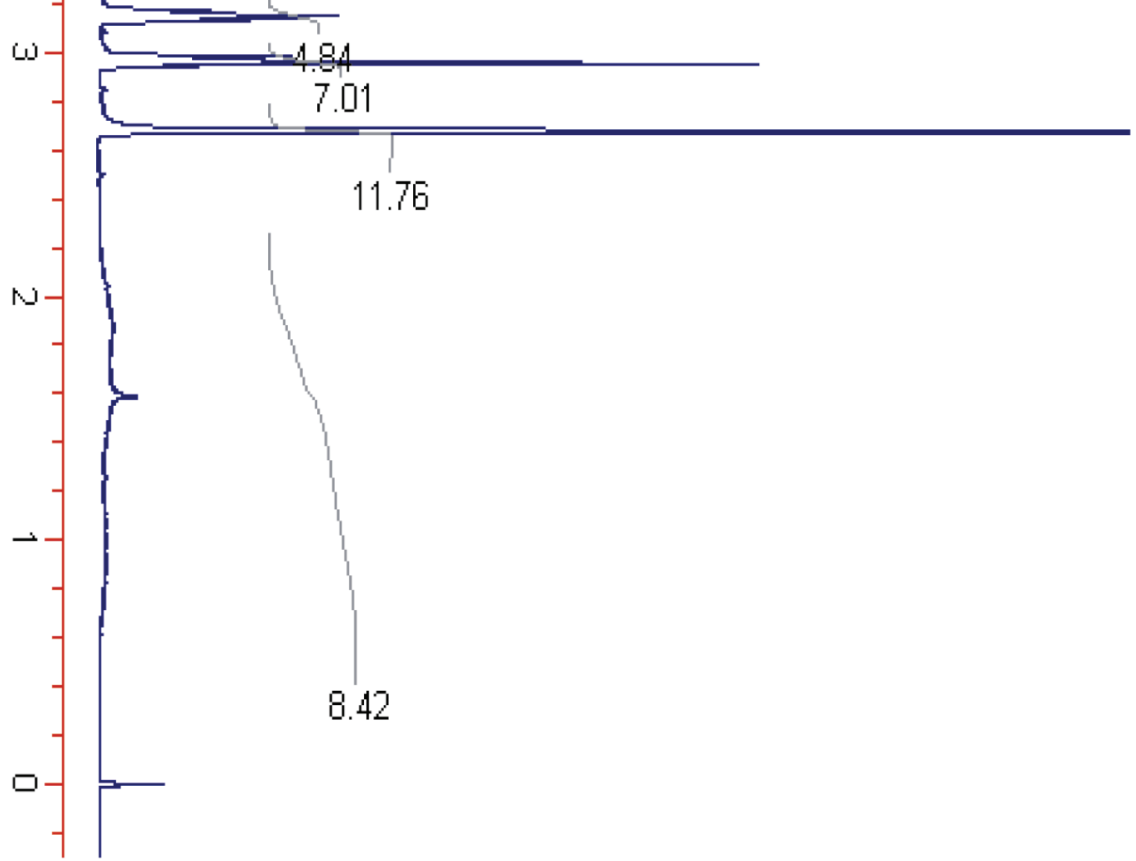


Tam et al.

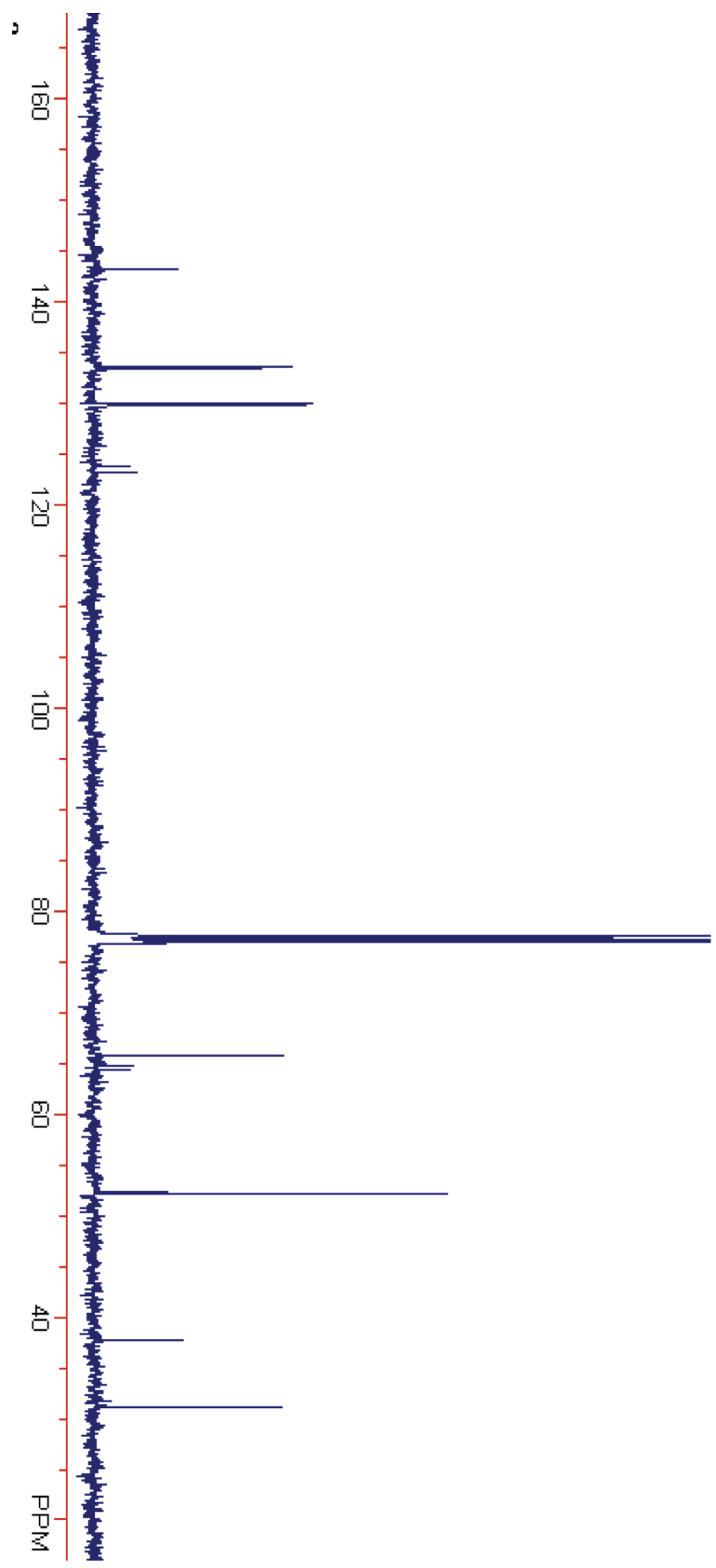

Supporting Information

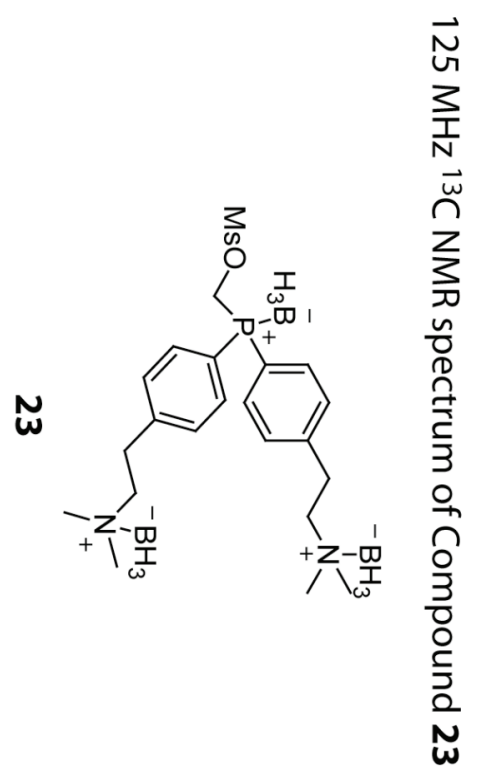



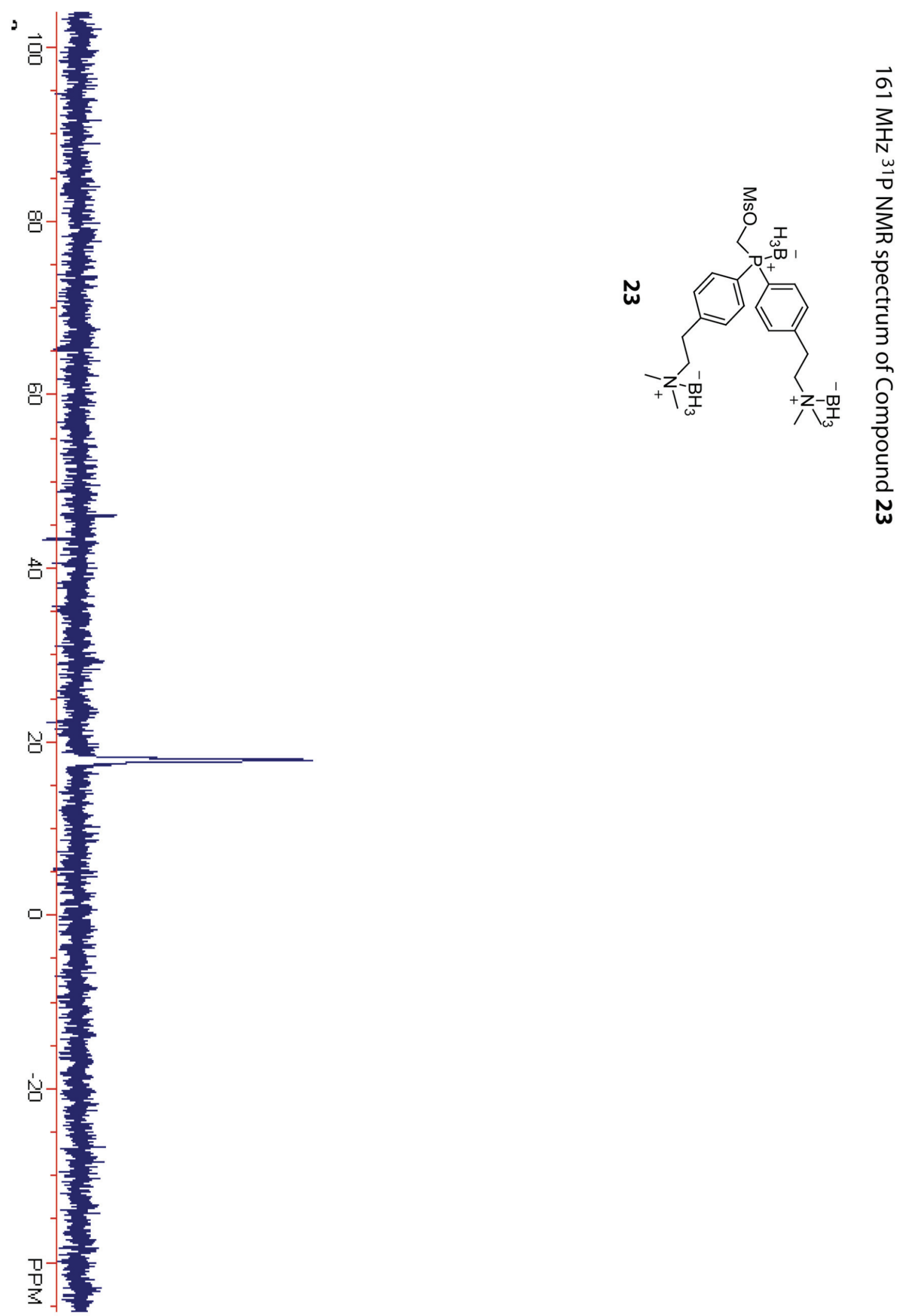


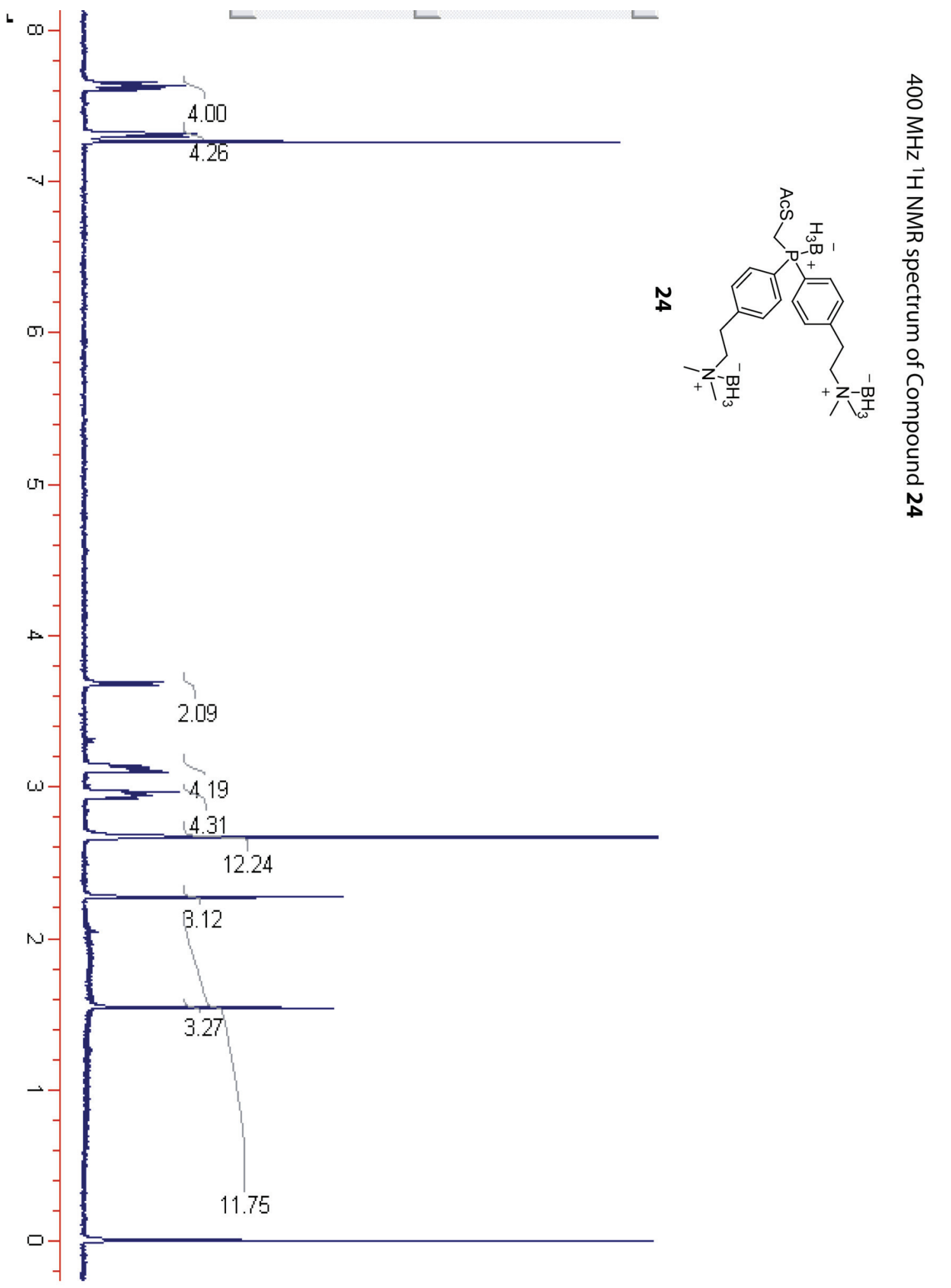


Tam et al.

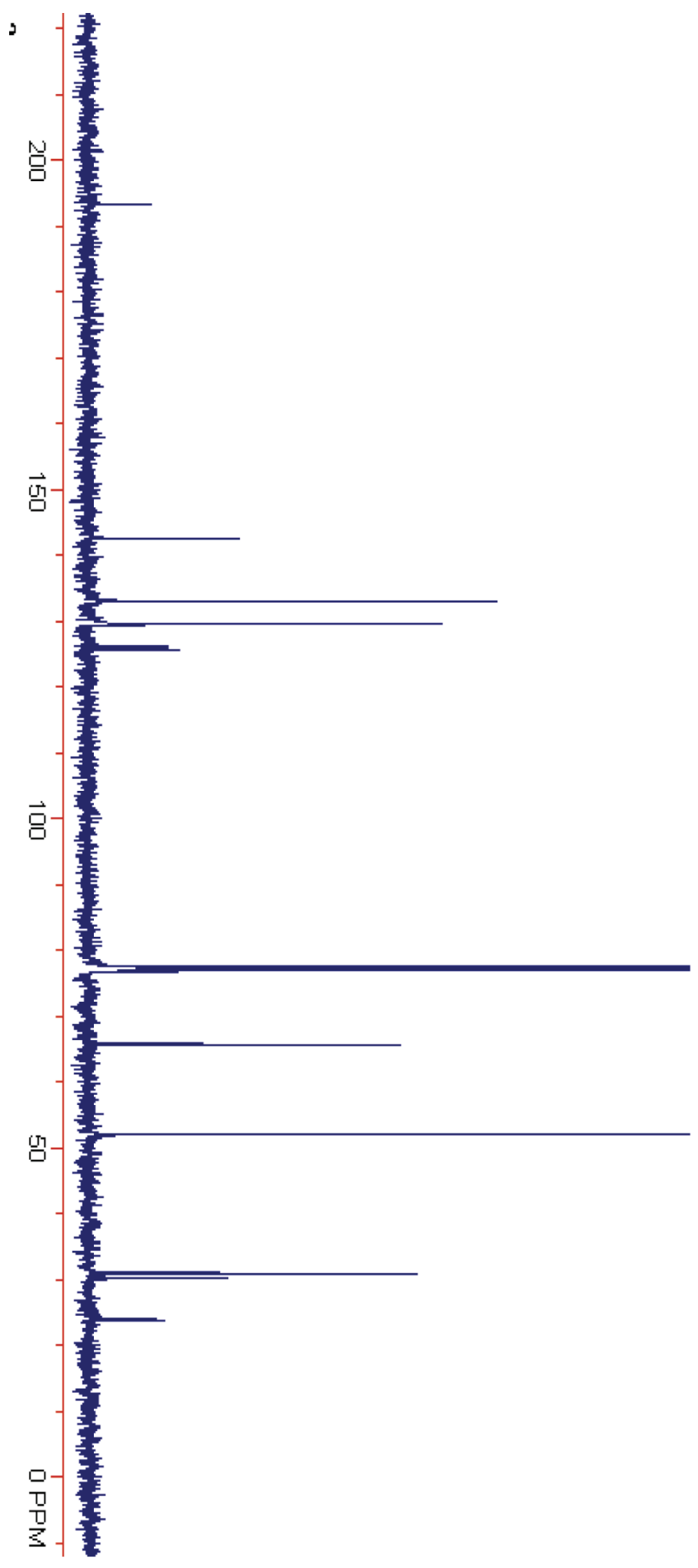

Supporting Information

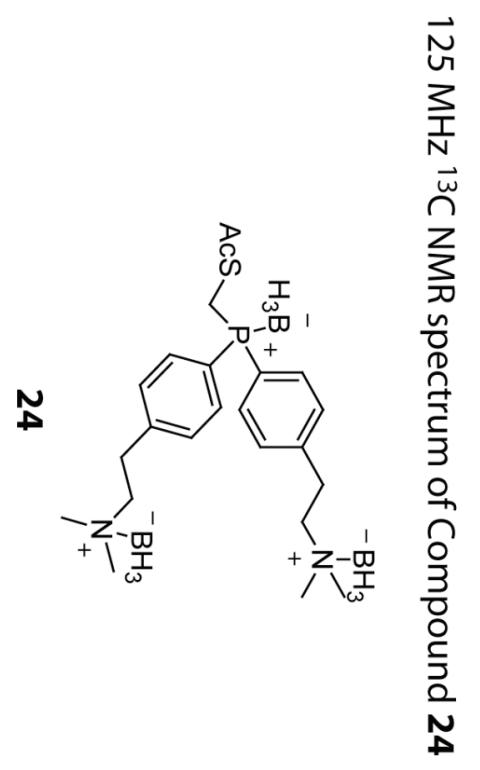



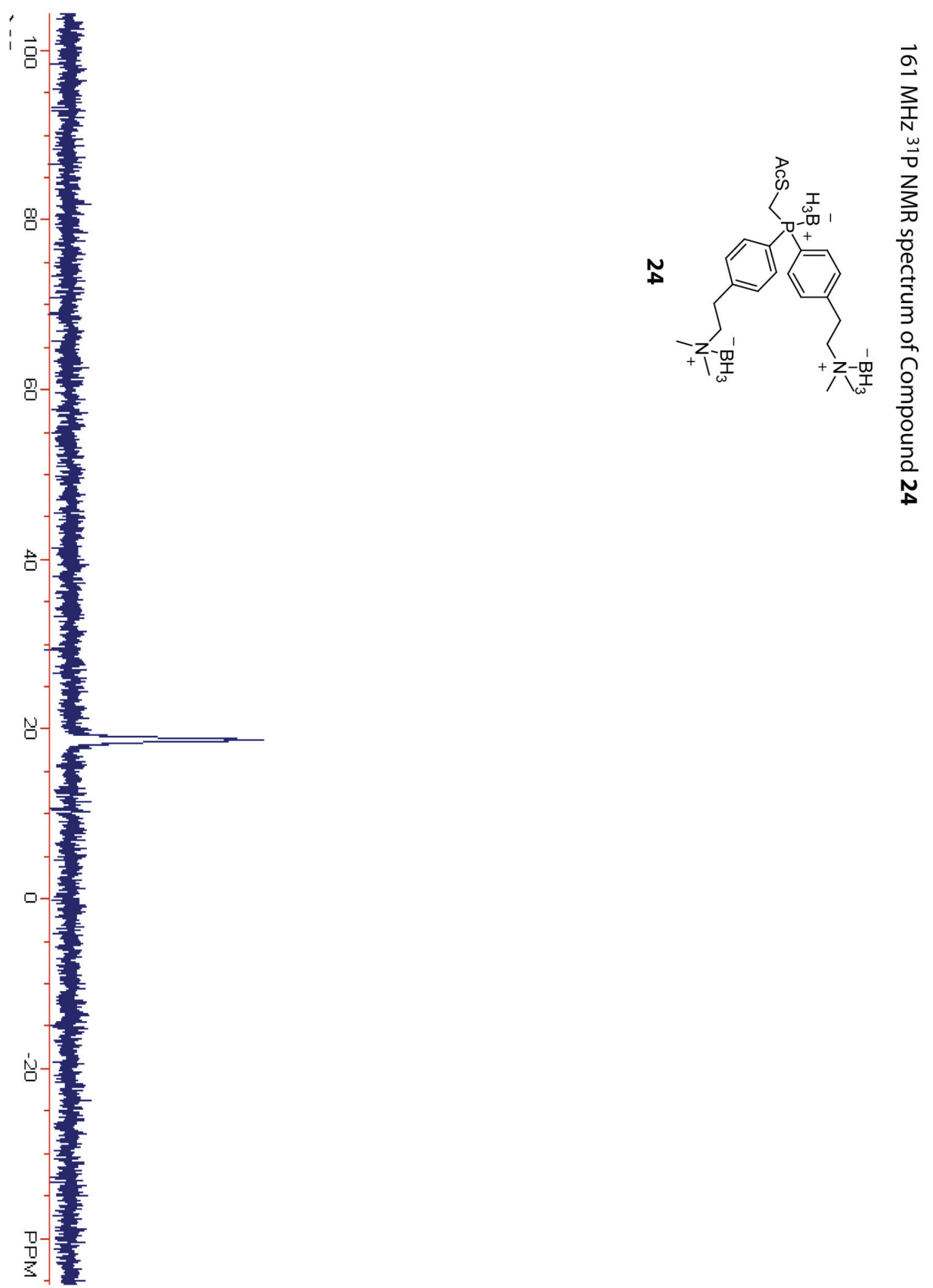

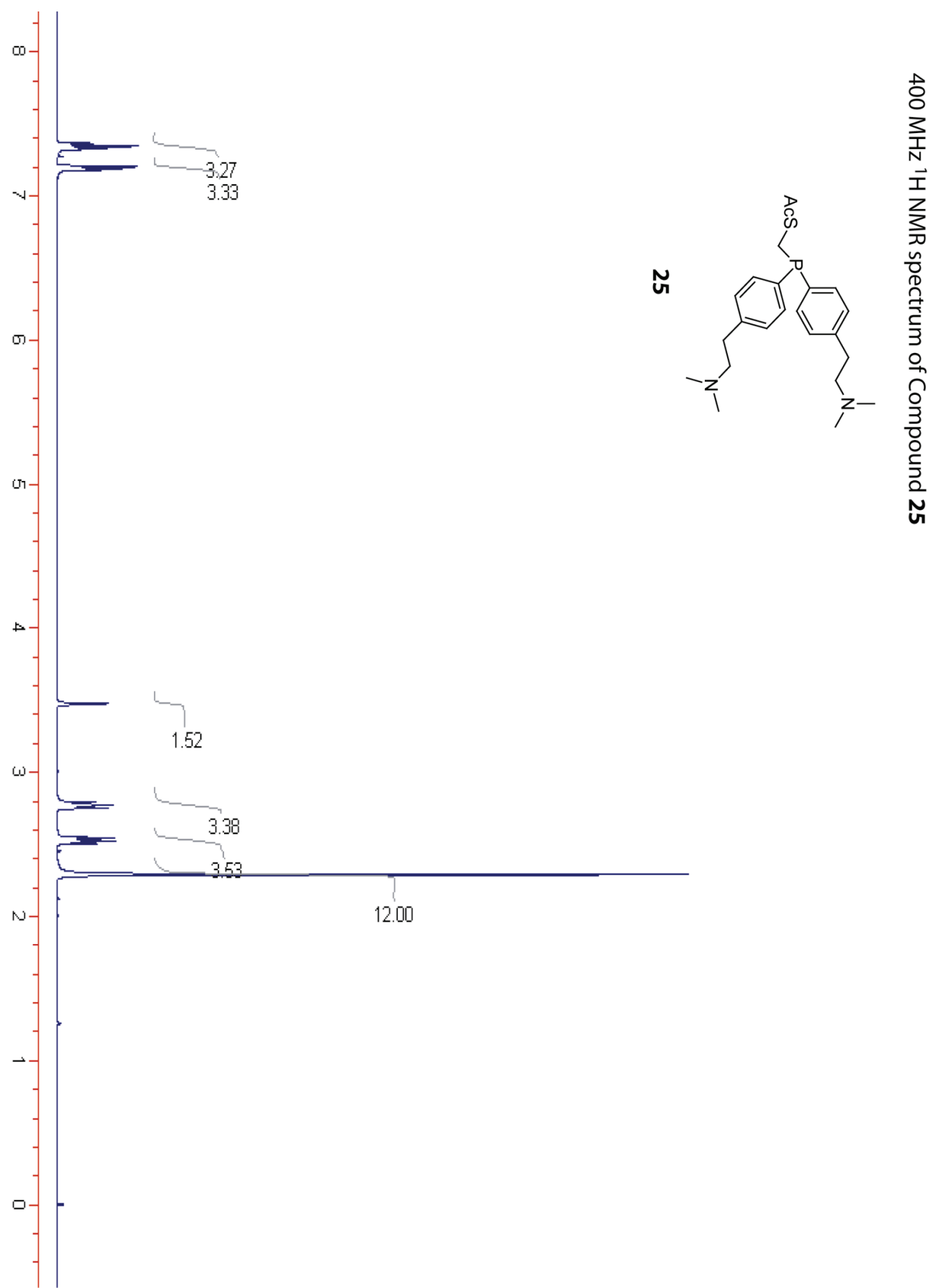


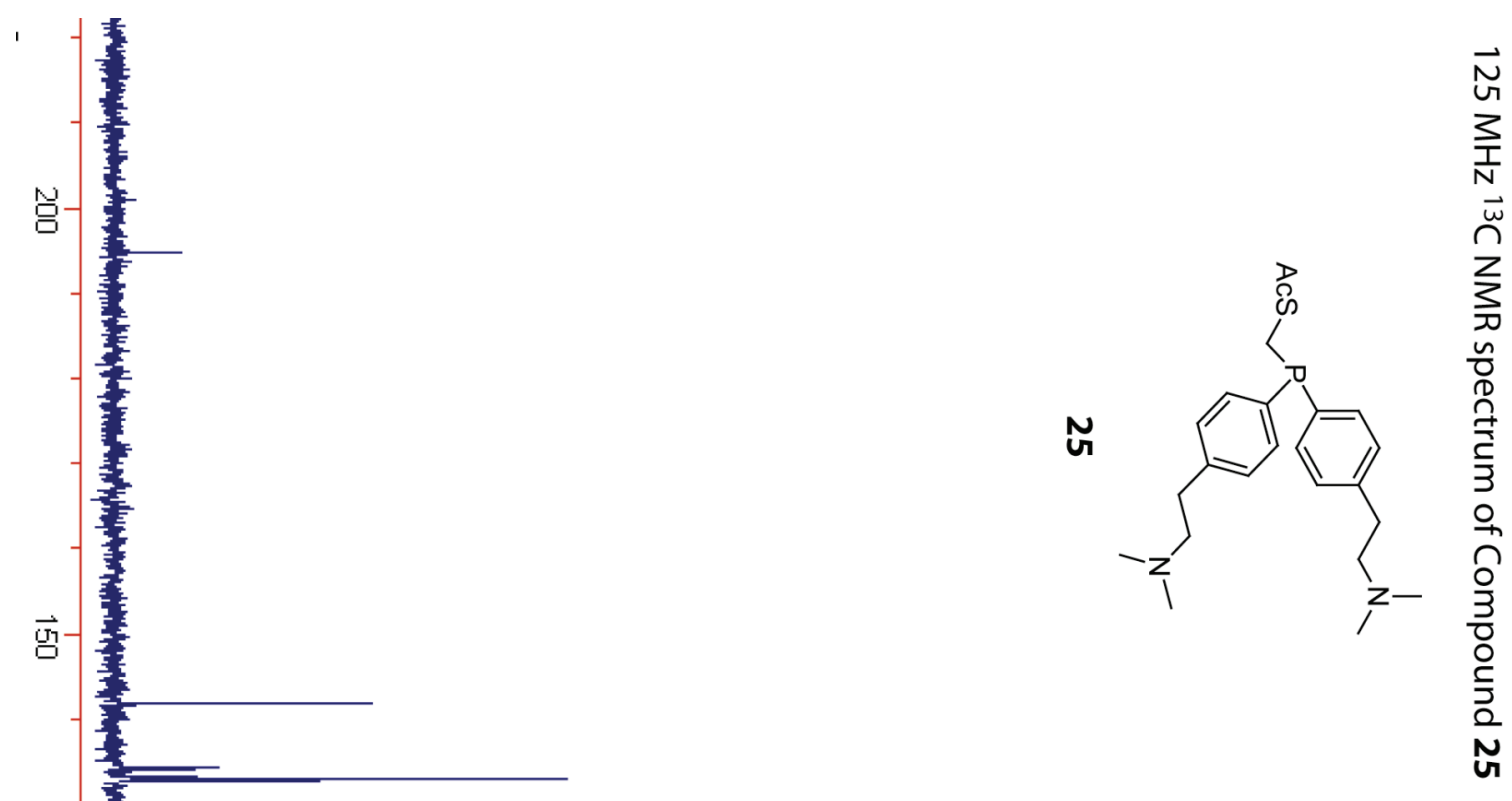

떰-

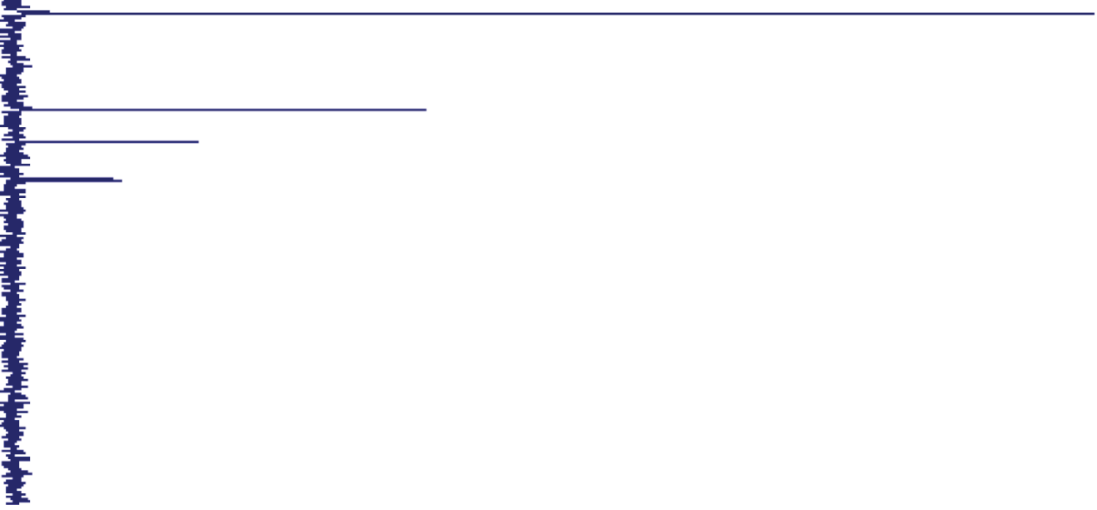



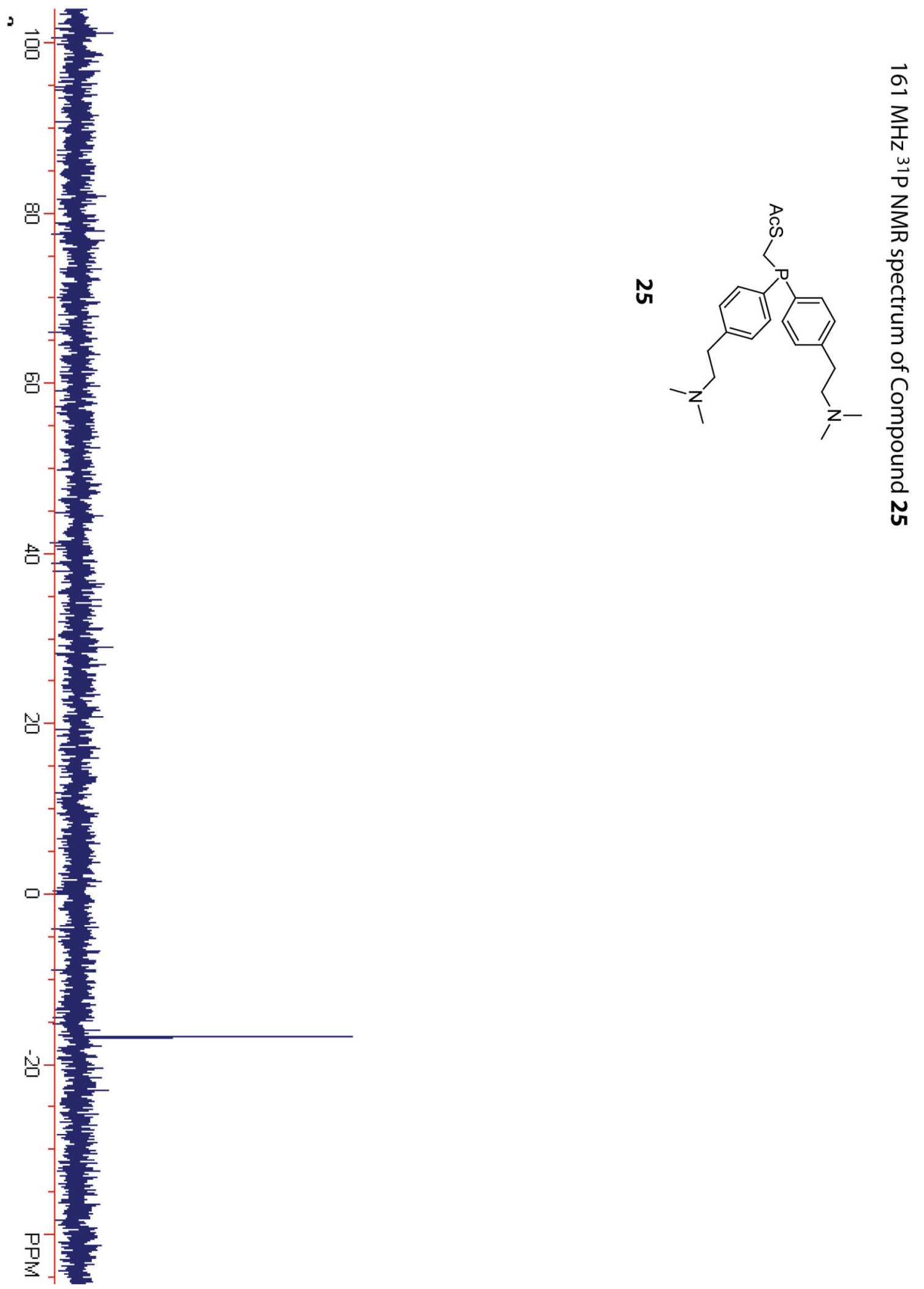
Tam et al.

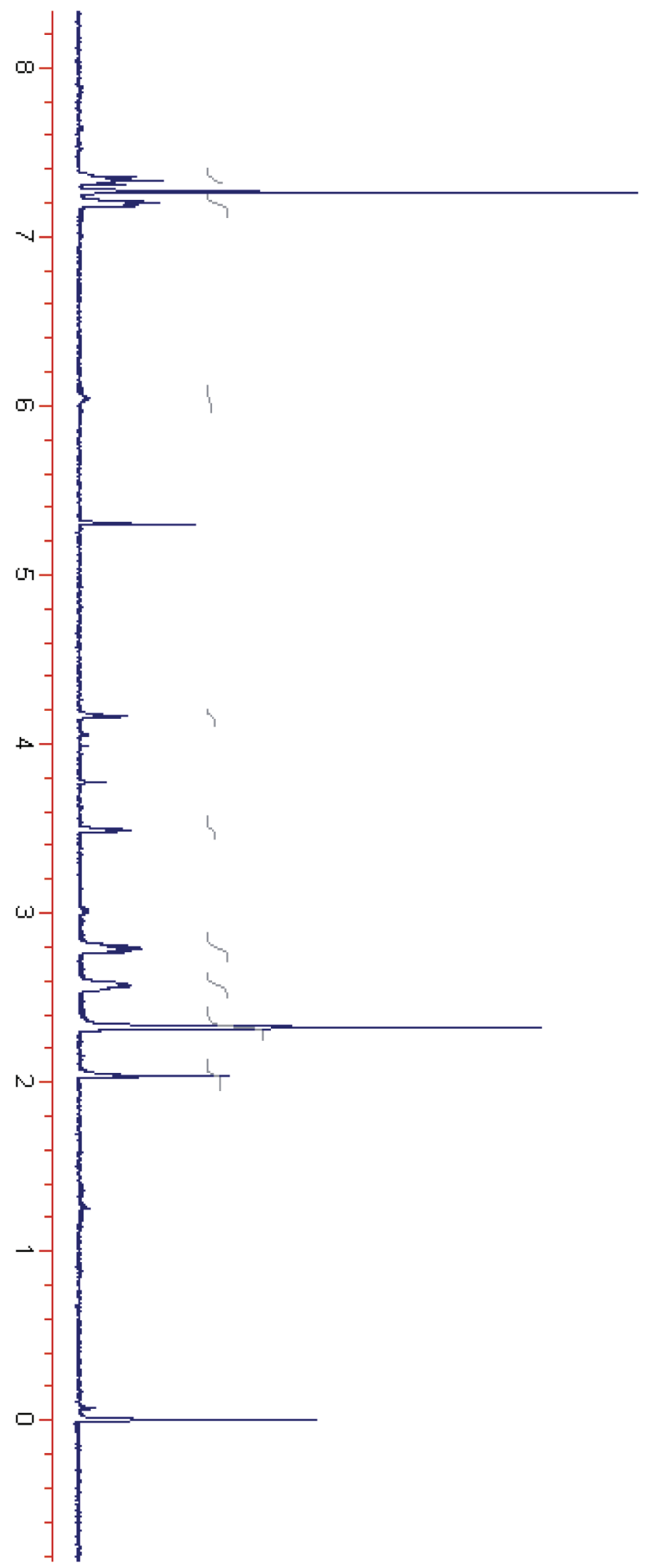

Supporting Information

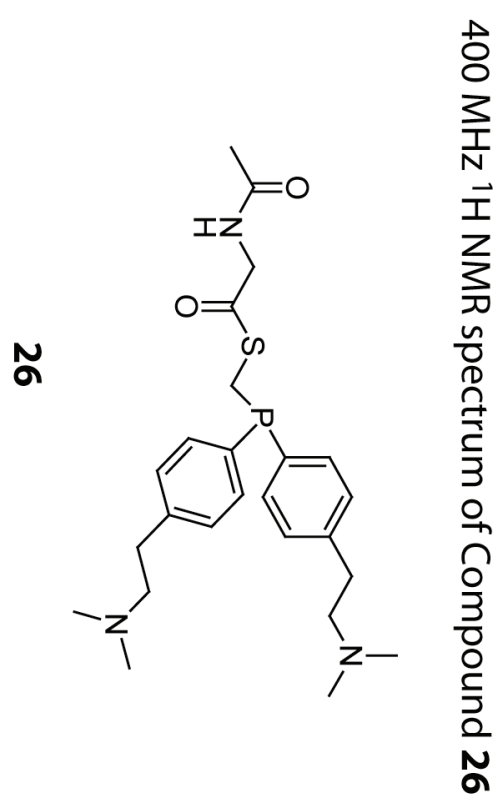


Tam et al.

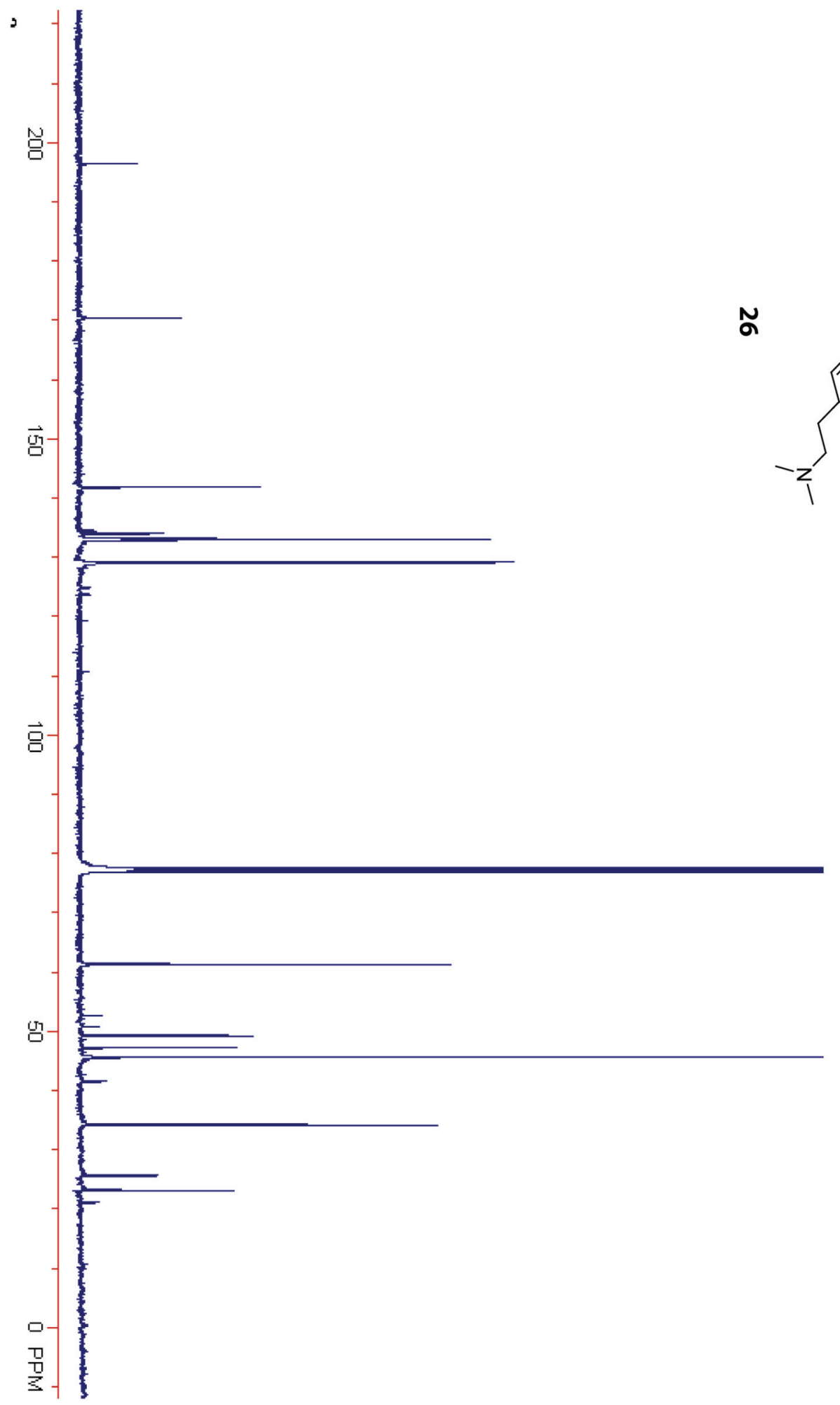

Supporting Information

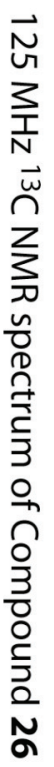


Tam et al.

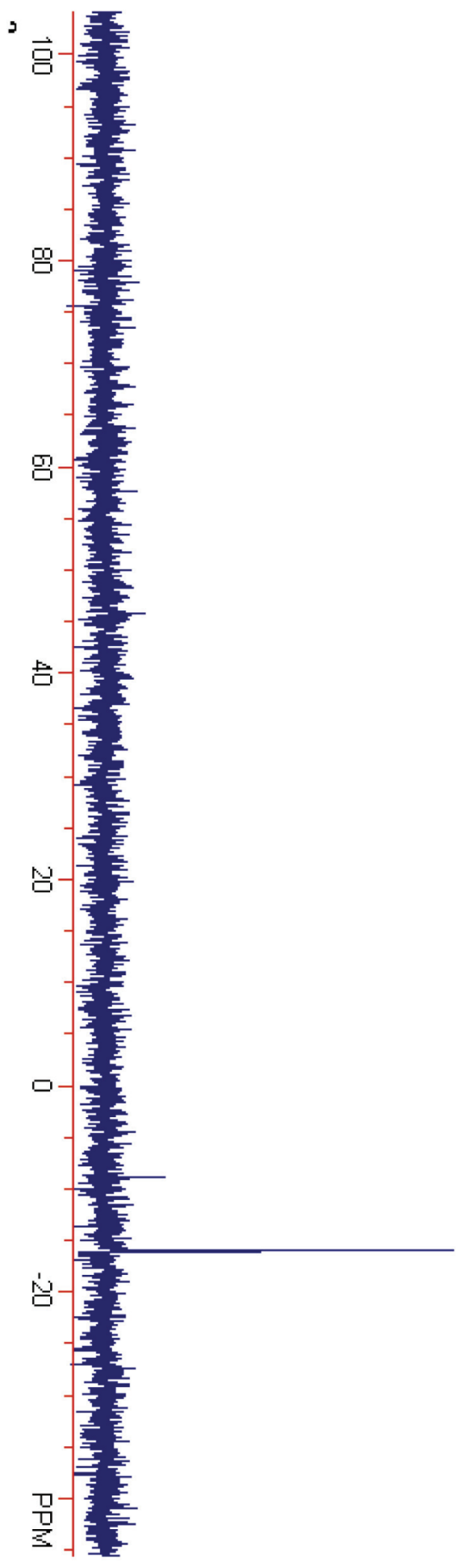

Supporting Information

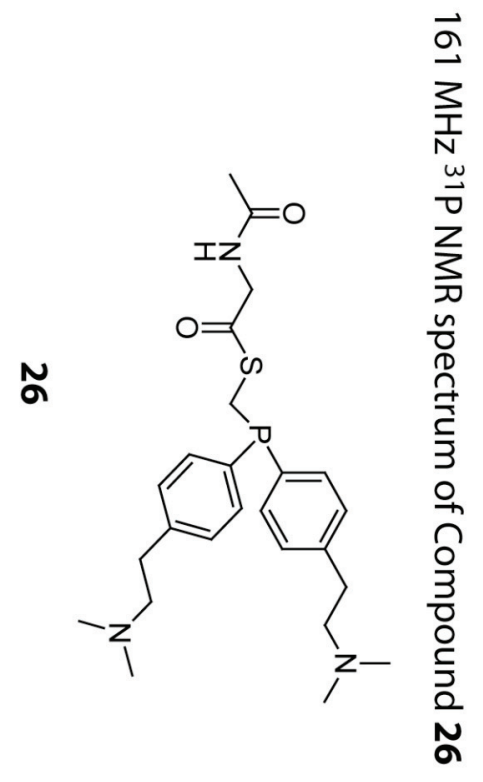

-S66- 
Tam et al.

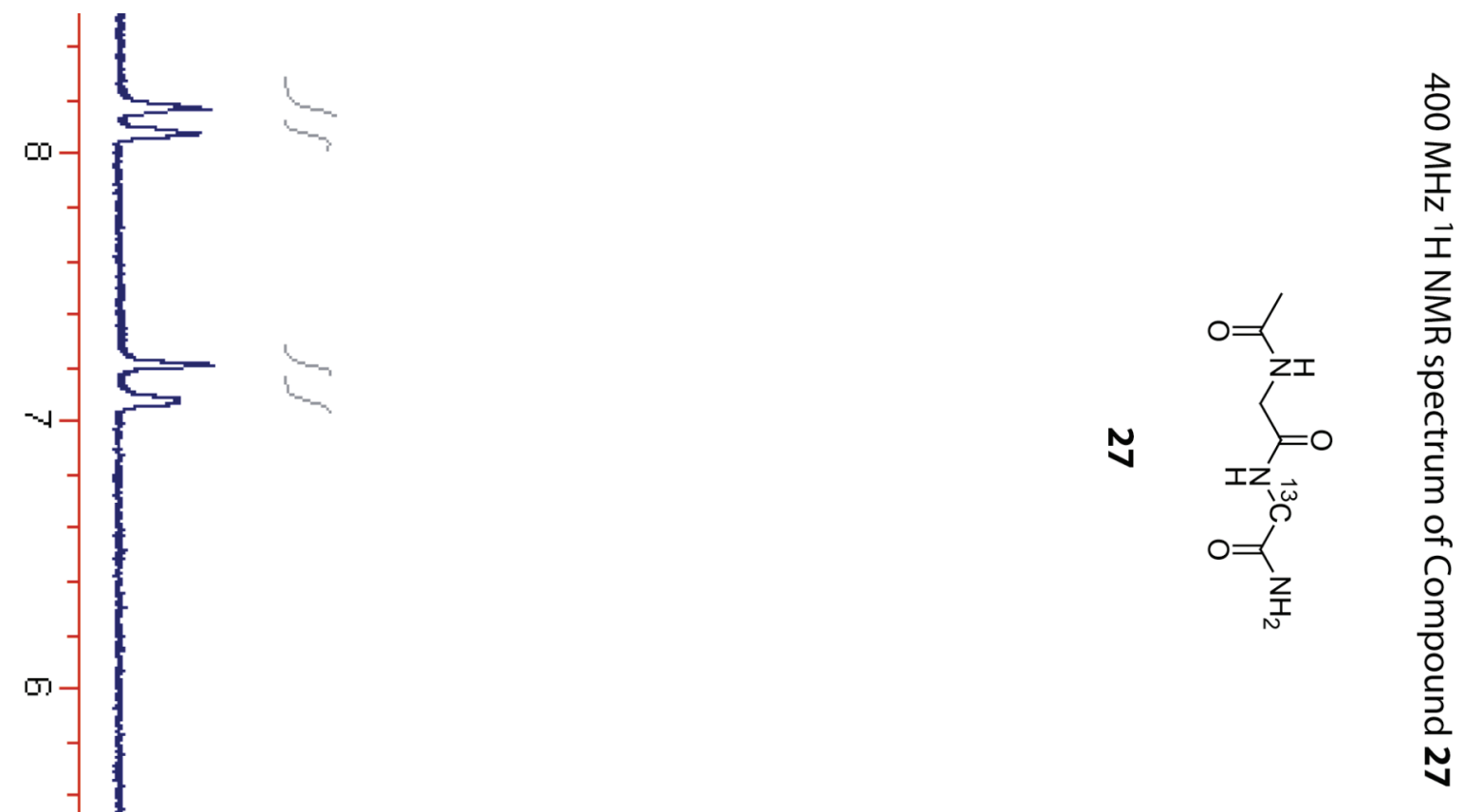

Supporting Information

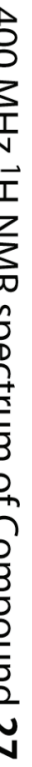

ט7

5
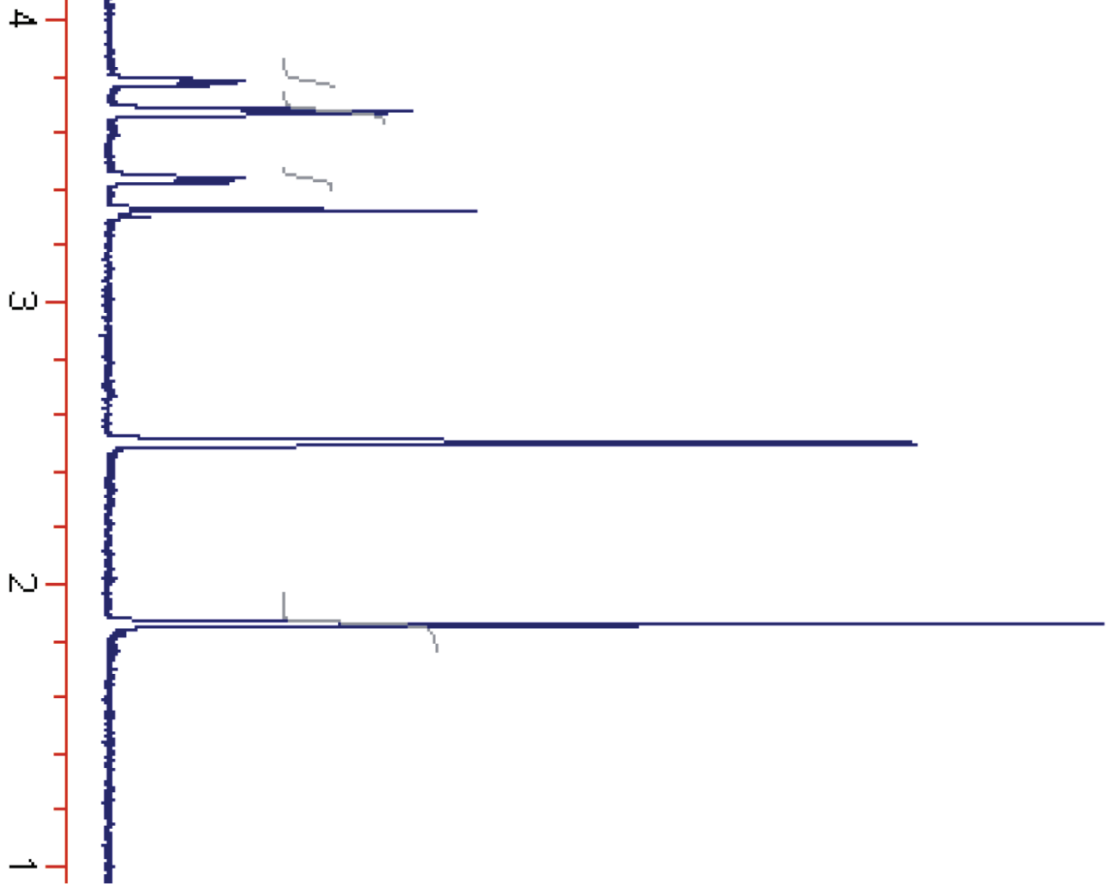

$\omega-$

$-$ 

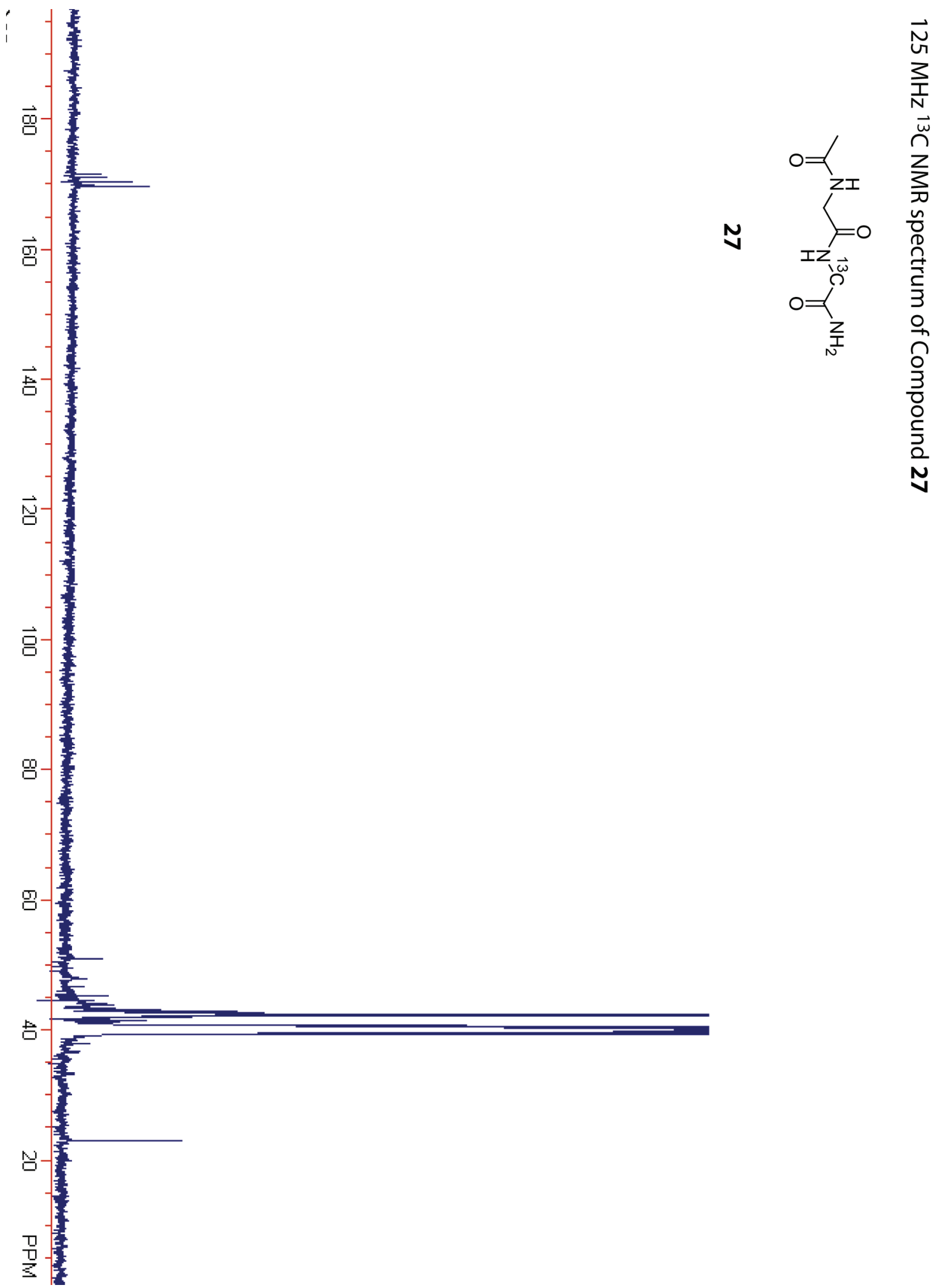


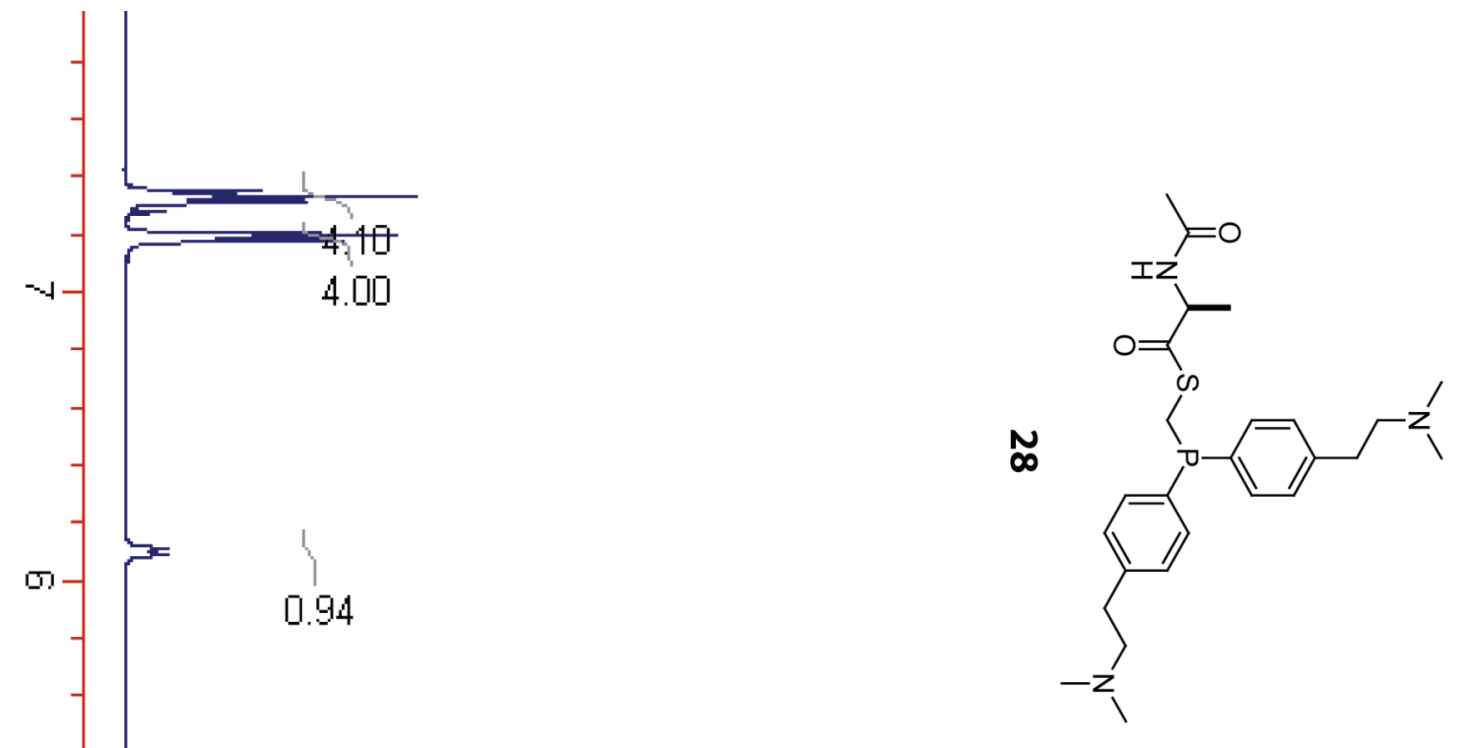

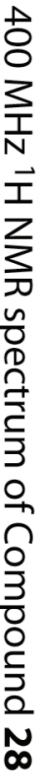

טT

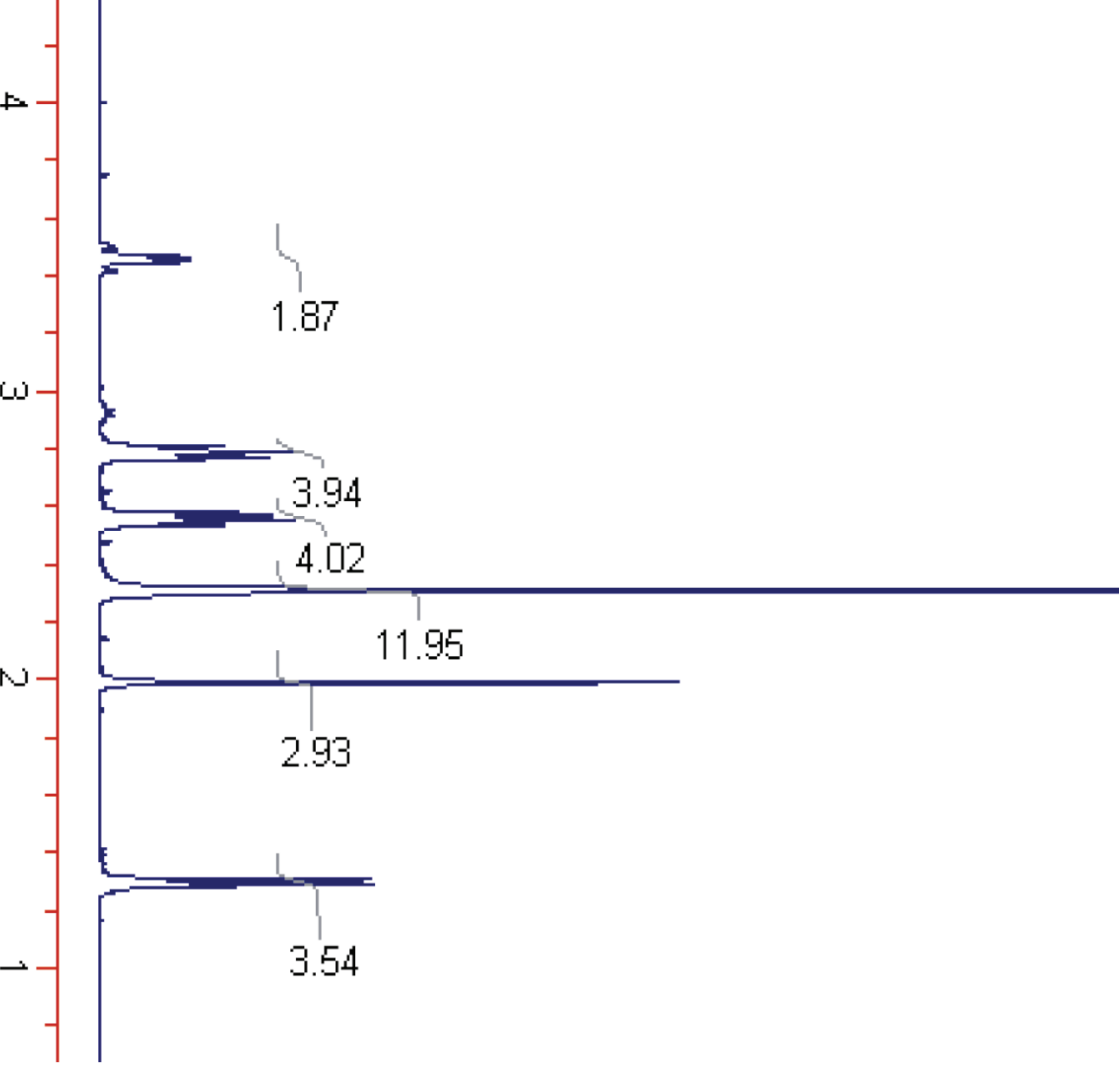



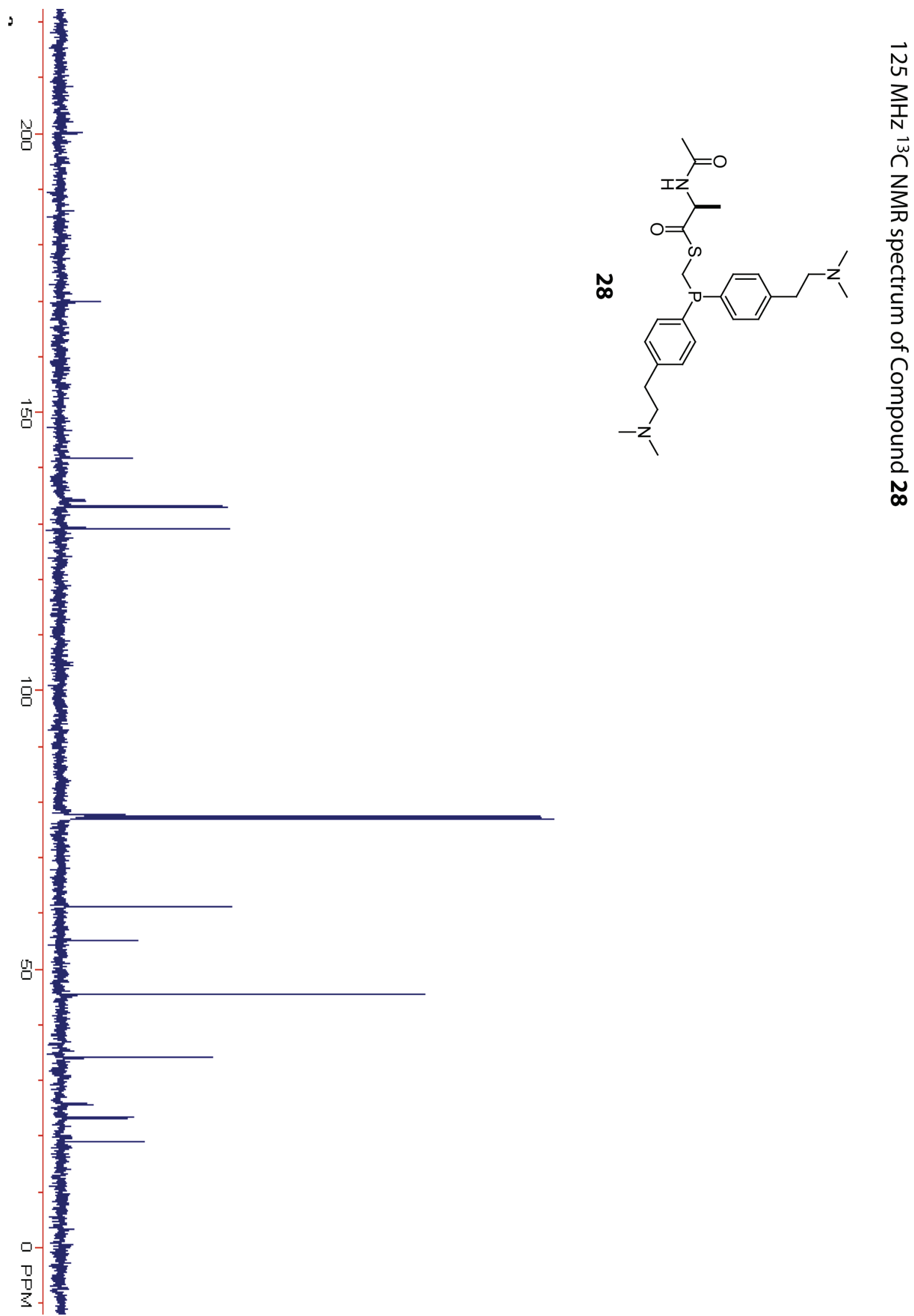

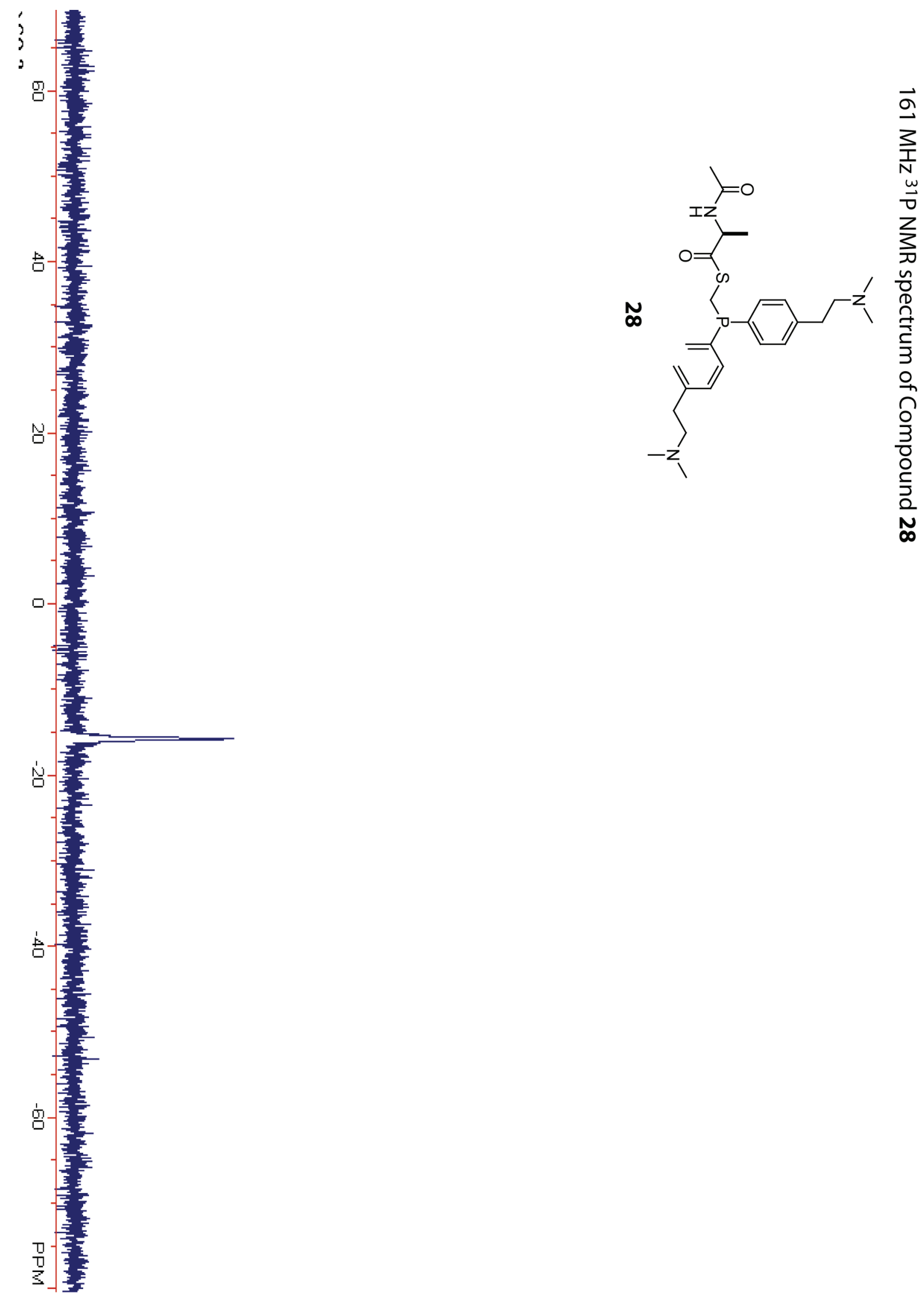


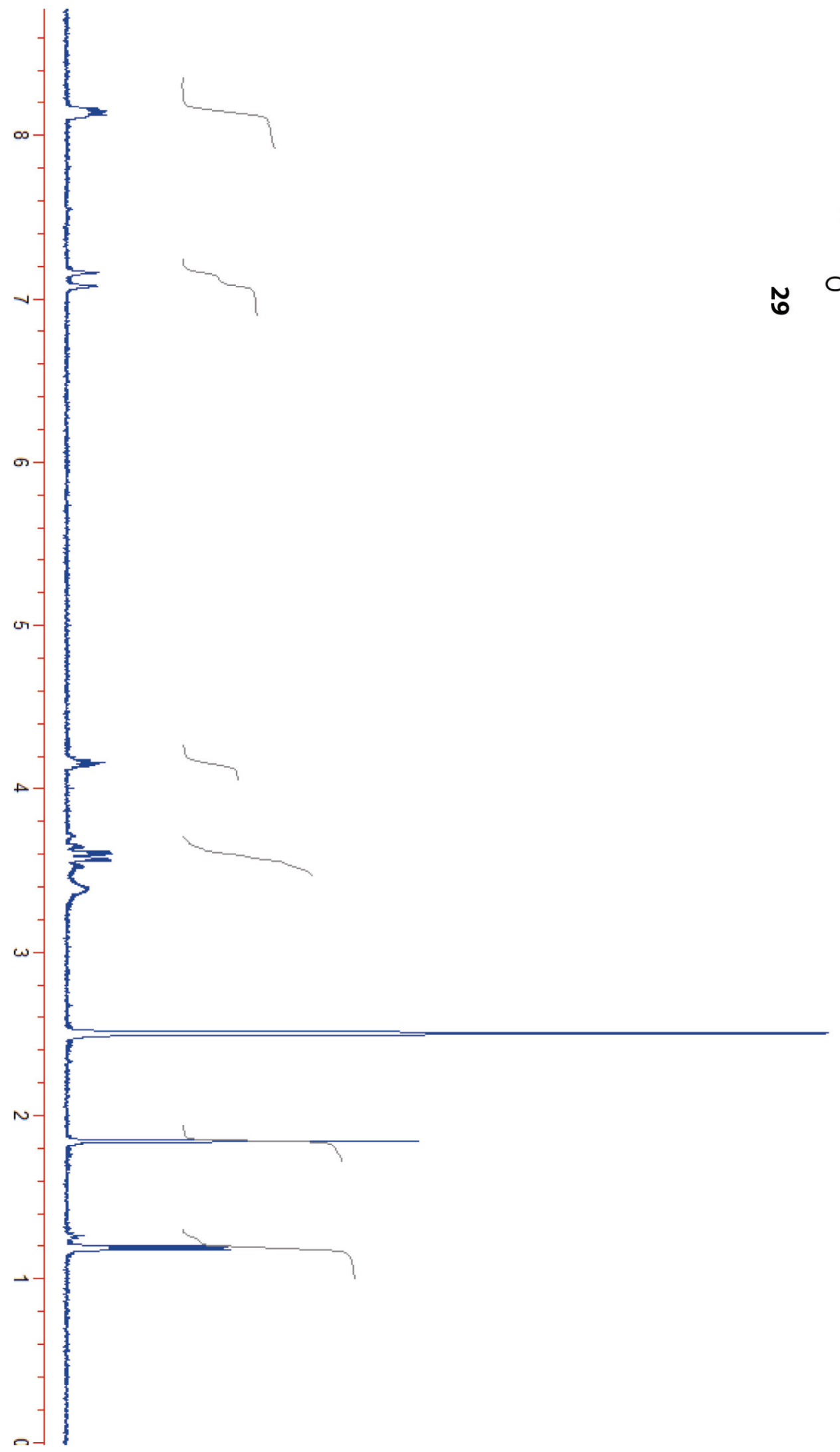



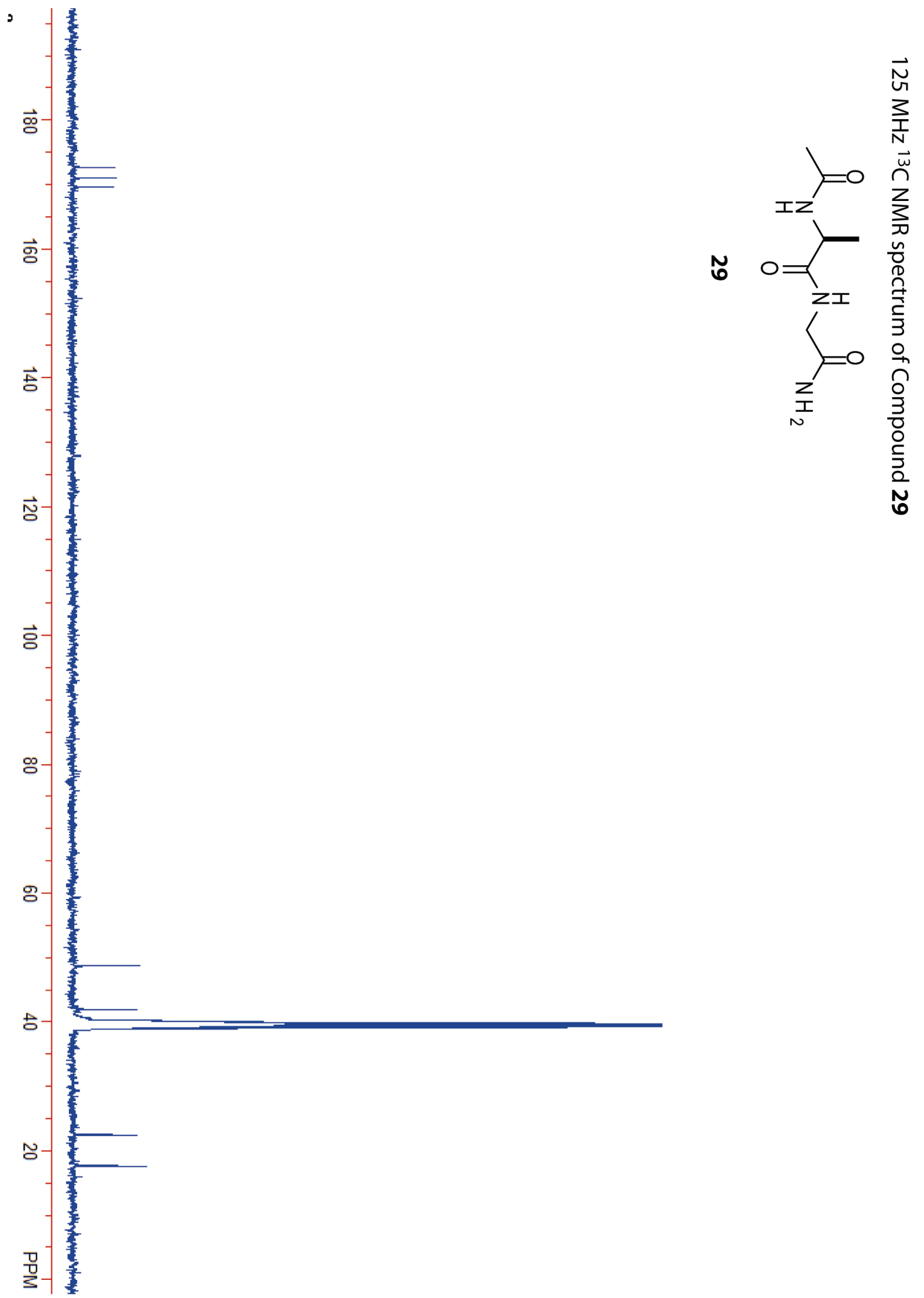

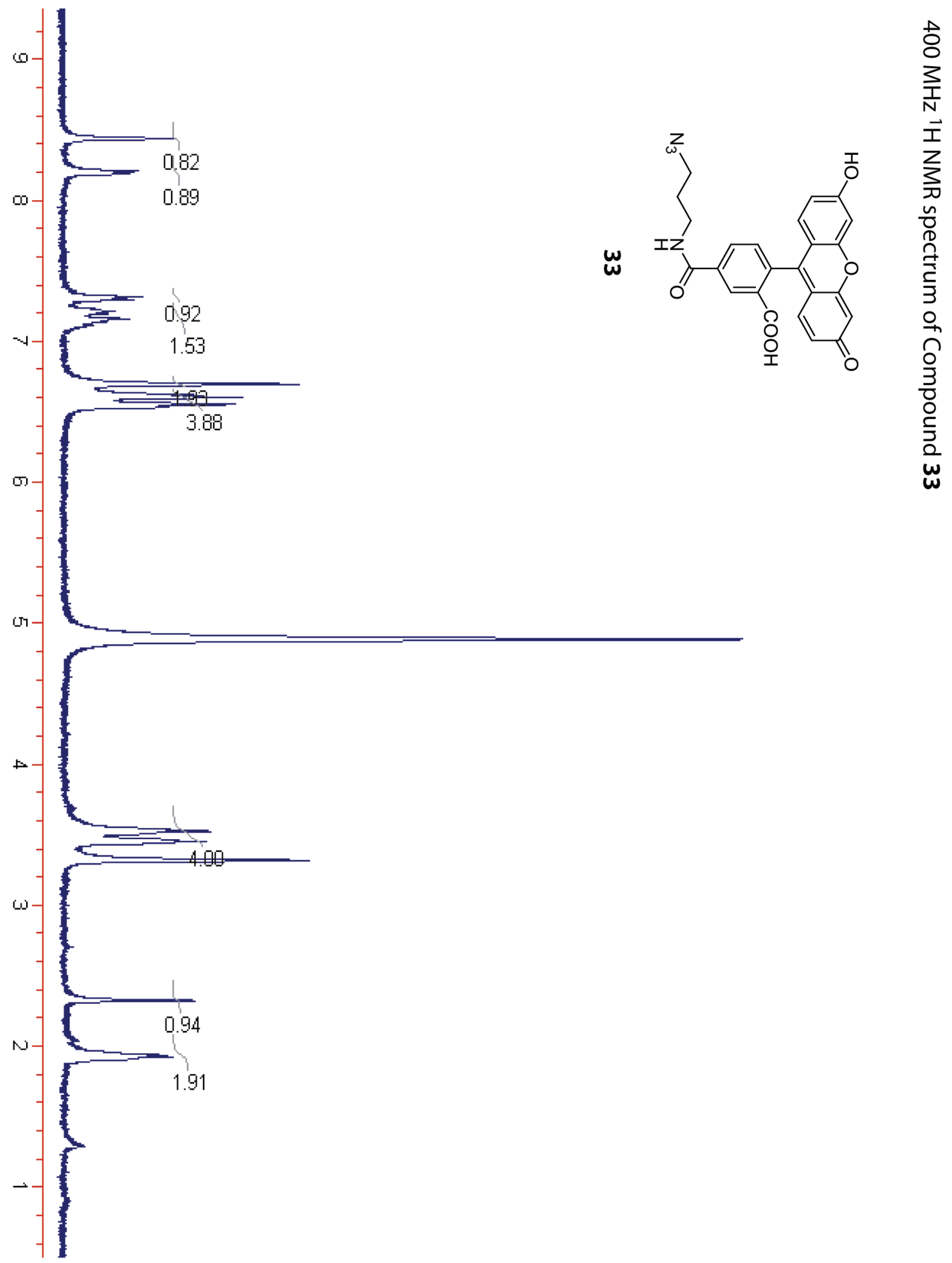
Tam et al.

2

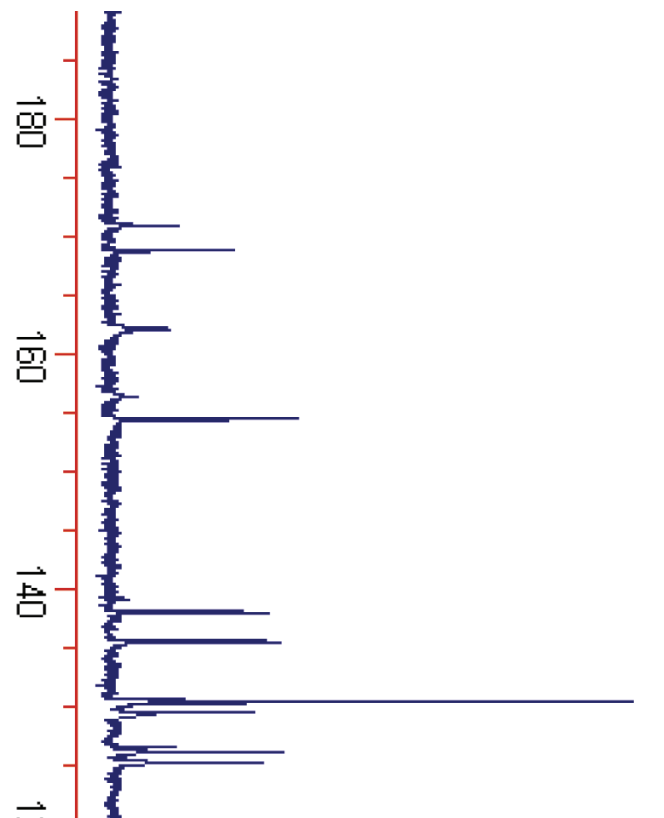

Supporting Information

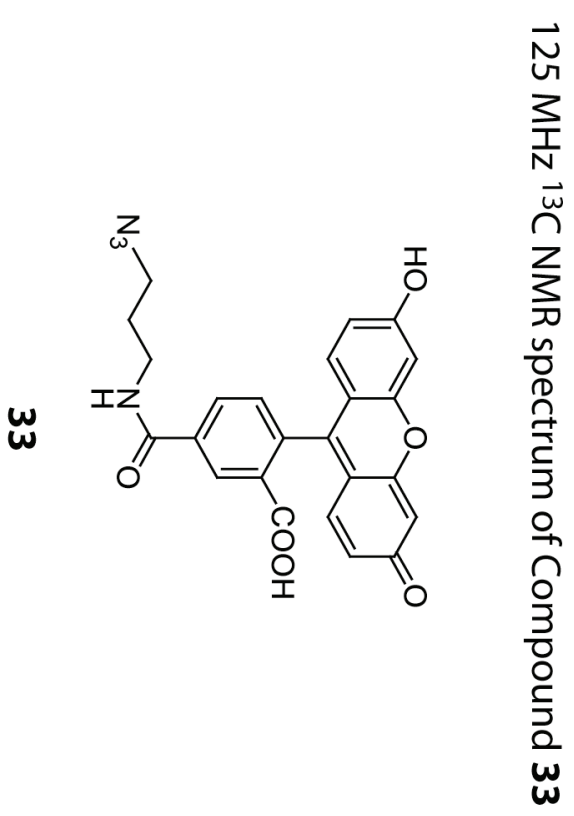

